\title{
DEVELOPMENT AND APPLICATION OF SPACEFLIGHT PERFORMANCE SHAPING FACTORS FOR HUMAN RELIABILITY ANALYSIS
}

By

\section{JENNIFER MINDOCK}

B.S. Aerospace Engineering, University of Florida, 2000

M.S. Aeronautics and Astronautics, Stanford University, 2003

\author{
A thesis submitted to the \\ Faculty of the Graduate School of the \\ University of Colorado in partial fulfillment \\ of the requirement for the degree of \\ Doctor of Philosophy \\ Department of Aerospace Engineering Sciences \\ University of Colorado, Boulder, CO
}


This thesis entitled:

Development and Application of Spaceflight Performance Shaping Factors for Human

Reliability Analysis

written by Jennifer Ann Mindock

has been approved for the Department of Aerospace Engineering Sciences

David M. Klaus

Alireza Doostan

Date

The final copy of this thesis has been examined by the signatories, and we Find that both the content and the form meet acceptable presentation standards Of scholarly work in the above mentioned discipline. 


\section{Mindock, Jennifer Ann (Ph.D., Aerospace Engineering Sciences)}

Development and Application of Spaceflight Performance Shaping Factors for Human

$$
\text { Reliability Analysis }
$$

Thesis directed by Associate Professor David M. Klaus

The ability of crewmembers to perform various critical functions during spacecraft operations is widely recognized as being essential to mission success. This necessity motivates the desire to better characterize factors that can influence crewmember performance so that those with positive effects can be enhanced, while those with negative impacts can be minimized. Established Human Reliability Analysis methods exist for analyzing performance within the context of myriad terrestrial scenarios. Many of the existing methods have their roots in nuclear power plant operations. While perhaps similar, the factors influencing performance traditionally used in these methods do not take into account the unique conditions encountered during spaceflight. Therefore, this research has identified a tailored set of factors that influence human task performance during space missions. This thesis describes an organizational scheme developed to aid in classifying and communicating the factors across disciplines and organizations. Definitions of identified factors are given for the spaceflight-specific context. A visual display of the factors, called the Contributing Factor Map, is presented and its use as a risk communication tool is discussed.

The Bayesian Network is discussed as a quantification approach allowing relationships between factors, in addition to the factor relationships to performance outcomes, to be modeled. A method for determining a network structure was developed for domains such as human spaceflight, in which a global set of data for analysis is not available. This method applied the Analytic Hierarchy Process, and causal latency concepts from the 
Human Factors Analysis and Classification System in a novel way to guide choices for modeling the dominant set of factors and relationships in a simplified Bayesian Network structure. In addition, an approach for modeling the factors as statistical variables in a Bayesian Network making use of existing design requirements and human performance data is discussed. Applications of this modeling approach in terms of requirement completeness assessment and identification of future research needs are also described. Finally, an illustrative quantified Bayesian Network for the spaceflight domain is given, built on the factor identification and structure development work throughout the thesis. Its use in a Human Reliability Analysis is demonstrated. 


\section{ACKNOWLEDGEMENTS}

I would like to acknowledge and thank the NASA Graduate Student Researchers Program (GSRP), the Zonta International Amelia Earhart Fellowship Program, the Achievement Rewards for College Scientists (ARCS) Foundation, the University of Colorado, College of Engineering and Applied Sciences, and the Aerospace Engineering Sciences Department for the funding supporting this research. The support from these organizations has gone well beyond funding, and I am grateful for the encouragement throughout the process.

I would like to thank my advisor, Dr. David Klaus, whose guidance, experience, support, wisdom and enthusiasm has made this research journey both enlightening and enjoyable. In addition, the interactions with my committee members, Dr. Louis Stodieck, Dr. Alireza Doostan, Dr. Peter Polson, and Dr. Richard Heydorn, have been invaluable. I thank them for the time and energy they each have provided throughout my research process. Joseph Tanner and Dr. Michael Mozer at the University of Colorado also provided priceless feedback and insight. I am additionally thankful for feedback and support from Teri Hamlin, Roger Boyer, and Debbie Johnson with NASA/JSC Safety \& Mission Assurance; Michael Richardson, Dr. Michelle Edwards, Dr. Wilma Anton, Elkin Romero, Dr. David Fitts, Dr. Craig Kundrot and the other members of the NASA Space Life Sciences Human System Risk Board and its Working Group; Susan Schuh, Dennis Pate, Marc Reagan, Dr. Walter Sipes, Dr. Kimberly Seaton, David Pogue, Dr. Stephen Robinson, Missy Gard, Mark Jernigan, Dr. Lauren Leveton, Dr. Sandra Whitmire, and Dr. Sudhakar Rajulu at NASA/JSC; Dr. Cynthia Null at the NASA Engineering and Safety Center; and Dr. Ali Mosleh from the University of Maryland. I would like to thank Dr. Katrina Groth from Sandia National Laboratories for many encouraging and collaborative discussions. 
I would also like to express deepest gratitude to my husband, John Carson, for the unbounded love and support throughout this research process. His encouragement and understanding provided more help than I could describe. I also cannot thank my parents enough for their unconditional love and support. I am additionally grateful to my brother, sister-in-law, and friends in all of the states in which I lived and called home during these few years, for their invaluable encouragement. 


\section{CONTENTS}

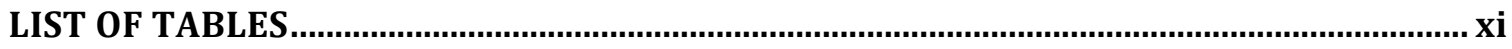

LIST OF FIGURES

1. INTRODUCTION

1.1 RATIONALE AND MOTIVATION FOR THE RESEARCH.................................................... 1

1.1.1 BROAD RATIONALE FOR THE RESEARCH …........................................................ 1

1.1.2 MOTIVATION FOR THE RESEARCH .................................................................... 2

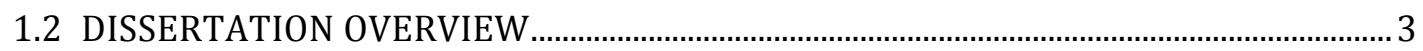

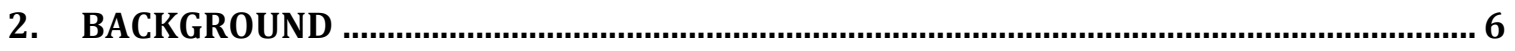

2.1 SPACECRAFT DESIGN CONTEXT

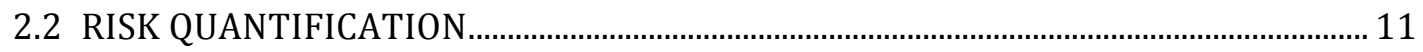

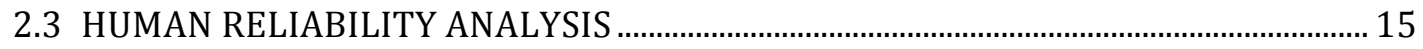

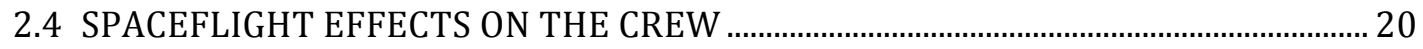

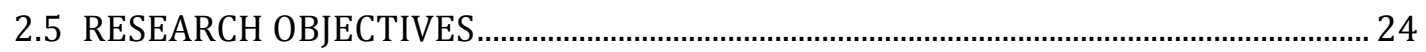

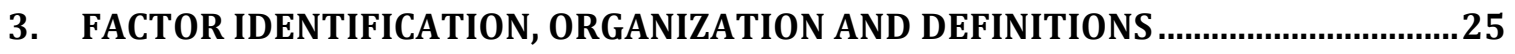

3.1 FACTOR IDENTIFICATION AND ORGANIZATION SCHEME ……................................. 25

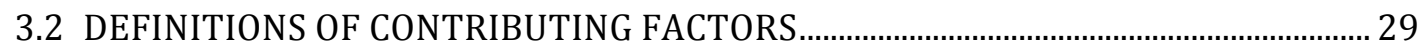

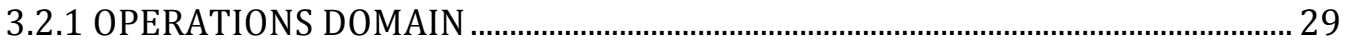

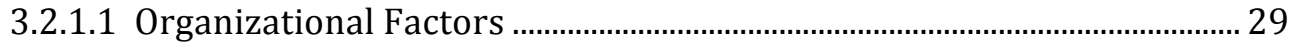

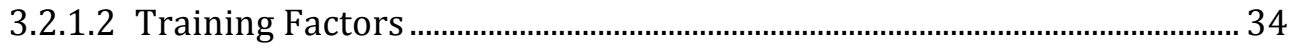

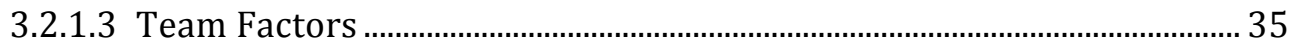

3.2.1.4 Task Specific Characteristics ………............................................................. 39

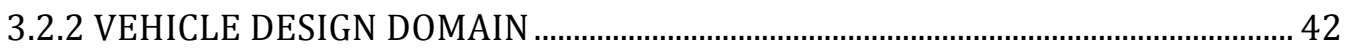

3.2.2.1 Physical Environment .................................................................................... 42 
3.2.2.2 Human System Interaction.

3.2.3 HUMAN DOMAIN . 58

3.2.3.1 Individual Mental Characteristics. .58

3.2.3.2 Individual Physical Characteristics. 64

3.3 USE OF FACTORS AND CFM DIAGRAM FOR COMMUNICATING RISKS. 72

3.4 CONCLUSIONS FOR FACTOR IDENTIFICATION AND ORGANIZATION 74

4. FRAMEWORK FOR QUANTIFICATION OF FACTOR INFLUENCES ..............................76

4.1 BAYESIAN NETWORK INTRODUCTION AND DEVELOPMENT CONTEXT ................. 76

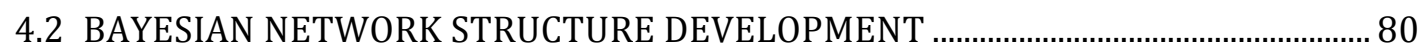

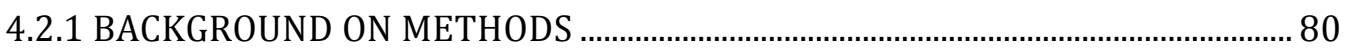

4.2.1.1 Analytic Hierarchy Process ......................................................................... 80

4.2.1.2 Human Factors Analysis and Classification System .................................. 81

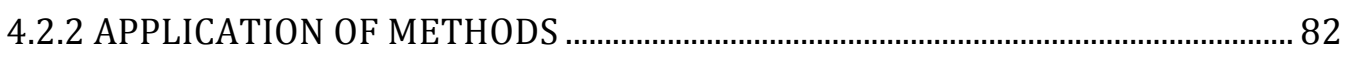

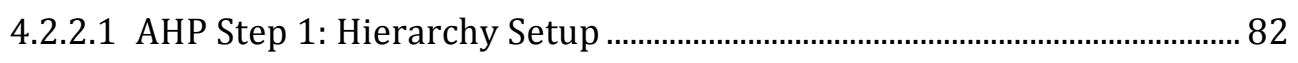

4.2.2.2 AHP Step 2: Pair-Wise Comparisons …………............................................... 83

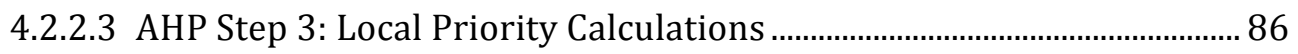

4.2.2.4 AHP Step 4: Global Priority Calculations ..................................................... 86

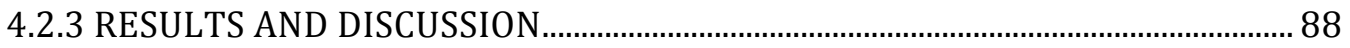

4.2.4 FUTURE WORK FOR STRUCTURE DEVELOPMENT ........................................... 92

4.2.5 CONCLUSIONS FOR STRUCTURE DEVELOPMENT ............................................ 93

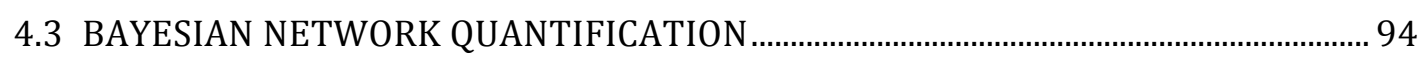

4.3.1 REQUIREMENT - AND DATA-INFORMED FACTOR MODELING ......................... 96

4.3.1.1 Parent Factor Characterization .................................................................... 96

4.3.1.2 Relationship Characterization ................................................................... 99

4.3.1.3 Child Factor Characterization …………….................................................100 
4.3.2.1 Acceleration/Gravity Level Parent Factor Characterization

4.3.2.2 Relationship Characterization 103

4.3.2.3 Visual Perception Function Child Factor Characterization .103

4.3.3 ANALYSES ENABLED 105

4.3.3.1 Requirement and Knowledge Gap Identification. 105

4.3.3.2 Commonality Assessment 106

4.3.3.3 Relevancy and Impact Assessments 106

\subsubsection{CONCLUSIONS FOR REQUIREMENT- AND DATA-INFORMED BN}

QUANTIFICATION 107

\section{APPROACH FOR APPLICATION OF FACTORS IN HUMAN RELIABILITY ANALYSIS} 109

5.1 DESCRIPTION OF EXAMPLE BAYESIAN NETWORK..................................................

5.1.1 REVIEW OF BN STRUCTURE AND DEVELOPMENT …....................................109

5.1.2 QUANTIFICATION OF EXAMPLE BN ..............................................................109

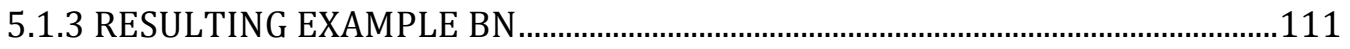

5.2 ENTERING SCENARIO EVIDENCE.................................................................................113

5.3 PROPAGATING EVIDENCE IN THE NETWORK …….....................................................115

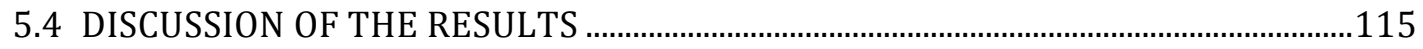

5.5 INCORPORATING RESULTS IN HRA AND PRA .........................................................117

5.6 CONCLUSIONS FOR THE BAYESIAN NETWORK APPLICATION EXAMPLE.............117

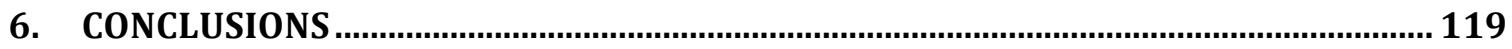

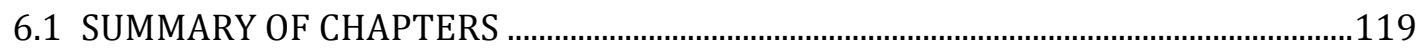

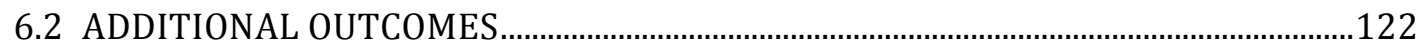

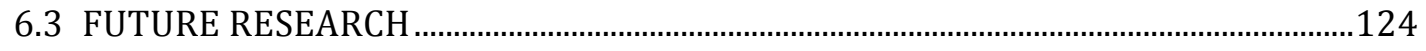




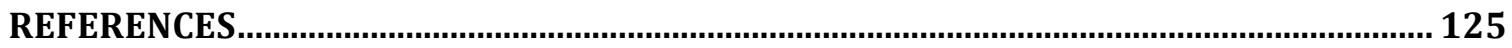

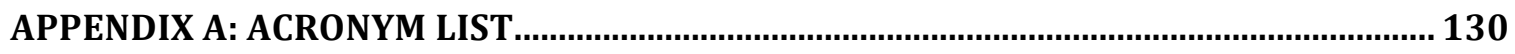

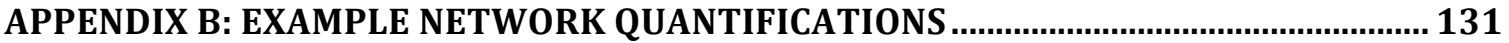




\section{LIST OF TABLES}

Table 1: CREAM Cognitive Functions and Nominal Failure Values .............................................. 17

Table 2: CREAM Common Performance Conditions and Weight Factors ................................... 18

Table 3: Sample CREAM Common Performance Condition Evaluations ....................................... 19

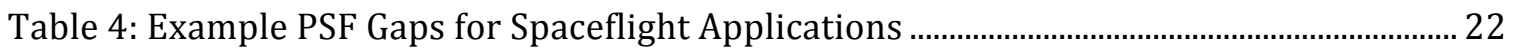

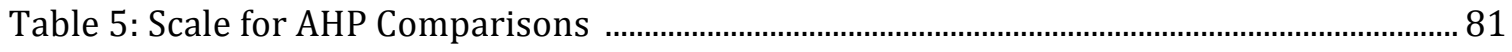

Table 6: Thresholds for Model Inclusion of Level C Factor Relationships to Level B .............. 90

Table 7: Acceleration/Gravity Level Factor Characterization Information ...............................101

Table 8: Relationship Characterization Information..................................................................103

Table 9: Visual Perception Child Factor Characterization Information ......................................103

Table 10: Execution Task Success Conditional Probability Table Values ...................................110

Table 11: Probability Scale ...............................................................................................................111

Table 12: Example Conditional Probability Table for Cognitive Adaptations............................111

Table 13: Evidence Entered in Example Bayesian Network for Scenario..................................114

Table B.1: Execution Task Success Node Probabilities .......................................................................131

Table B.2: Situational Awareness Node Probabilities..............................................................................132

Table B.3: Cognitive Adaptations Node Probabilities ........................................................................133

Table B.4: Psychological Conditions Node Probabilities ……………...........................................133

Table B.5: Non-Standard Physical Conditions Node Probabilities ...............................................133

Table B.6: Physiological Adaptations Node Probabilities ...............................................................134

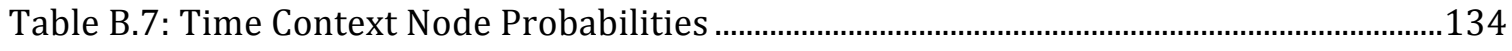

Table B.8: Task Familiarity Node Probabilities .......................................................................................134

Table B.9: Vehicle Physical Environment Node Probabilities ........................................................134

Table B.10: Work Load Node Probabilities .................................................................................135

Table B.11: User Interfaces Node Probabilities ....................................................................................135 
Table B.12: Task Planning and Scheduling Node Probabilities

Table B.13: Training Quality Node Probabilities

Table B.14: Mission Planning Node Probabilities...........................................................................135

Table B.15: Organizational Support Node Probabilities ..............................................................135 


\section{LIST OF FIGURES}

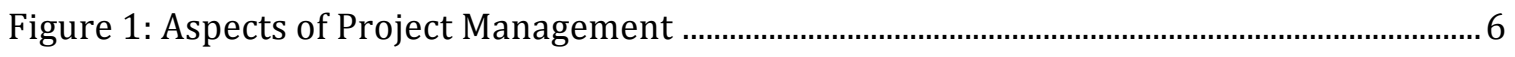

Figure 2: Risk Management Processes ............................................................................................ 8

Figure 3: Risk-Informed Decision Making Process .......................................................................... 9

Figure 4: Continuous Risk Management Process .......................................................................... 10

Figure 5: Probabilistic Risk Assessment Process .............................................................................. 13

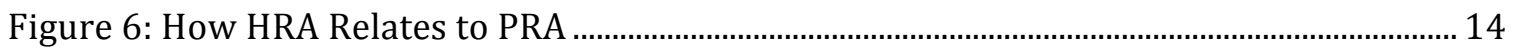

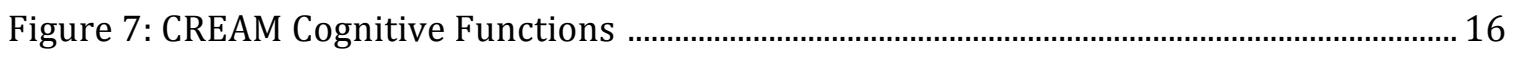

Figure 8: Physiological Changes in the Body Due to Spaceflight ................................................. 23

Figure 9: Factor Generalization/Specialization Hierarchy.......................................................... 26

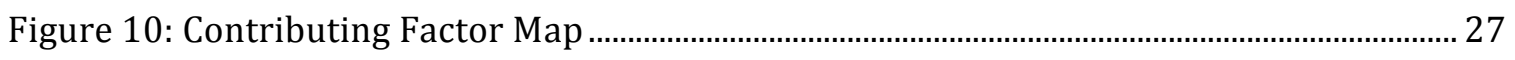

Figure 11: Contributing Factor Map with Influence Arrows for Examples .................................. 73

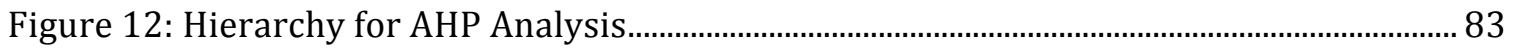

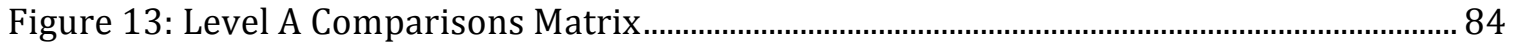

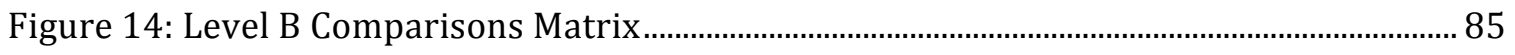

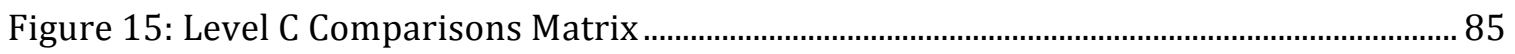

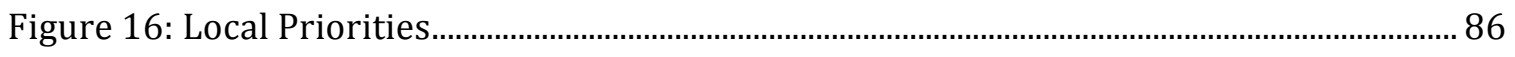

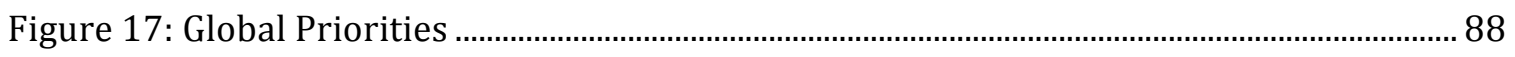

Figure 18: Bayesian Network Structure Resulting from AHP Analysis....................................... 91

Figure 19: Representative Nodes and their CPTs in a Bayesian Network ................................ 96

Figure 20: Example Parent Factor Characterization Information ................................................102

Figure 21: Requirement Reference for Threshold Definition ...................................................102

Figure 22: Example Child Factor Characterization Information..................................................105

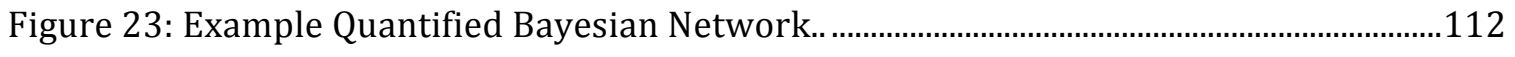

Figure 24: Example Bayesian Network with Output Based on Evidence Set. ...........................116 


\section{CHAPTER 1}

\section{INTRODUCTION}

\subsection{RATIONALE AND MOTIVATION FOR THE RESEARCH}

\subsubsection{BROAD RATIONALE FOR THE RESEARCH}

In various types of operational environments such as aviation, trucking, and nuclear power plants, human error is considered one of the primary contributors to accidents $[1,2]$. In aviation, for example, there is common agreement that approximately $70 \%$ to $80 \%$ of accidents can be at least partially attributed to human error [3]. In the human spaceflight domain such statistics are not so readily attainable; however, the importance of crew performance during space missions is widely recognized for mission success, as the human ability to respond to unexpected and dynamic situations depends on effective crew performance capabilities.

Two primary functions that a human space system must provide with respect to its crew can be summarized as:

1. Protect the crewmembers.

2. Utilize the crewmembers' capabilities [4].

These functions represent the fundamental tenets of human rating for a space vehicle [4], and engineers must consider how to best meet these needs by design. Risks that can cause harm to the crewmembers and/or negatively impact crewmembers' abilities to perform their tasks must be managed for safe and effective spaceflight.

The importance of enabling effective crew operations motivates the need to characterize factors that can influence their performance. Doing so allows those factors exerting a positive influence to be enhanced, while those imparting a negative influence can be minimized. Analysis of 
these factors and resulting crew performance within operational scenarios can lead to insights for improving environmental conditions in the current habitat or for future design of mission elements comprising the spacecraft and its operations.

Various Human Reliability Analysis (HRA) methods exist for analyzing the reliability of human performance within the context of operational scenarios. Most of the existing methods have their roots in nuclear power plant operations [2]. The factors influencing human performance in this terrestrial working environment, however, do not take into account the unique conditions of spaceflight that can affect performance, such as physiological changes due to the crewmember's exposure to microgravity or cognitive impacts arising as a result of limitations in the rather spartan habitat. NASA's Human Integration Design Handbook [5] cites various specific research needs related to factors affecting human performance in space, such as:

"-Quantify the risk of impaired performance and injury due to reduced muscle mass, strength, and endurance as a function of mission duration and gravity level. -Quantify the risk of reduced physical performance due to reduced aerobic capacity. -Quantify the risk of impaired ability to maintain control of vehicles and other complex systems."

These types of physical impacts, along with a number of psychological and cognitive factors, must be considered when analyzing human performance in space.

\subsubsection{MOTIVATION FOR THE RESEARCH}

In 2006, NASA held a Technical Interchange Meeting (TIM) to discuss which existing HRA methods would be most appropriate for application to NASA's space missions. As a result of this TIM, a few methods were recommended for use in the near term, but there was also a recommendation to develop a set of factors affecting performance specifically for use in a spaceflight HRA analysis [6]. This research begins to address that recommendation. 
Related work is being undertaken in the Space and Life Sciences community within NASA. The Bioastronautics Roadmap [7] NASA developed in recent years to aid in management of risks to crew health and performance was reviewed by the Institute of Medicine [8]. The results of this review reinforced the need to regularly examine human system risks [9], and accordingly, NASA has begin using a risk management approach called Continuous Risk Management (CRM) for managing human health and performance risks in the spaceflight context. CRM iterates through steps of risk identification, analysis, planning, tracking, and controlling, with continuous communication and documentation throughout. A Human System Risk Board (HSRB) was established to manage this process [10]. In addition, a new Human Research Roadmap website (http://humanresearchroadmap.nasa.gov/), communicating the content of the Integrated Research Plan for NASA's Human Research Program [11], superseded the Bioastronautics Roadmap. This research is relevant to the analysis portion of the human system risk application of CRM, as it brings quantitative analytical techniques from HRA forward to support these management efforts.

\subsection{DISSERTATION OVERVIEW}

This dissertation provides the background information describing the context and detailed motivation for the research in Chapter 2. The spacecraft design context is described first, which sets the stage for risk quantification needs. Once risk quantification techniques are addressed, the dissertation focuses on the human contribution to risk, and describes the Human Reliability Analysis context for the research. Next, the need to identify factors shaping human performance in spaceflight is discussed.

Chapter 3 presents an organizational scheme used to provide structure to the influences on human performance in space identified through this research. Next, a visual display of factors 
influencing performance, called the Contributing Factor Map (CFM), is presented. Each of the factors shown on the CFM are then described by aerospace domain-specific summaries and supporting references from the aerospace, human performance, and human reliability domains. Chapter 3 next discusses an application of the set of factors as common terminology for communicating across disciplines and organizations, especially in the context of human health and performance risks.

Chapter 4 introduces the Bayesian Network as an approach for modeling the influences of the factors on each other and performance. It next describes a novel method for determining the structure of a Bayesian Network in the absence of a global set of data spanning performance outcomes due to influences from the entire set of factors, as is the case in the human spaceflight domain. The Human Factors Analysis and Classification System (HFACS) is used as guidance for the development of initial network structural constraints. The Analytic Hierarchy Process (AHP) is then applied to support determination of the dominant set of factors to include in a simplified network structural model in the case when expert opinion, not data, is available. This method is demonstrated by an example, with illustrative results shown.

Chapter 4 continues with the presentation of an approach for quantifying a Bayesian Network that makes use of existing requirements and human performance data relevant to the spaceflight domain. Information to characterize factors and their relationships such that they can be modeled as statistical variables in a Bayesian Network is described. Then, this chapter discusses how existing requirements and human performance data can inform the statistical models, and an example for two factors and their relationship is shown. This example is followed by a discussion of requirement and research gap analyses that can be supported by a model containing the characterization information as described in this chapter.

Chapter 5 provides an example of how a Bayesian Network can be applied in a spaceflight domain Human Reliability Analysis. An illustrative quantified network is shown, along with the 
process for using such a network in the analysis of a scenario of interest. The work in the thesis is then related to its higher-level context by describing how the example Bayesian Network results for an HRA would fit within a Probabilistic Risk Assessment. 


\section{CHAPTER 2}

\section{BACKGROUND}

\subsection{SPACECRAFT DESIGN CONTEXT}

Human spacecraft design projects are complex socio-technical endeavors requiring utilization of appropriate project management practices for spacecraft design and mission success to be possible. Project management is commonly viewed to have two equally important aspects, systems engineering and project control. Responsibilities for each of these aspects, including areas of overlap, are shown notionally in Figure 1, as represented in the NASA Systems Engineering Handbook [12].

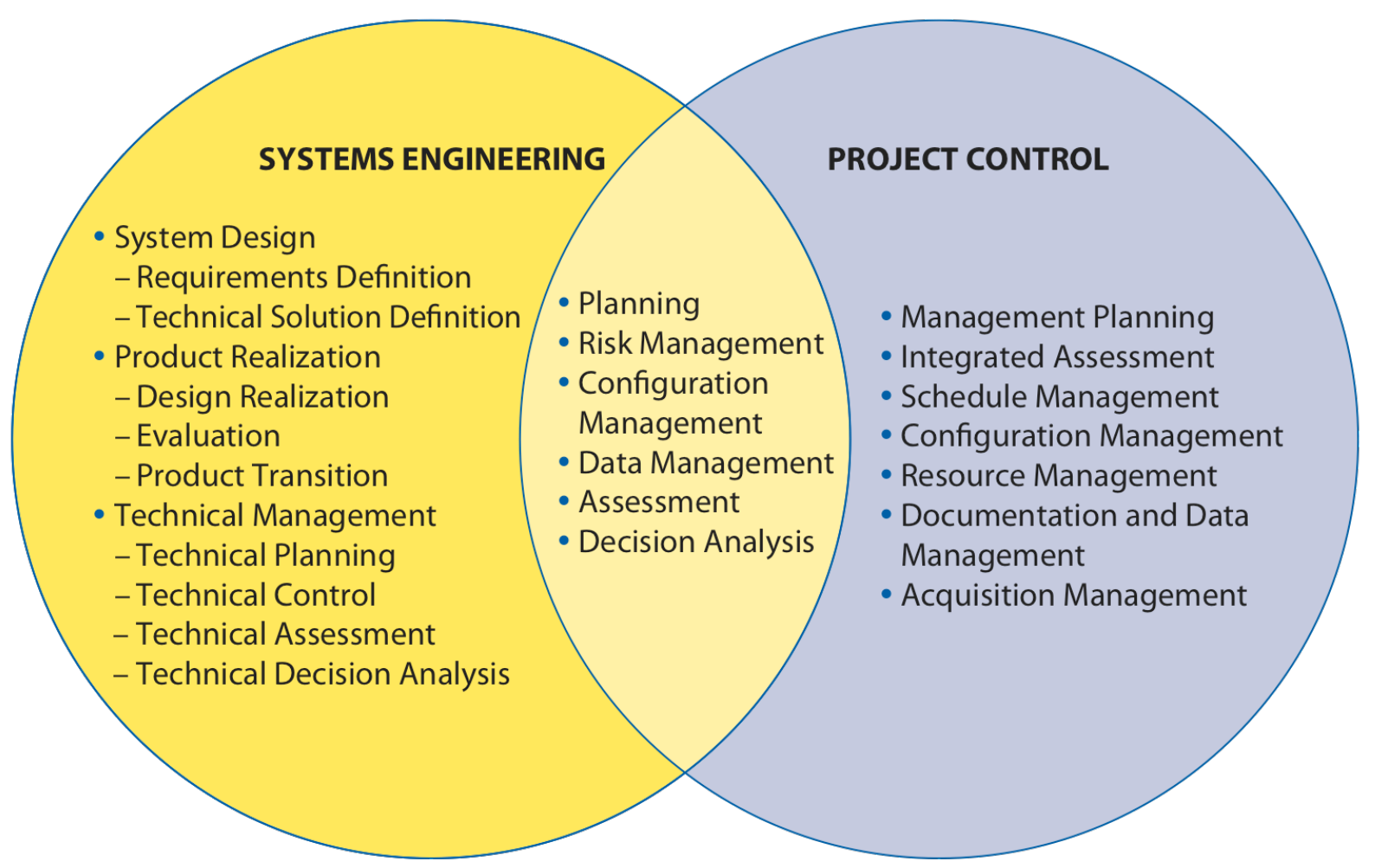

Figure 1: Aspects of Project Management [12] 
One of the fundamental responsibilities shown in the overlap area is that of risk

management. In NASA's Agency Risk Management Procedural Requirements [13] pp.3, risk is given the following definition:

"In the context of mission execution, risk is the potential for performance shortfalls, which may be realized in the future, with respect to achieving explicitly established and stated performance requirements. The performance shortfalls may be related to institutional support for mission execution or related to any one or more of the following mission execution domains:
(1) Safety
(2) Technical
(3) Cost
(4) Schedule"

This research will be primarily concerned with risks related to the safety and technical domains.

Prior to the mid-1990s, NASA operated under a paradigm Tumer et al. described in 2005 [14] as "rule-based", in which requirements were treated as the rule, and all available resources were applied to mitigate hazards identified. As cost constraints became tighter in the 1990s, yet safety was not intended to be sacrificed, the level of risk acceptable for the mission as a whole was partitioned among the remaining mission execution domains of cost, schedule, and technical performance. This way of approaching the design process allowed for risk identification and analysis to support the decisions for accepting or implementing mitigations for the risks in the appropriate mission execution domains.

The particular risk management process that guided this newer way of thinking is called Continuous Risk Management (CRM). The Software Engineering Institute at Carnegie Mellon University originally developed CRM in the 1990s, with support from the Department of Defense, industry, and NASA [10]. CRM primarily focuses on managing risk during the implementation phases of a project, and in 2008, NASA established a complementary process called Risk-Informed Decision Making (RIDM). RIDM is intended to support important, direction-setting decisions [15] 
that are then tracked throughout implementation using CRM. A complete Risk Management (RM) process is now seen as the combination of RIDM and CRM, as shown in Figure 2 [15].

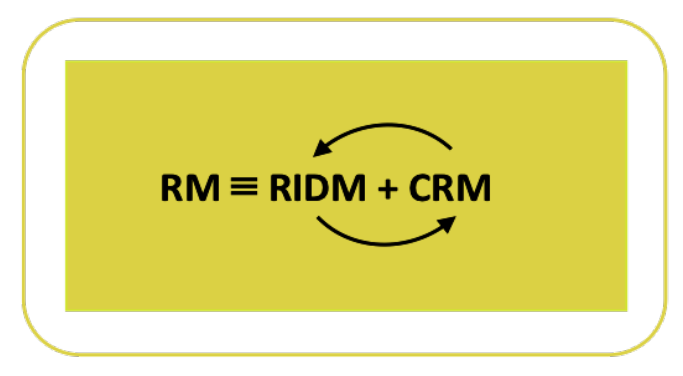

\section{Figure 2: Risk Management Processes [15]}

The Risk-Informed Decision Making Process consists of three main parts, as shown in Figure 3. The first part, Identification of Alternatives, includes efforts to identify objectives that are then decomposed in a hierarchy leading to quantitative performance measures. Constraints are also identified during this stage, and the available alternatives are identified based on ways to meet the objectives while remaining within constraints [15]. 


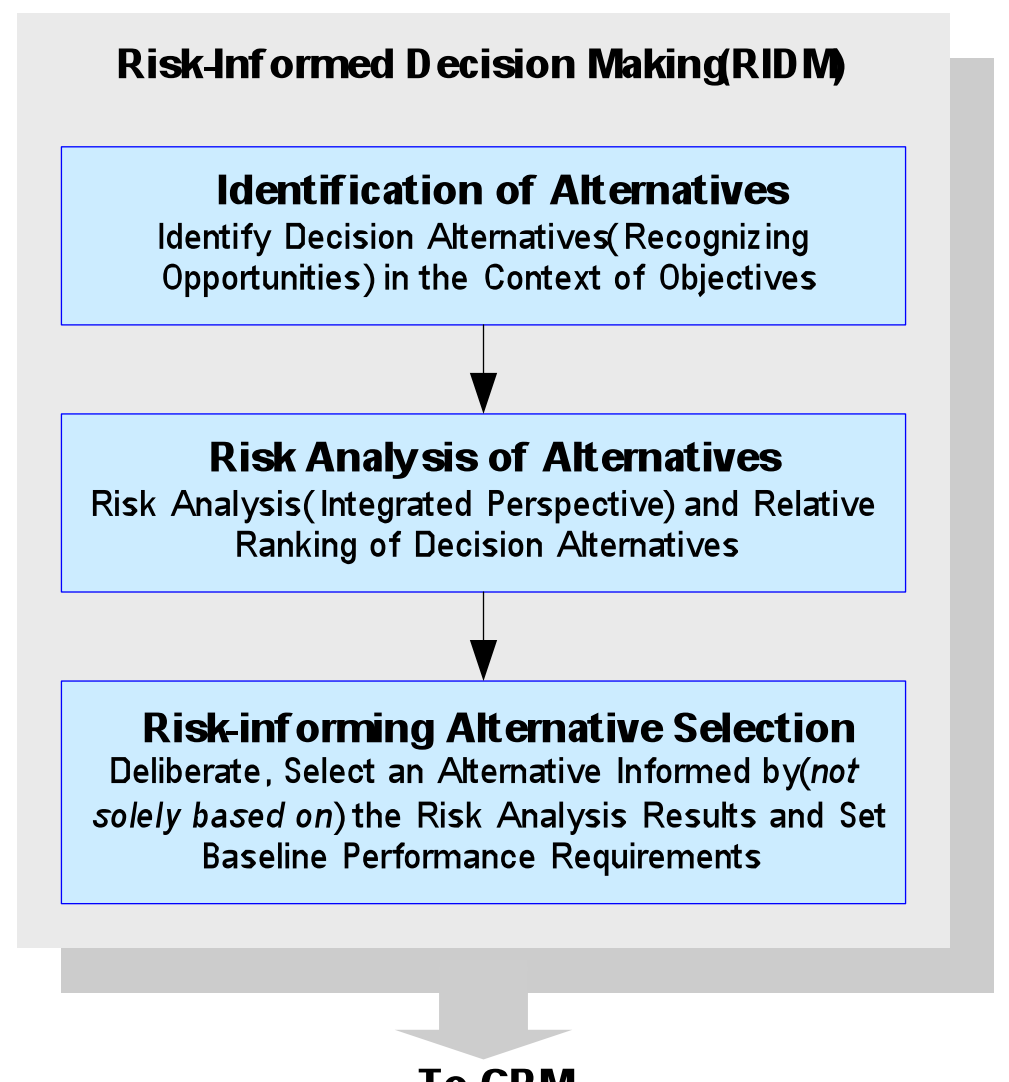

\section{To CRM}

Figure 3: Risk-Informed Decision Making Process [13]

The second part of the RIDM process, Risk Analysis of Alternatives, involves quantifying the performance measures for each alternative. There are various methodologies that can be used during this part of the RIDM process, depending on the details available for the design and whether the performance measure is in the safety, technical, cost, or schedule domain [13]. The research described here fits within this step of the RIDM process, primarily supporting analysis of performance measures in the safety and technical domains. Logical modeling techniques such as fault tress and event trees are commonly used for such analyses, and this research supports an improved capability to include human spaceflight crews in these analyses.

The third part of the RIDM process, Risk-Informed Alternative Selection, is when the decision-maker deliberates with the stakeholders and makes use of the analysis in coming to a 
decision. However, the process is called Risk-Informed Decision Making, and not Risk-Based Decision Making, as it is understood that the risk analysis inputs are one set of inputs to the process. Stakeholder concerns and non-technical factors that may not have been captured in the previous parts of the process must be considered, as well. Once a decision is made, the stage is set for entering the Continuous Risk Management process, as shown in Figure 4.

\section{From RIDM}

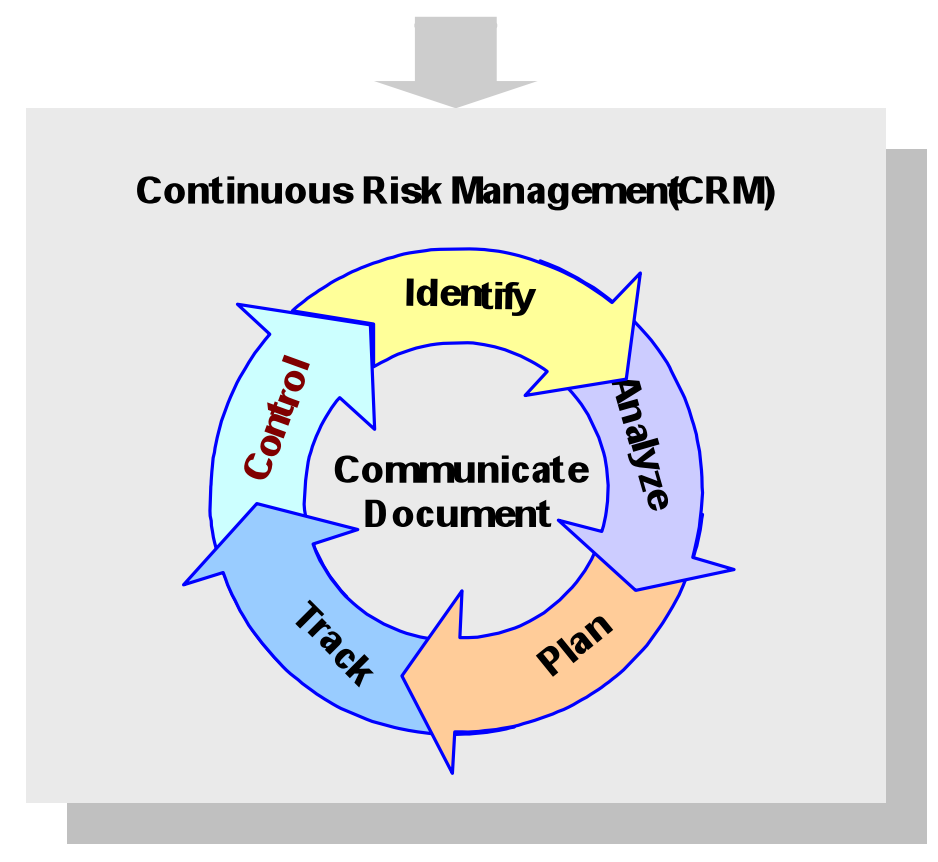

Figure 4: Continuous Risk Management Process [13]

The NASA Agency Risk Management Procedural Requirements document [13] pp.8

describes the steps in the CRM process in this way:

"(1) Identify: Identify contributors to risk (shortfalls in performance relative to the baseline performance requirements).

Note: Sometimes the relationship between an identified risk and performance measures is indirect, but risks within the proper scope of CRM are addressed precisely because they may affect one or more performance measures.

(2) Analyze: Estimate the probability and consequence components of the risk through analysis, including uncertainty in the probabilities and consequences and, as appropriate, estimate aggregate risks.

(3) Plan: Decide on risk disposition and handling, develop and execute mitigation plans, and decide what will be tracked. 
(4) Track: Track observables relating to performance measures (e.g., technical performance data, schedule variances).

(5) Control: Control risk by evaluating tracking data to verify effectiveness of mitigation plans, making adjustment to the plans as necessary, and executing control measures.

(6) Communicate and document: Communicate and document the above activities throughout the process."

Similar to how this research fits within the RIDM process, the second step of the CRM process, "Analyze", provides context during the implementation phases of a project for this research. Again, this research is aimed at supporting the analysis of risks that have a component due to crew performance.

\subsection{RISK QUANTIFICATION}

With the understanding of the context of risk management and analysis in evaluating and developing design options, ways to quantify risk must next be considered. A common analytical methodology for identifying and quantifying risks in a variety of systems is Probabilistic Risk Assessment (PRA). In the Probabilistic Risk Assessment Procedures Guide for NASA Managers and Practitioners [16], PRA is described as,

“...a comprehensive, structured, and logical analysis method aimed at identifying and assessing risks in complex technological systems for the purpose of costeffectively improving their safety and performance."

Currently, NASA’s Procedural Requirements document 8705.5A, Technical Probabilistic Risk Assessment (PRA) Procedures for Safety and Mission Success for NASA Programs and Projects [17], requires aerospace programs and projects to include PRA techniques throughout the development phases to support key design decisions and reviews, with increasing scope and level of detail as the design process continues. The overall objectives, scope, and level of detail for a 
program's or project's use of PRA techniques depend on the risk classification of the program or project, with nationally significant, complex, and high cost missions usually requiring a larger scope and level of detail [18].

At this point the question of how to include human performance in a risk quantification effort must be addressed. For this research, PRA techniques are the framework within which this question is addressed, given their required use within NASA. In addition to the quantitative framework PRA provides, PRA analyses allow scenarios of interest to be captured, thus giving insight into the consequences of the failures identified and quantified. The activities involved in the PRA process are shown in Figure 5. 

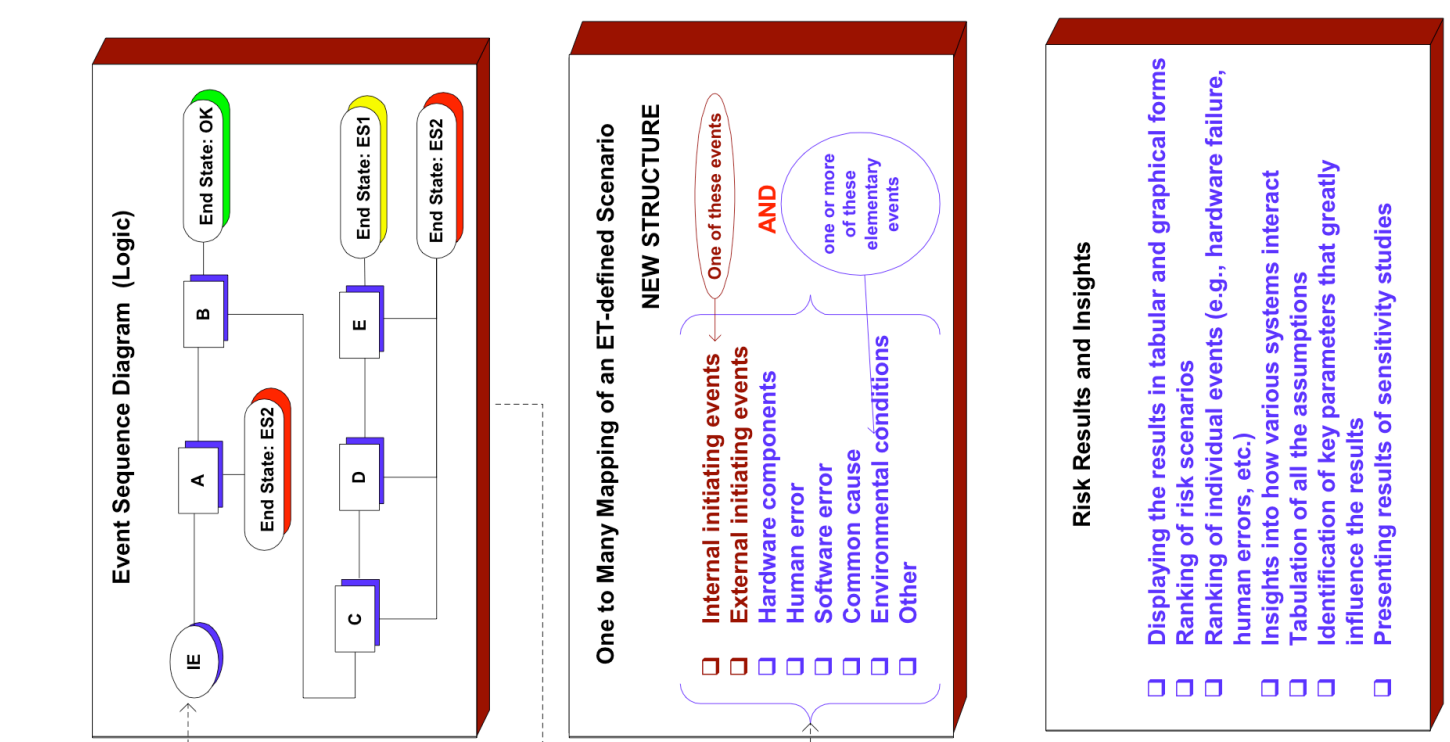

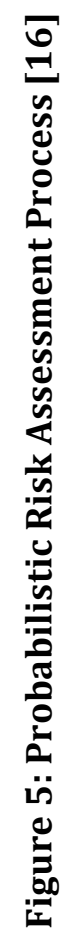
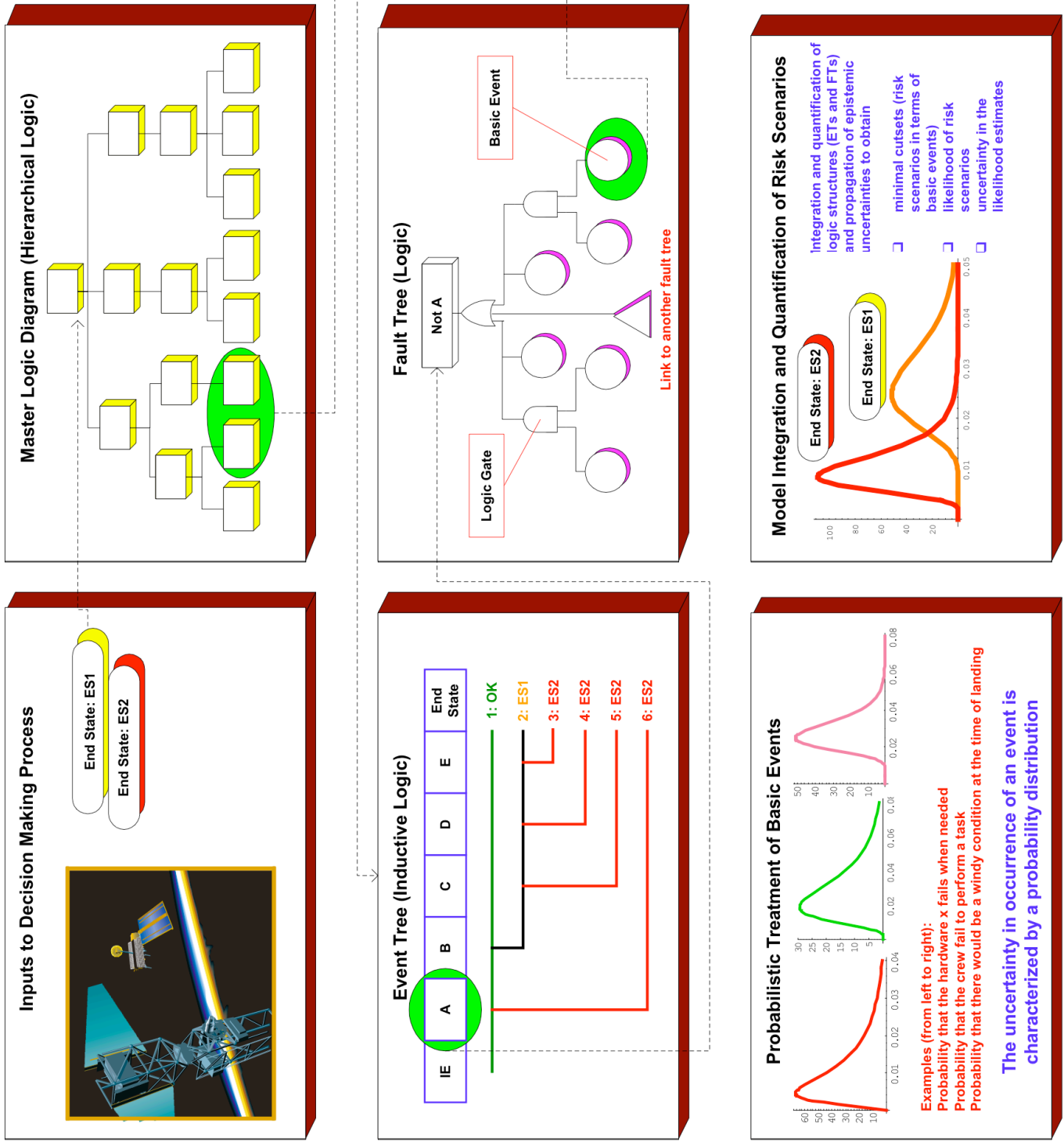
In the middle of Figure 5, one can see the activity for creating Fault Trees. Fault Trees are deductive logic models in which a high-level system failure is hypothesized, and failure events in decreasing levels of generality are shown until reaching basic events such as component hardware failures, software errors, or human errors. The basic events are linked using logic gates (i.e. AND gates and OR gates), and their failure probabilities are combined using Boolean logic to obtain the probability of the top failure event occurring [16]. The basic events modeling human errors are the points in a PRA where human performance and reliability are taken into account. Human Reliability Analysis (HRA) methods provide the techniques for assigning error probabilities to the human error events, as indicated in Figure 6.

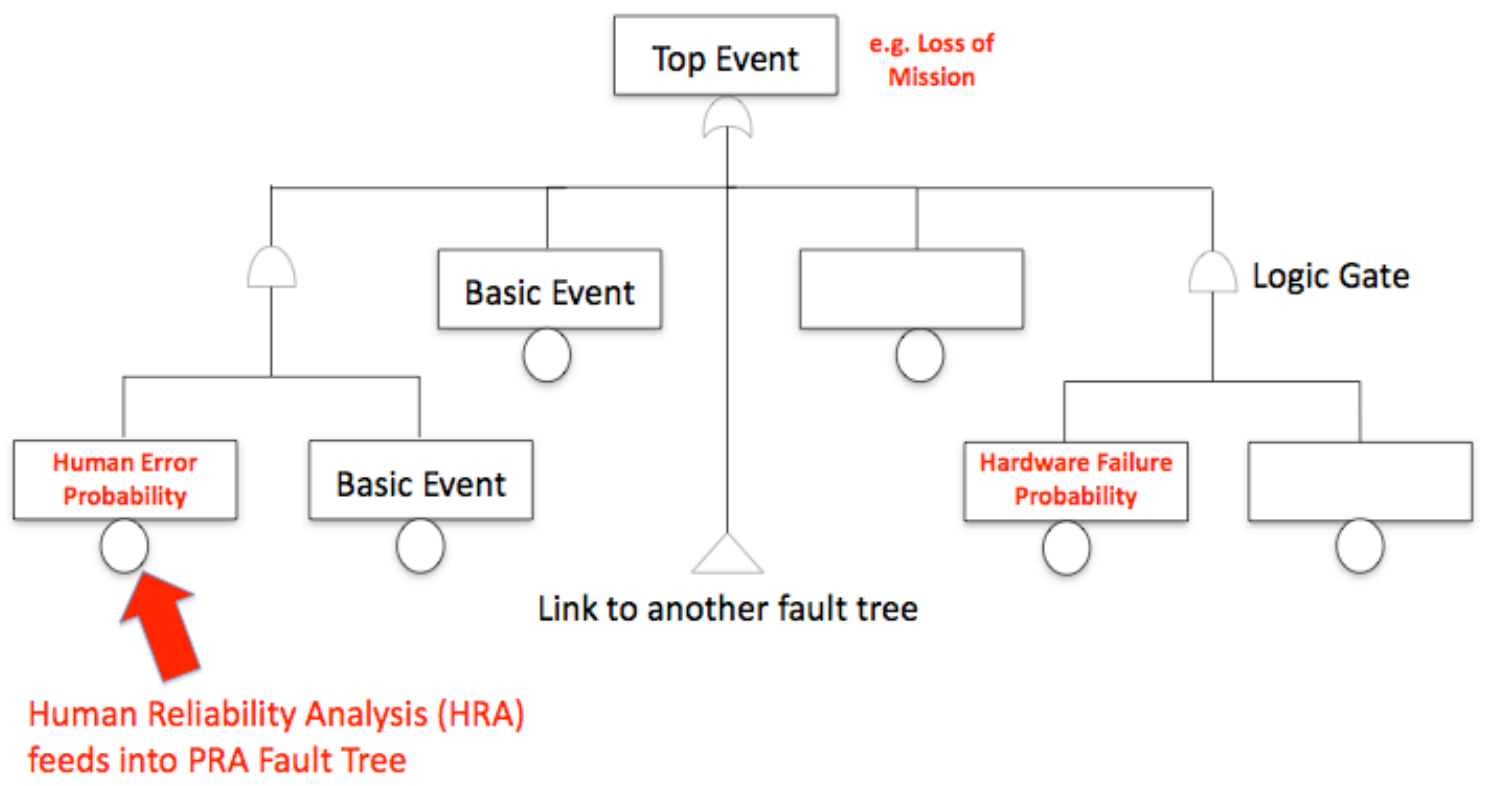

Figure 6: How HRA Relates to PRA

Now that the approach for including human performance in risk quantification efforts has been described, the need for a Human Reliability Analysis (HRA) method can be understood. However, before beginning to fill the need for an HRA method within the spaceflight context, the functional, performance, and integration requirements [19] of a suitable method must be determined by the appropriate customers, such as NASA program personnel and PRA analysts. 
Another set of viewpoints to consider at this level of the research is that of human performance domain experts, whose performance data will inform the set of contributing factors and their effects. There will inevitably be tension between the "usability/practicality" [19] concerns of management users and HRA practitioners, and the "explanatory power" [19] concerns of domain experts wanting to ensure proper behavior modeling. The non-trivial effort of finding common ground in the application of an appropriate HRA method has begun to be addressed in this research.

\subsection{HUMAN RELIABILITY ANALYSIS}

There exist more than 35 to 40 assorted approaches for analyzing human reliability in various environments, and many methods have their roots in the nuclear safety industry [2]. In 2006, NASA held a Technical Interchange Meeting (TIM) to discuss which methods would be most appropriate for application to NASA's space missions. NASA currently uses the Cognitive Reliability and Error Analysis Method (CREAM) [2] for detailed analysis of human reliability [20].

Many of the existing HRA approaches, including CREAM, describe procedures for conducting both qualitative and quantitative analyses. Recall, however, that for the purposes of this research, the analysis results must include human error probabilities (HEP) that are fed into the larger system PRA fault trees. Therefore, this work focused on the quantitative performance prediction aspect of HRA.

At the point in the PRA analysis process when an HRA is required, the HRA analyst is typically concerned with a particular task performed by a human within a given scenario, and will produce the associated HEP. In the CREAM method, the analyst begins by determining if the task is mainly one of 4 cognitive functions shown in Figure 7: Observation, Interpretation, Planning, or Execution [2]. These cognitive functions form the basis for the performance predictions. 


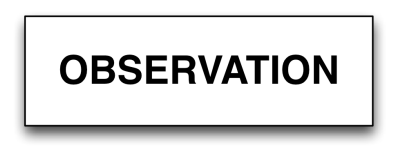

\section{INTERPRETATION}

\section{PLANNING} EXECUTION

\section{Figure 7: CREAM Cognitive Functions [2]}

Next in the CREAM method, the analyst determines the likely cognitive function failure associated with the main cognitive function, with the failure options shown in Table 1 . The associated nominal failure value is then obtained, also given in Table 1. These nominal failure values are dominantly derived from nuclear power plant operations [2].

Once the likely cognitive function failure and associated nominal failure value has been determined, the analyst evaluates what CREAM calls Common Performance Conditions (CPCs). These conditions are conceptually similar to what many other HRA methods and literature sources term Performance Shaping Factors (PSFs). PSFs are used to take into account the conditions under which a human is performing tasks. In the CREAM method, these conditions are evaluated, and associated weights are then used to modify the nominal failure values. The CREAM factors are shown in Table 2, along with the weights for each of the condition states. A weight value greater than 1 increases the failure probability for the task under analysis, and a factor value less than 1 decreases the failure probability [2]. 


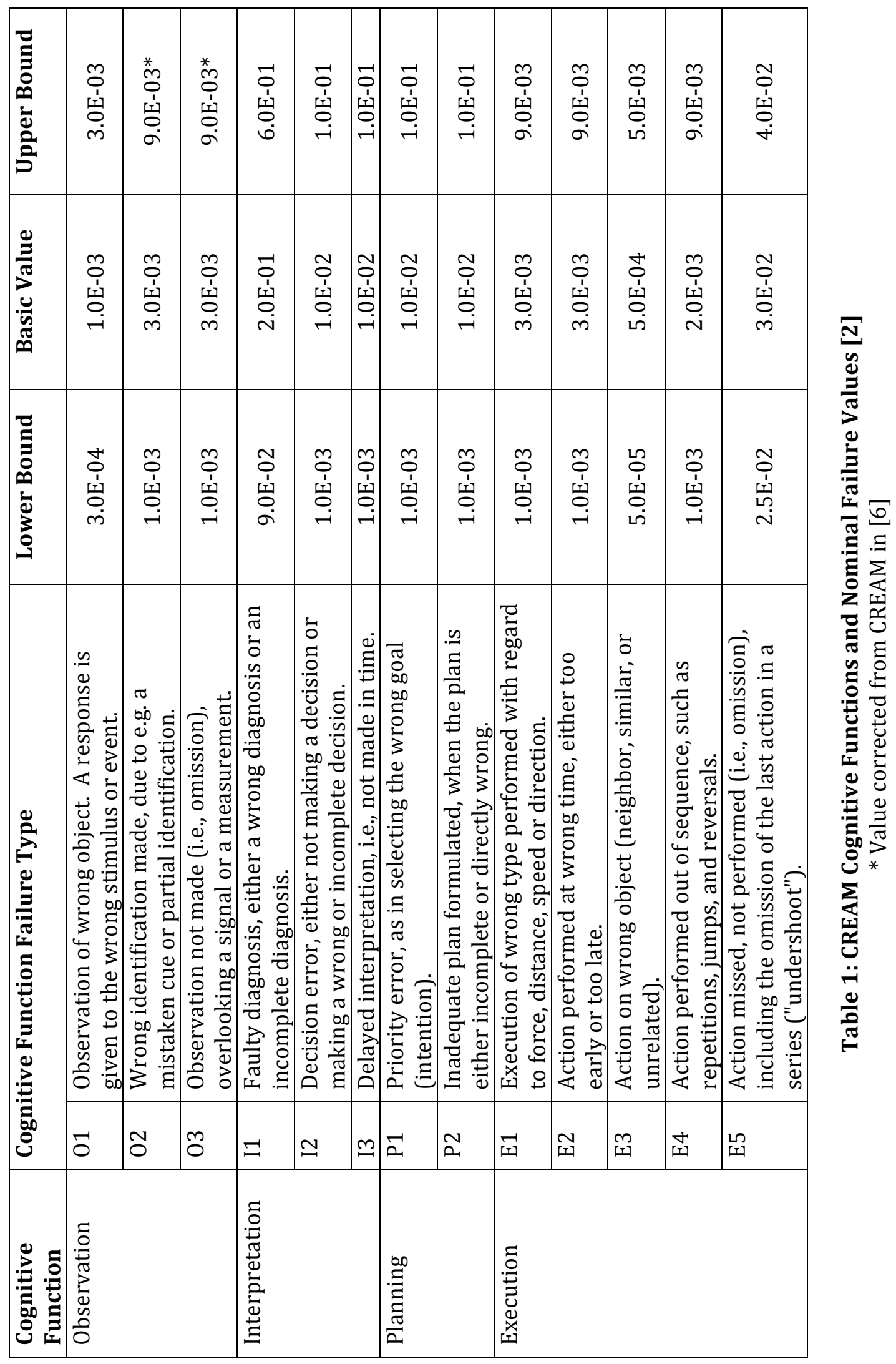




\begin{tabular}{|c|c|c|c|c|c|}
\hline \multirow[t]{2}{*}{ Factor } & \multirow[t]{2}{*}{ Level } & \multicolumn{4}{|c|}{ Cognitive Function } \\
\hline & & Observation & Interpretation & Planning & Execution \\
\hline \multirow{4}{*}{$\begin{array}{l}\text { Adequacy of } \\
\text { organization }\end{array}$} & Very efficient & 1.0 & 1.0 & 0.8 & 0.8 \\
\hline & Efficient & 1.0 & 1.0 & 1.0 & 1.0 \\
\hline & Inefficient & 1.0 & 1.0 & 1.2 & 1.2 \\
\hline & Deficient & 1.0 & 1.0 & 2.0 & 2.0 \\
\hline \multirow{3}{*}{$\begin{array}{l}\text { Working } \\
\text { conditions }\end{array}$} & Advantageous & 0.8 & 0.8 & 1.0 & 0.8 \\
\hline & Compatible & 1.0 & 1.0 & 1.0 & 1.0 \\
\hline & Incompatible & 2.0 & 2.0 & 1.0 & 2.0 \\
\hline \multirow{4}{*}{$\begin{array}{l}\text { Adequacy of } \\
\text { MMI and } \\
\text { operational } \\
\text { support }\end{array}$} & Supportive & 0.5 & 1.0 & 1.0 & 0.5 \\
\hline & Adequate & 1.0 & 1.0 & 1.0 & 1.0 \\
\hline & Tolerable & 1.0 & 1.0 & 1.0 & 1.0 \\
\hline & Inappropriate & 5.0 & 1.0 & 1.0 & 5.0 \\
\hline \multirow{3}{*}{$\begin{array}{l}\text { Availability of } \\
\text { procedures / } \\
\text { plans }\end{array}$} & Appropriate & 0.8 & 1.0 & 0.5 & 0.8 \\
\hline & Acceptable & 1.0 & 1.0 & 1.0 & 1.0 \\
\hline & Inappropriate & 2.0 & 1.0 & 0.5 & 2.0 \\
\hline \multirow{3}{*}{$\begin{array}{l}\text { Number of } \\
\text { simultaneous } \\
\text { goals }\end{array}$} & $\begin{array}{l}\text { Fewer than } \\
\text { capacity }\end{array}$ & 1.0 & 1.0 & 1.0 & 1.0 \\
\hline & $\begin{array}{l}\text { Matching current } \\
\text { capacity }\end{array}$ & 1.0 & 1.0 & 1.0 & 1.0 \\
\hline & $\begin{array}{l}\text { More than } \\
\text { capacity }\end{array}$ & 2.0 & 2.0 & 5.0 & 2.0 \\
\hline \multirow[t]{3}{*}{ Available time } & Adequate & 0.5 & 0.5 & 0.5 & 0.5 \\
\hline & $\begin{array}{l}\text { Temporarily } \\
\text { inadequate }\end{array}$ & 1.0 & 1.0 & 1.0 & 1.0 \\
\hline & $\begin{array}{l}\text { Continuously } \\
\text { inadequate } \\
\end{array}$ & 5.0 & 5.0 & 5.0 & 5.0 \\
\hline \multirow{2}{*}{$\begin{array}{l}\text { Time of day } \\
\text { (circadian } \\
\text { rhythm) }\end{array}$} & $\begin{array}{l}\text { Day-time } \\
\text { (adjusted) }\end{array}$ & 1.0 & 1.0 & 1.0 & 1.0 \\
\hline & $\begin{array}{l}\text { Night-time } \\
\text { (unadjusted) }\end{array}$ & 1.2 & 1.2 & 1.2 & 1.2 \\
\hline \multirow{3}{*}{$\begin{array}{l}\text { Adequacy of } \\
\text { training and } \\
\text { experience }\end{array}$} & $\begin{array}{l}\text { Adequate, high } \\
\text { experience }\end{array}$ & 0.8 & 0.5 & 0.5 & 0.8 \\
\hline & $\begin{array}{l}\text { Adequate, low } \\
\text { experience }\end{array}$ & 1.0 & 1.0 & 1.0 & 1.0 \\
\hline & Inadequate & 2.0 & 5.0 & 5.0 & 2.0 \\
\hline \multirow{4}{*}{$\begin{array}{l}\text { Crew } \\
\text { collaboration } \\
\text { quality }\end{array}$} & Very efficient & 0.5 & 0.5 & 0.5 & 0.5 \\
\hline & Efficient & 1.0 & 1.0 & 1.0 & 1.0 \\
\hline & Inefficient & 1.0 & 1.0 & 1.0 & 1.0 \\
\hline & Deficient & 2.0 & 2.0 & 2.0 & 5.0 \\
\hline
\end{tabular}

Table 2: CREAM Common Performance Conditions and Weight Factors [2] 
An example evaluation of factors and their associated weights for an Observation function is shown in Table 3. For each factor, the analyst determines the condition level with support from experts having insight into the particular scenario being examined. The weight for each factor is then found from Table 2, and the weights are multiplied together to give a total product. This product is multiplied by the nominal failure value found from Table 1 to produce a value that takes the conditions into account.

\begin{tabular}{|l|l|c|}
\hline \multicolumn{1}{|c|}{ Factor } & \multicolumn{1}{c|}{ Level } & Observation Weight \\
\hline Adequacy of organization & Very efficient & 1.0 \\
\hline Working conditions & Compatible & 1.0 \\
\hline $\begin{array}{l}\text { Adequacy of MMI and operational } \\
\text { support }\end{array}$ & Supportive & 0.5 \\
\hline Availability of procedures/plans & Acceptable & 1.0 \\
\hline Number of simultaneous goals & More than capacity & 2.0 \\
\hline Available time & Continuously inadequate & 5.0 \\
\hline Time of day (circadian rhythm) & Night-time (unadjusted) & 1.2 \\
\hline $\begin{array}{l}\text { Adequacy of training and } \\
\text { experience }\end{array}$ & Adequate, high experience & 0.8 \\
\hline Crew collaboration quality & Very efficient & 0.5 \\
\hline \multicolumn{1}{|c|}{ Total Product } & 2.4 \\
\hline
\end{tabular}

Table 3: Sample CREAM Common Performance Condition Evaluations

One shortfall in this approach is that in multiplying the weight factors together, the assumption is that the factors are independent [21]. Guidelines are given for how to take dependencies into account, however, they are not explicit, and provide the chance for different analysts to adjust for dependencies differently. One goal of this research has been to enable modeling of dependencies between Performance Shaping Factors explicitly. 


\subsection{SPACEFLIGHT EFFECTS ON THE CREW}

Given that NASA currently uses the Cognitive Reliability and Error Analysis Method (CREAM) [2] for detailed analysis of human reliability [22], we would like to understand how the Performance Shaping Factors (PSFs) for spaceflight may be different than those of existing methods, such as in CREAM, and why those differences are important. Let us look at each of the CREAM PSFs, and discuss examples of why important differences for spaceflight applications may exist. Table 4 is adapted from prior work [23].

\begin{tabular}{|c|c|c|}
\hline Factor & CREAM Definition [2] & Potential Gap for Spaceflight Application \\
\hline $\begin{array}{l}\text { Adequacy of } \\
\text { organization }\end{array}$ & $\begin{array}{l}\text { The quality of the roles } \\
\text { and responsibilities of } \\
\text { team members, additional } \\
\text { support, communication } \\
\text { systems, Safety } \\
\text { Management System, } \\
\text { instructions and guidelines } \\
\text { for externally oriented } \\
\text { activities, role of external } \\
\text { agencies, etc. }\end{array}$ & $\begin{array}{l}\text { This factor may need to additionally include } \\
\text { NASA organizational aspects such as mission } \\
\text { planning responsibilities. The duration, } \\
\text { destination, and orbits for the mission are } \\
\text { aspects of mission planning determined by } \\
\text { the organization. An example of why these } \\
\text { aspects are important is the desire to select } \\
\text { orbits to minimize radiation exposure, and } \\
\text { thus reduce impacts to crew health and } \\
\text { performance [24]. }\end{array}$ \\
\hline $\begin{array}{l}\text { Working } \\
\text { conditions }\end{array}$ & $\begin{array}{l}\text { The nature of the physical } \\
\text { working conditions such } \\
\text { as ambient lighting, glare } \\
\text { on screens, noise from } \\
\text { alarms, interruptions from } \\
\text { the task, etc. }\end{array}$ & $\begin{array}{l}\text { Unlike working conditions on Earth, a } \\
\text { spacecraft is a closed, isolated environment } \\
\text { in microgravity or partial gravity conditions. } \\
\text { There are additional health concerns without } \\
\text { the benefit of atmospheric composition and } \\
\text { toxin dilution provided by Earth's } \\
\text { environment. One example is carbon dioxide, } \\
\text { produced by human metabolic processes } \\
\text { [24]. Carbon dioxide levels that are too high } \\
\text { may degrade crewmember performance, and } \\
\text { are a source of concern [25] that are not } \\
\text { currently addressed in existing PSFs. }\end{array}$ \\
\hline $\begin{array}{l}\text { Adequacy of } \\
\text { MMI and } \\
\text { operational } \\
\text { support }\end{array}$ & $\begin{array}{l}\text { The Man-Machine } \\
\text { Interface in general, } \\
\text { including the information } \\
\text { available on control } \\
\text { panels, computerized } \\
\text { workstations, and } \\
\text { operational support } \\
\text { provided by specifically } \\
\text { designed decision aids. }\end{array}$ & $\begin{array}{l}\text { In microgravity, the human neutral body } \\
\text { position is altered from that on Earth. An } \\
\text { upright posture is no longer the default, but } \\
\text { more of a stooped position is the norm [5]. } \\
\text { This creates different positions that are } \\
\text { comfortable for working with a user- } \\
\text { interface, and may influence performance } \\
\text { differently than is captured in the current } \\
\text { PSFs. }\end{array}$ \\
\hline
\end{tabular}




\begin{tabular}{|c|c|c|}
\hline $\begin{array}{l}\text { Availability of } \\
\text { procedures / } \\
\text { plans }\end{array}$ & $\begin{array}{l}\text { Procedures and plans } \\
\text { include operating and } \\
\text { emergency procedures, } \\
\text { familiar patterns of } \\
\text { response heuristics, } \\
\text { routines, etc. }\end{array}$ & $\begin{array}{l}\text { This factor may not have an influence very } \\
\text { different in microgravity than it does on } \\
\text { Earth. It is a concern in spaceflight as well as } \\
\text { on Earth, especially in situations where } \\
\text { procedure inputs may come to the crew from } \\
\text { various sources and in different formats with } \\
\text { varying formality. This may force } \\
\text { crewmembers to spend extra time } \\
\text { coordinating the inputs [26]. This factor } \\
\text { must still be included in a set of spaceflight } \\
\text { PSFs. }\end{array}$ \\
\hline $\begin{array}{l}\text { Number of } \\
\text { simultaneous } \\
\text { goals }\end{array}$ & $\begin{array}{l}\text { The number of tasks a } \\
\text { person is required to } \\
\text { pursue or attend to at the } \\
\text { same time (i.e. evaluating } \\
\text { the effects of actions, } \\
\text { sampling new information, } \\
\text { assessing multiple goals, } \\
\text { etc.). }\end{array}$ & $\begin{array}{l}\text { This factor may have a different weight and } \\
\text { threshold for its influence in spaceflight due } \\
\text { to additional stressors in the environment. } \\
\text { An example of how this factor can affect crew } \\
\text { performance is when the Skylab } 4 \text { crew went } \\
\text { on "strike" for a day due to over-work [27]. }\end{array}$ \\
\hline Available time & $\begin{array}{l}\text { The time available to carry } \\
\text { out a task and corresponds } \\
\text { to how well the task } \\
\text { execution is synchronized } \\
\text { to the process dynamics. }\end{array}$ & $\begin{array}{l}\text { Performance of tasks in space may take } \\
\text { longer than anticipated by design on the } \\
\text { ground }[26,28] \text {, and this factor's influence } \\
\text { may be affected by such a difference. In } \\
\text { addition, the dynamic aspects of space flight } \\
\text { during phases such as launch and entry may } \\
\text { need to be addressed specifically in this PSF. }\end{array}$ \\
\hline $\begin{array}{l}\text { Time of } \\
\text { day/circadian } \\
\text { rhythm }\end{array}$ & $\begin{array}{l}\text { The time of day (or night) } \\
\text { describes the time at } \\
\text { which the task is carried } \\
\text { out, in particular whether } \\
\text { or not the person is } \\
\text { adjusted to the current } \\
\text { time (circadian rhythm). } \\
\text { Typical examples are the } \\
\text { effects of shift work. It is a } \\
\text { well-established fact that } \\
\text { the time of day has an } \\
\text { effect on the quality of } \\
\text { work, and that } \\
\text { performance is less } \\
\text { efficient if the normal } \\
\text { circadian rhythm is } \\
\text { disrupted. }\end{array}$ & $\begin{array}{l}\text { This factor must be addressed in a way that } \\
\text { captures the fact that day and night have } \\
\text { different meanings in microgravity. In Low- } \\
\text { Earth Orbit, for example, there is a day/night } \\
\text { cycle approximately every } 90 \text { minutes [24]. } \\
\text { A similar factor to consider in crewmember } \\
\text { performance is the International Space } \\
\text { Station (ISS) practice of "slam shifting", } \\
\text { which is when a large sleep schedule shift } \\
\text { occurs due to an upcoming critical event, } \\
\text { such as docking [26]. Slam shifting may } \\
\text { influence crewmember performance, and is } \\
\text { not currently addressed specifically in a PSF. }\end{array}$ \\
\hline $\begin{array}{l}\text { Adequacy of } \\
\text { training and } \\
\text { experience }\end{array}$ & $\begin{array}{l}\text { The level and quality of } \\
\text { training provided to } \\
\text { operators as } \\
\text { familiarisation to new } \\
\text { technology, refreshing old } \\
\text { skills, etc. It also refers to } \\
\text { the level of operational }\end{array}$ & $\begin{array}{l}\text { Because spaceflight crewmembers must not } \\
\text { only work together, but live together as well, } \\
\text { this factor may need to address aspects of } \\
\text { psychosocial adaptation that benefit from } \\
\text { training [26]. In addition, on long-duration } \\
\text { missions for example, crewmembers may } \\
\text { need to perform tasks for which they have }\end{array}$ \\
\hline
\end{tabular}




\begin{tabular}{|l|l|l|}
\hline & experience. & $\begin{array}{l}\text { not been trained. The balance between } \\
\text { skills-based and task-based training may be } \\
\text { different in the spaceflight context than is } \\
\text { captured in the current definition of this } \\
\text { factor [26]. }\end{array}$ \\
\hline $\begin{array}{l}\text { Crew } \\
\text { collaboration }\end{array}$ & $\begin{array}{l}\text { The quality of the } \\
\text { collaboration between } \\
\text { crew members, including } \\
\text { the overlap between the } \\
\text { official and unofficial } \\
\text { structure, the level of trust, } \\
\text { and the general social } \\
\text { climate among the crew } \\
\text { members, }\end{array}$ & $\begin{array}{l}\text { travel activities is not specifically addressed } \\
\text { in the original definition of this factor, and } \\
\text { may provide for different influences. } \\
\text { Research based on Shuttle/Mir missions } \\
\text { suggest that crew interpersonal compatibility } \\
\text { is important for success [26], yet any } \\
\text { differences compared to the definition of the } \\
\text { Earth-based PSF have not yet been } \\
\text { considered. }\end{array}$ \\
\hline
\end{tabular}

Table 4: Example PSF Gaps for Spaceflight Applications

The conditions of the crewmembers' mental and physical states must also be considered, which are not currently captured in the above CREAM factors. Spaceflight involves crewmembers being separated from their family and friends [29], and this has the potential to affect performance as a consequence of psychological factors. Physiological changes also take place in crewmembers' bodies, such as a cephalic fluid shift [26], a decrease in bone strength [30], altered balance functionality [25], and visual perception changes [5]. A summary of physiological changes is represented in Figure 8 [31]. These changes and many others certainly have the potential to impact crewmembers' performance, and must be taken into account in the set of PSFs, as well. 


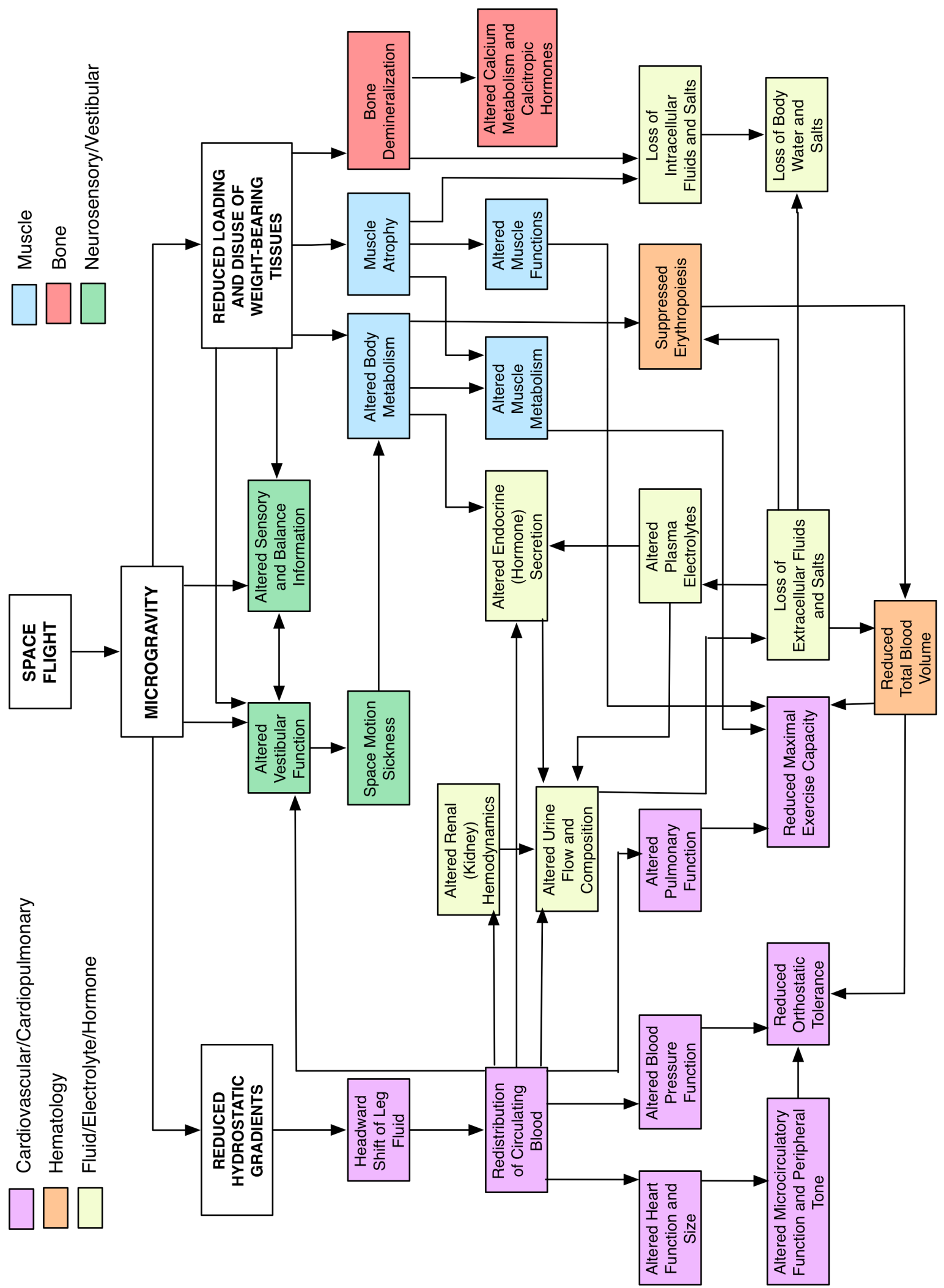

年 


\subsection{RESEARCH OBJECTIVES}

With the context and motivation of this research discussed, the next sections address how the research objectives were met. In summary, the objectives of this research were to:

1. Identify factors influencing the performance of crewmembers in spaceflight.

2. Develop a framework to quantify Performance Shaping Factor influences on task performance for spaceflight applications.

3. Develop an approach to apply new Performance Shaping Factors within a Human Reliability Analysis method for spaceflight applications. 


\section{CHAPTER 3}

\section{FACTOR IDENTIFICATION, ORGANIZATION AND DEFINITIONS}

\subsection{FACTOR IDENTIFICATION AND ORGANIZATION SCHEME}

In order to identify factors that specifically influence human performance in space, a literature review was conducted spanning several disciplines. The intent was to avoid overlooking influential factors as a result of searching from a single point of view. Thus, literature from areas such as human health and performance (including medical, psychological, and cognitive perspectives), human factors, spacecraft design, spaceflight experience, and of course, Human Reliability Analysis, was reviewed to identify relevant factors [1-3, 5, 6, 8, 19, 21, 24-30, 32-43]. In addition, personal discussions have been held with medical, psychological, human factors, mission operations, crew, and safety personnel within NASA for suggested inputs on performance influences.

As discussed in [10], NASA is "struggling with the identification of risk at the right level". As progress through the work of identifying these factors was made, it became evident that there was a need to organize them in order to support the continued characterization of how they can affect performance. A hierarchical scheme, shown in Figure 9, has been developed as part of this research to aid in factor organization and categorization. 


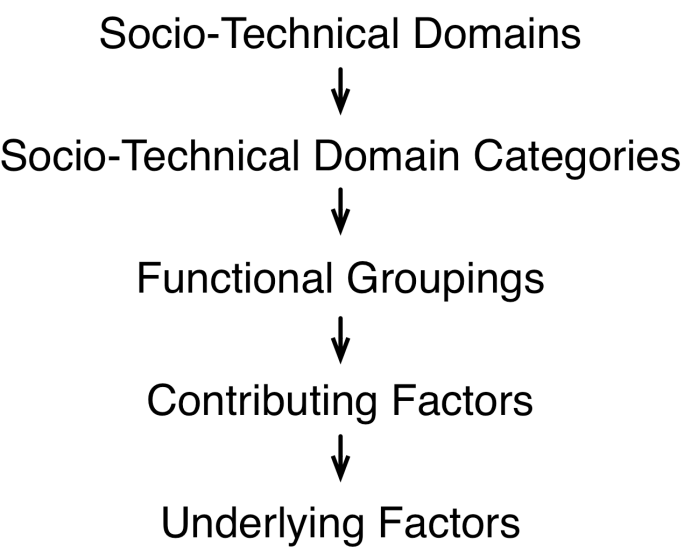

Figure 9: Factor Generalization/Specialization Hierarchy

The hierarchy begins at the most general level with the three major parts of the sociotechnical system within which space missions are built: Operations, Vehicle Design, and the Human. These domains are shown as the colored boxes in the lower left corner of Figure 10 to provide the color key for that diagram. At the next level down, there are "Categories" for ease of decomposition, shown along the vertical left side of Figure 10. These categories are arranged on the diagram in approximately increasing latency of influence, a concept similar to that used in the Human Factors Analysis and Classification System (HFACS) [44] and discussed in [45], with factors directly influencing performance of tasks at the bottom of the diagram, and more latently influencing factors at the top. Next are "Functional Groupings", which are functions the particular domain of the socio-technical system (e.g. Operational Domain) must provide or manage (e.g. Task Familiarity, Work Load, Quality of Procedures). These are shown as the colored boxes in the center of Figure 10, aligned horizontally with their respective Categories. Next, there are "Contributing Factors", that capture aspects of a Functional Grouping that affect either overall task performance or another contributing factor in a different Functional Grouping. Contributing Factors are shown as white boxes inside the colored Functional Groupings. Finally, there are "Underlying Factors", identified as factors that do not have any known direct effects on anything outside their Functional Grouping. The complete list of Underlying Factors is too numerous to be shown in Figure 10. 


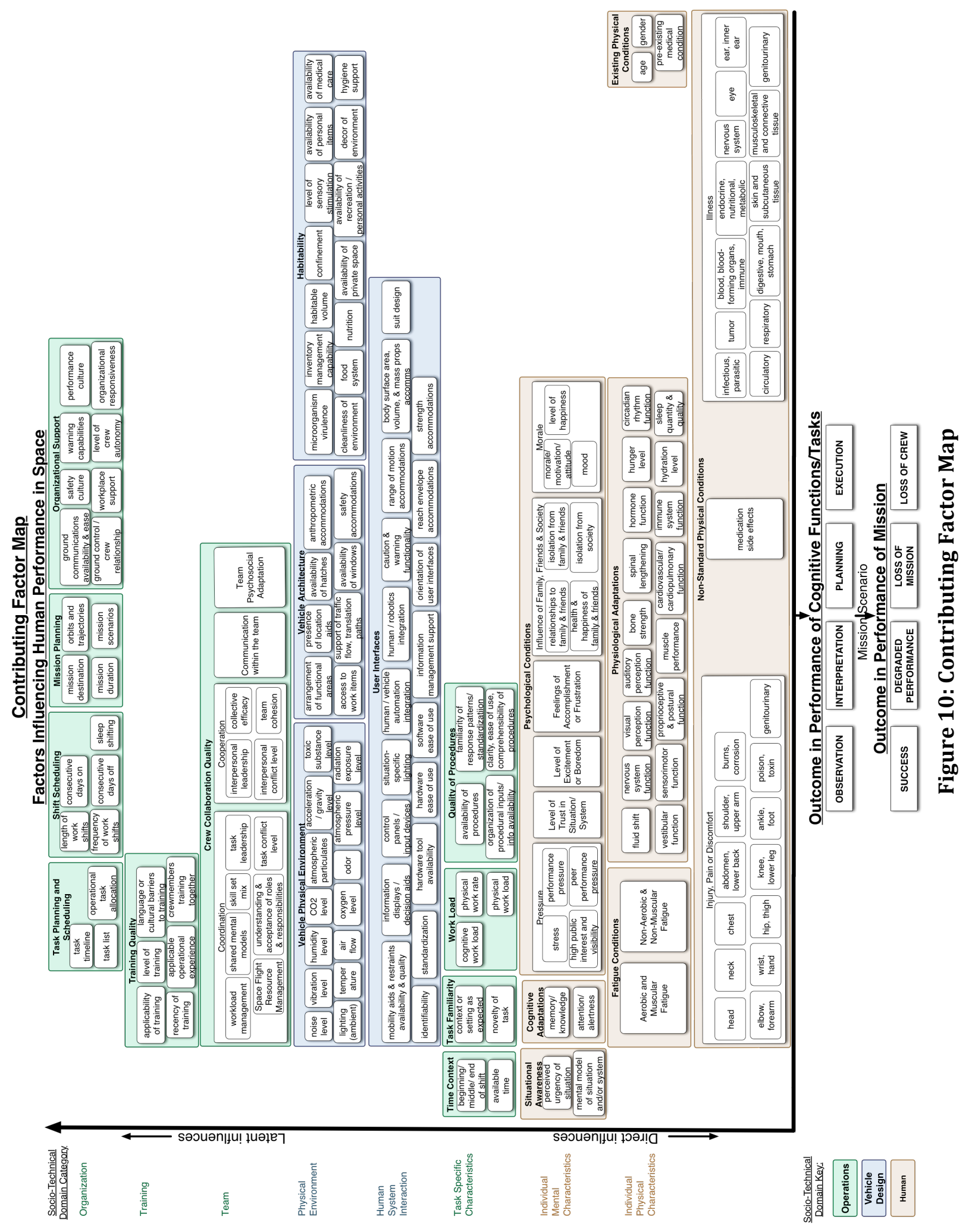


The diagram shown in Figure 10 also provides visual context for relating the set of factors influencing performance to overall mission success. Above the bottom horizontal line are the factors influencing performance of tasks. Below the line is an arrow pointing to the types of tasks crewmembers must perform, as used in the CREAM method [2]. These functions must be performed as part of various mission scenarios, represented by the next arrow pointing down, and are often captured in a Probabilistic Risk Assessment (PRA) framework. When the mission scenarios are analyzed in such as framework, the outcome in terms of overall mission success can be evaluated. Typical outcomes of interest are represented by the lowest set of boxes in Figure 10. Next we discuss each of the Contributing Factors shown in Figure 10 and some of their potential influences on other factors and/or performance of tasks. 


\subsection{DEFINITIONS OF CONTRIBUTING FACTORS}

Identifying the contributing factors influencing performance in space is an early step toward defining a set of PSFs for spaceflight applications. This section discusses the set of Contributing Factors and their space-domain definitions that form the starting point for determining the PSFs. The section is organized according to the organizational hierarchy. For references that are hundreds of pages in length, the associated page numbers are provided.

\subsubsection{OPERATIONS DOMAIN}

The Operations Domain, as represented by the green box in the lower left corner of Figure 10, is decomposed into the Domain Categories of Organization, Training, Team and Task Specific Characteristics. This section discusses the Contributing Factors within the Operations Domain.

\subsubsection{Organizational Factors}

The Organization Domain Category, shown on the upper left side of the latency axis in Figure 10, is decomposed into the Functional Groupings of Task Planning and Scheduling, Shift Scheduling, Mission Planning and Organizational Support.

\section{Task Planning and Scheduling}

$\underline{\text { Task Timeline }}$

Task Timeline addresses if there are too few or too many tasks to be accomplished during a work period, the flexibility of their ordering or necessity for being accomplished during the work period, and if adequate direction and context is provided for tasks outside of the procedures. 
Procedure adequacy is addressed by quality of procedures factors. This factor also addresses the management of the balance between high intensity task timelines with adrenaline and excitement and lower intensity timelines to allow for rejuvenation, especially during long-duration missions. [[26] pps. 21, 258, 361; [24] pps. 164-165; [33, 36]]

$\underline{\text { Task List }}$

Task List refers to the existence of tasks that are not currently assigned on the task timeline, but are noted in case time is available to fit them in. The state of this factor may influence factors such as work load, performance pressure, or feelings of accomplishment. [[26] pps. 21, 258; [24] pps. 164-165; [33, 36]]

\section{$\underline{\text { Operational Task Allocation }}$}

Operational Task Allocation refers to the appropriateness of the operational, as opposed to design, task assignment to an individual, vehicle automation, and/or robotics. This factor addresses whether the tasks are assigned to crewmembers, ground personnel, or automation with the proper capabilities, availability, training, and experience, but does not include an evaluation of the training or experience themselves, as covered by training and task familiarity factors. [[26] pps. 21, 269; [24] pps. 139-141; [29] pps. 208-209; [36, 44]]

\section{Shift Scheduling}

\section{Length of Work Shifts}

Length of Work Shifts addresses whether the work period is too long and may contribute to fatigue, or too short to allow for transition into and out of tasks. [[26] pps. 88, 94, 107; [5] pp. 181; [25] pp. 49; [24] pp. 164-165; [44, 46]]

\section{Frequency of Work Shifts}

Frequency of Work Shifts addresses whether the time in between consecutive work shifts is long enough for rest, relaxation, and recovery. [[26] pps. 88, 94, 107; [5] pp. 181 ; [24] pp. 164-165; $[44,46]]$ 


\section{Consecutive Days On}

Consecutive Days On addresses whether the number of consecutive days with work periods is too many and may contribute to fatigue, or too short to allow for accomplishment of longerduration tasks. [[26] pps. 21, 94, 107; [5] pp. 181 ; [24] pp. 164-165; [44, 46]] Consecutive Days Off

Consecutive Days Off refers to whether the time between groups of work shifts is too short to allow for rest, relaxation, and recovery, or if it is too long and contributes to slower adjustment to the work situation. [[26] pps. 21, 94, 107; [5] pp. 181; [24] pp. 164-165; [44, 46]]

\section{Sleep Shifting}

Sleep Shifting addresses the severity of the time zone shift(s) in terms of number of hours shifted, how often shifts have been required in recent days, and amount of sleep scheduled. This factor captures effects due to the practice of slam shifting, which is often undertaken before critical events such as docking. [[26] pps. 20, 85, 94, 99, 107; [24] pps. 164-165; [44, 46]]

\section{Mission Planning}

\section{Mission Destination}

Mission Destination allows for influences of destination characteristics and environmental factors, such as radiation environment, thermal environment, magnetic properties, surface composition, and atmospheric composition to be included as more latent influences than the more direct vehicle physical environment factors. [[5] pps. 443-447; [24] pp. 162; [34] pps. 109-110] Mission Duration

Mission Duration allows for the influence the length of the mission itself may have on other, less latent, factors such as those in the psychological conditions, physiological adaptations, and nonstandard physical conditions groupings. [[24] pp. 162; [26] pp. 69; [34] pps. 109-110] 


\section{$\underline{\text { Orbits and Trajectories }}$}

Orbits and Trajectories accounts for the influences the mission design of orbits, maneuvers, and trajectories may have on factors such as mission destination, mission duration and the vehicle physical environment. [[24] pp. 162]

$\underline{\text { Mission Scenarios }}$

Mission Scenarios addresses the influences the planned scenarios have on shift scheduling, task planning and scheduling, other mission planning, and mental and physical characteristic factors. This includes accounting for whether scenarios exist to achieve a safe state or reach a safe environment, and the influence the knowledge of this capability may have on the crew. [[26] pp. 5, 21]

\section{Organizational Support [2]}

\section{Ground Communications Availability and Ease}

Ground Communications Availability and Ease refers to the technological capabilities supporting communication between ground and flight. This takes into account the clarity, reliability during normal and emergency (e.g. sabotage or hurricane) conditions, and available frequency or time delay of voice, visual, and text communication. It includes bandwidth capabilities of the communication, as well. It is not intended to cover relationship aspects between the crewmembers and ground personnel. [[26] pps. 68, 263; [47] pps. 151-154; [25]; [24] pps. 161, $165,166]$

\section{Ground Control/Crew Relationship}

Ground Control/Crew Relationship accounts for the quality of the relationship in terms of openness, honesty, and level of trust between crewmembers and ground control. This factor addresses the relationships between crewmembers and ground control, but does not include relationships to family and friends on the ground. Observed tension in this relationship is sometimes categorized as crew "displacement". The factor "Level of Crew Autonomy" may be 
related because as crew autonomy decreases, the importance of this factor may increase. [[26] pps. 10, 21, 45, 283; [30] pps. 36, 43; [24] pp. 158]

\section{$\underline{\text { Safety Culture }}$}

Safety Culture addresses the organization's attention and dedication to safety, safety processes, open communication regarding safety issues, and support of safety-conscious actions without inhibiting the efficiency of the organization. It also takes into account if the organizational safety culture allows for the development of complacency over time or if effective processes are in place to prevent that. [[26] pp. 269, [5] pp. 232; [29] pp. 241; [33, 36, 44, 48]]

\section{$\underline{\text { Organizational Responsiveness }}$}

Organizational Responsiveness refers to the ability of processes such as operational activity planning, system engineering, logistics, material and acquisitions to respond to crew needs. This may be related to "Ground Control/Crew Relationship" as the relationship may act as and initial channel for feedback from the crew to the ground regarding various needs. [44] Workplace Support

Workplace Support allows for the influence of human resources, employee relations, psychological, and medical consultation support offered by the organization during a mission. This includes support offered to crew family members during a mission, as well. [[26] pp. 67; [30] pp. 47; [29] pps. 197-205; [24] pps. 169-188; [33]]

\section{Level of Crew Autonomy}

Level of Crew Autonomy addresses the amount of independence from ground support the crewmembers have in decision-making, planning, and implementation of activities in the context of the mission and its tasks. [[26] pps. 21, 48, 64, 68-69, 289-291; [24] pp. 165; [49]]

\section{Performance Culture}

Performance Culture refers to the organization's expectation for task accomplishment quality and quantity. There may be an expectation of flawless performance imposing additional 
stress. This factor may be related to "Task Planning and Scheduling" factors and "Psychological Conditions" factors such as "Morale”. [[24] pp. 165; [44]]

Warning Capabilities

Warning capabilities refers to the technological abilities of the organization to give the crewmembers advanced notice of impending environmental (i.e. not easily detectable by vehicle systems) danger, such as a solar particle radiation event. [[26] pps. 183-184]

\subsubsection{Training Factors}

The Training Domain Category, shown on the upper left side of the latency axis in Figure 10, is defined by its Functional Grouping Training Quality.

\section{Training Quality $[2,44]$}

\section{Applicability of Training}

Applicability of Training addresses the similarities between training for a task and the performance of the task in the operational setting, including how realistic the training is. It differs from Task Familiarity factors in that it covers the applicability of training materials, facilities, training hardware and software, simulators, and training processes for on-orbit and ground training, but not the task-specific context and circumstance similarities. [[26] pp. 55; [5] pps. 218$219 ;[33]]$

\section{$\underline{\text { Recency of Training }}$}

Recency of Training accounts for how much time has passed between training or similar task performance and the current operational setting. The training may have been on the ground or in-flight. This differs from "Task Familiarity" factors in that it addresses the time gap between 
skill practice and current operations, not whether a task is novel in its occurrence in the operational setting. [[26] pp. 285; [50]]

Level of Training

Level of Training refers to whether the training the crewmember has received is at a beginning, moderate, or advanced level. [[5] pps. 218-219]

Applicable Operational Experience

Applicable Operational Experience accounts for whether the crewmember has had previous experience performing tasks in the operational environment beyond training exercises. [[5] pps. 218-219]

Language or Cultural Barriers to Training

Language or Cultural Barriers to Training addresses the international nature of many spaceflight efforts by taking into account that language and culture may influence the effectiveness of the training process. [27]

Crewmembers Training Together

Crewmembers Training Together also refers to the international nature of many spaceflight efforts and other logistical factors that may cause difficulties in scheduling crewmember training activities together. This factor likely influences the factors within "Crew Collaboration Quality". [[26] pps. 45, 55, 56, 58; [25]]

\subsubsection{Team Factors}

The Team Domain Category, shown near the middle of the latency axis in Figure 10, is defined by its functional Grouping Crew Collaboration Quality. 


\section{Crew Collaboration Quality [2]}

\section{Coordination $[11,36,44]$}

Coordination is further decomposed into seven factors:

\section{Workload Management}

Workload Management addresses how well the crewmembers as a team identify work priorities and efficiently allocate tasks within the team. This factor may be especially influential in management of situations requiring team coordination, such as emergencies, large maintenance efforts, or docking operations. This factor may be influenced by pre-assigned operational task allocations. [[26] pps. 57, 283; [5] pps. 244-245; [44]]

Space Flight Resource Management

Space Flight Resource Management refers to how well the crewmembers utilize the resources on board the vehicle besides themselves, such as hardware and software. This factor may be especially important when international assets or international coordination is involved. [[26] pp. 57; [44]]

\section{Shared Mental Models}

Shared Mental Models accounts for the influences of crewmembers on a team having a common understanding of the system, the situation and the team's relationships to the system and situation. This factor may be influenced by training factors. [[26] pps. 54, 56, 62; [5] pps. 225-226] Skill Set Mix

Skill Set Mix addresses how complementary the combined set of crewmember skills may be. This includes technical skills, knowledge, and interpersonal skills, as well. This factor also includes the awareness and understanding of other team members' skills each individual may have. [[26] pps. 48, 53, 58; [30] pp. 218; [5] pps. 227-228, 238-255; [24] pp. 164; [36]] 


\section{Understanding and Acceptance of Roles and Responsibilities}

Understanding and Acceptance of Roles and Responsibilities accounts for the awareness and adherence to the assignment of roles and responsibilities given either externally or from within the team. The satisfaction with the assignment of the roles and responsibilities is included in this factor, also, and is likely seen by the degree of acceptance. [[26] pps. 49, 54, 57, 64-65, 283; [24] pps. 164, 166; [33, 36]]

\section{Task Leadership}

Task Leadership addresses the presence and suitability of the guidance within the team for accomplishing tasks. "Interpersonal Leadership" is a similar factor discussed as an aspect of cooperation, but differs from this task-focused factor. [[26] pps. 49, 55, 63; [5] pps. 241-243; [36, 44]]

\section{Task Conflict Level}

Task Conflict Level refers to the existence of friction over how to accomplish tasks, handle work situations or choose alternatives. Certain levels of task conflict may be beneficial to performance, especially if crewmembers catch each others' mistakes or discuss ideas from different viewpoints. International and cultural differences may influence approaches to decision-making and implementation, and may contribute to this factor, as well. [[26] pps. 54, 61; [5] pp. 232]

\section{Cooperation [11]}

Cooperation is further decomposed into four factors. These factors relate more to the interpersonal aspects of crew collaboration than the task-focused coordination factors. Interpersonal Leadership

Interpersonal Leadership addresses the presence and suitability of counsel and guidance within the team for non-task issues and situations. This type of leadership does not necessarily need to be provided by the same person or people as task leadership, and its quality can influence the underlying dynamics for task performance. [[26] pps. 49, 55, 63; [5] pps. 241-243] 
Interpersonal Conflict Level

Interpersonal Conflict Level refers to the presence of friction due to personality, political, cultural, spiritual, religious, or any other personal differences. As with "Task Conflict Level", certain levels of interpersonal conflict may be beneficial, such as when different views expand opposing perspectives and contribute to improved ideas. However, severe levels of interpersonal conflict may influence performance in damaging ways. [[26] pps. 45, 49, 54, 58, 61; [30] pps. 34-35; [5] pp. 232]

Collective Efficacy

Collective Efficacy addresses the effectiveness of the team working together to accomplish tasks and create a cooperative living and working environment. This addresses the aspects of living and working together, especially for peripheral tasks such as living and working neatly and cleanly, that make the experience as a whole proceed more smoothly and effectively. [[26] pp. 45]

\section{Team Cohesion}

Team Cohesion accounts for the sense of unity, trust and bonds present between the crewmembers, creating a desire to support each other and live and work together in a positive manner. If the state of cohesion is less than desirable, motivation to act as a collaborative team may be reduced. [[26] pps. 45, 55, 63; [5] pps. 230-231; [36]]

\section{Communication Within the Team [11]}

Communication Within the Team addresses the quality of the verbal and non-verbal communication crewmembers have with each other. Certainly international, cultural and personality differences are influential to this factor, along with training, cooperation and even noise and vehicle communication hardware factors. [[26] pps. 9, 45, 54, 57; [5] pps. 229-230, 237; [36, 44]] 


\section{Team Psychosocial Adaptation [11]}

Team Psychosocial Adaptation refers to the social climate and social support available within the team. It addresses how well the crewmembers adjust psychologically and socially to the new working and living environment and develop an inclusive social structure. This factor may be influenced by task and shift scheduling factors in terms of providing time, such as meal times, for the crewmembers to be together in a social setting. It may also be influenced by vehicle habitability factors such as habitable volume for provision of community space. [[26] pps. 9, 12, 13, 44, 48, 53, 58, 59, 65; [5] pps. 233, 237; [30] pps. 33-50; [24] pp. 158; [51] pps. 427-430]

\subsubsection{Task Specific Characteristics}

The Task Specific Characteristics Domain Category, shown near the middle of the latency axis in Figure 10, is decomposed into the Functional Groupings of Time Context, Task Familiarity, Work Load and Quality of Procedures.

\section{Time Context}

$\underline{\text { Available Time }}$

Available Time addresses the dynamics of a situation by accounting for the amount of time available compared to what is needed for a task's completion. This is particularly important during dynamic phases of a mission such a launch or entry. [[26] pp. 258; [5] p. 181; [47] pp. 24; [2, 33, 36, 44]]

Beginning/Middle/End of Shift

Beginning/Middle/End of Shift refers to any effects on performance due to the inertia of starting a shift, lulls during a shift, or fatigue or rushing at the end of a shift. [[26] pp. 94; [46]] 


\section{Task Familiarity}

\section{Context or Setting as Expected}

Context or Setting as Expected addresses whether the information provided by the context or setting for the task allows for the correct interpretation of the information or brings confusion to the true meaning and task requirements because it is not provided in the expected manner. [[5] pp. $218 ;[36]]$

Novelty of Task

Novelty of Task accounts for the influence of having experience performing a particular task. For example, performance (in terms of time to complete, number of errors, etc.) of a new task may differ from performance of a task that has been completed many times by the crewmember. [[5] pps. 218-219]

\section{Work Load [2]}

\section{$\underline{\text { Cognitive Work Load }}$}

Cognitive Work Load refers to the number and complexity of simultaneous cognitive demands. Too little cognitive work load may affect performance by leading to boredom, complacency, or lack of proficiency. A large cognitive work load may be more than the crewmember can process and execute successfully. An appropriate amount of work load may offer beneficial stimulation. Abrupt changes in work load, such as in an emergency or after intense time periods, may influence performance, also. [[26] pps. 10, 48, 87-89, 100, 284-285, 304; [5] pps. 190 222, 911; [47] pp. 25; [24] pp. 164; [33, 36, 42, 44, 50]]

\section{Physical Work Rate}

Physical Work Rate addresses if physical tasks are required at a rate incompatible with human capabilities. This differs from the Available Time factor in that it is with respect to human capabilities, not the dynamics of the vehicle or system. [[26] pp. 87; [33]] 
$\underline{\text { Physical Work Load }}$

Physical Work Load addresses if physical tasks are required at an intensity or load incompatible with human capabilities. This addresses whether the task load is compatible with cardiovascular, pulmonary, and musculoskeletal capabilities. This does not, however, address user interface Strength Accommodations considerations. [[26] pp. 87; [5] pps. 94-102; [34] pp. 156; [33]]

\section{Quality of Procedures [2, 44]}

\section{$\underline{\text { Availability of Procedures }}$}

Availability of Procedures addresses if procedures are close-at-hand or easily accessible, either electronically or physically. This also addresses whether procedures exist for the task or situation. [[26] pp. 255; [33, 36]]

\section{Organization of Procedural Inputs/Information Availability}

Organization of Procedural Inputs/Info Available refers to how well the information needed to complete the task is consolidated or easily found by the crewmember. This addresses the effects of having to locate necessary information outside of pertinent procedures in order to complete the task. [[26] pp. 256, 260-261, 285; [47] pps. 136-137; [33]]

\section{Familiarity of Response Patterns/Standardization}

Familiarity or Response Patterns/Standardization addresses the commonality and consistency of procedure styles and patterns. It accounts for the use of having bold, simple, highlighted, bulleted and indented formats consistently across procedures. It also addresses the use of common terminology and nomenclature. It may relate to "Applicability of Training" when using the same procedures and standard formats during training and operations, and "Task Familiarity" for experience with of patterns of steps. [[26] pp. 256; [47] pps. 131-133; [33]] 


\section{Clarity, Ease of Use, Comprehensibility of Procedures}

Clarity, Ease of Use, Comprehensibility or Procedures accounts for the usability of the procedures. It addresses if the procedures are properly developed for an expert versus a new user. It also includes whether procedures support the crewmember's ability to find a place in a procedure easily. Especially important are the procedure's inclusion of images, especially for tasks such as maintenance on which crewmembers may not have specifically trained. This factor also addresses emergency procedure clarity, including providing them in each crewmember's native language. A relationship to "Organizational Responsiveness" may exist to account for data availability within the organization for procedure writers to create accurate procedures. [[26] pps. $256,258,286 ;[33,36]]$

\subsubsection{VEHICLE DESIGN DOMAIN}

The Vehicle Design Domain, as represented by the blue box in the lower left corner of Figure 10, is decomposed into the Domain Categories of Physical Environment and Human System Interaction. This section discusses the Contributing Factors within the Vehicle Design Domain.

\subsubsection{Physical Environment}

The Physical Environment [1] Domain Category, shown near the upper left in Figure 10, is decomposed into the Functional Groupings of Vehicle Physical Environment, Vehicle Architecture and Habitability. 


\title{
Vehicle Physical Environment
}

\author{
$\underline{\text { Noise Level }}$
}

Noise Level refers to the acoustic environment in the vehicle. Noises may exist due to launch, entry, or emergency conditions, or from equipment with moving parts such as motors, fans and payloads during nominal operations. This factor addresses the influences of noise over various time frames, from intense acoustic levels over brief time spans, to lower levels persistent over time. [[26] pps. 21, 98, 258, 270; [5] pps. 181, 396-417; [47] pps. 53-60; [25, 43]; [24] pps. 104, 116-118, 164; [52] pps. 95-122; [36]]

Vibration Level

Vibration Level accounts for any physical vibration imparted to the crewmember. It may be influenced by "Orbits and Trajectories" and "Mission Scenarios". This factor may influence physical comfort, organ health, fatigue, vision, and motor control. [[26] pp. 21; [47] pps. 60-62; [5] pp. 418; [24] pps. 104, 118-120; [52] pps. 95-122;]

\section{Lighting (Ambient)}

Lighting (Ambient) refers to the ambient lighting throughout the vehicle. Localized, or task, lighting is addressed in the factor "Situation-Specific Lighting". This factor takes into account such conditions as a 90-minute day-night cycle in Low Earth Orbit and stowage obstructing ambient light. It also addresses the influence of ambient lighting on color perceptions, glare, circadian rhythm function, fatigue, mood, and task performance. [[26] pps. 85, 99-108, 115, 263, 270-272; [5] pps. 624-643; [47] pps. 107-109; [52] pps. 95-122; [24] pps. 104, 121, 164; [36, 43]]

\section{Temperature}

Temperature addresses the thermal conditions within the vehicle. "Mission Planning" factors such as "Mission Destination", "Orbits and Trajectories", and "Mission Scenarios" influence the external thermal conditions for the vehicle. This factor accounts for any temperature influences 
on comfort, health, and performance. [[26] pp. 98; [5] pps. 332-338; [47] pps. 30-32; [52] pps. 6173; [25, 43]; [24] pps. 55, 104, 111-113, 164; [34] pps. 91-93]

$\underline{\text { Humidity Level }}$

Humidity Level addresses the moisture conditions within the vehicle. This factor may be influenced by "Mission Scenarios" due to crew activities, such as exercise countermeasures, that produce increased respiration and perspiration. It may influence comfort, health, and performance similar to the factor "Temperature". [[5] pp. 339; [47] pp. 29; [34] pps. 91-93; [25]; [24] pp. 105] $\underline{\text { Air Flow }}$

Air Flow refers to the circulation of air within the vehicle. Except for phases on the surface of planetary bodies, the lack of gravity, and therefore convection, during spaceflight often requires air flow within the vehicle to be driven by fans. The state of this factor may influence comfort, health, and performance. [[26] pp. 263; [5] pp. 340; [47] pp. 33; [24] pp. 110] $\underline{\mathrm{CO}_{2}} \underline{\text { Level }}$

$\mathrm{CO}_{2}$ (Carbon Dioxide) Level addresses the affects caused by this gas produced by human respiration. This factor may be influenced by "Mission Scenarios" due to crew activities, such as exercise countermeasures, that produce increased respiration. It may also be influenced by “Air Flow", as pockets of $\mathrm{CO}_{2}$ have been noted to develop in areas immediately near crewmembers without circulation. It may influence comfort, health, and performance. [[5] pps. 314-331; [47] pp. 27; [52] pps. 21-25; [34] pps. 91-93; [25]]

\section{Oxygen Level}

Oxygen Level takes into account influences due to having too much or too little oxygen in the vehicle atmosphere, leading to hyperoxia or hypoxia, respectively. The presence of atmospheric particulates such as lunar dust and high partial pressures of other gases such as $\mathrm{CO}$ and $\mathrm{CO}_{2}$ may lead to altered levels of oxygen in the vehicle atmosphere, influenced by "Mission Scenarios". This 
factor influences health and cognitive performance. [[25]; [5] pps. 182-183, 314-331; [47] pp. 27;

[52] pps. 13-21; [34] pps. 91-93; [53]]

$\underline{\text { Atmospheric Particulates }}$

Atmospheric Particulates addresses effects due to particles in the vehicle environment.

"Habitability" factors such as "Cleanliness of Environment" will influence this factor due to the presence of nuisance dust or lunar dust, for example. "Safety Accommodations" may influence this factor, as well, depending on the type of fire prevention devices present in the vehicle and the particles produced by them. This factor may influence "Oxygen Level" by causing obstructions on the lungs and may increase possibility of eye injury. [[26] pps. 263, 317-330; [5] pps. 342, 345; [47] pps. 42-43; [52] pps. 37-57; [34] pps. 91-93; [25]; [24] pp. 110, 125]

$\underline{\text { Odor }}$

Odor refers to scents within the vehicle and their influences. Odors may be due to vehicle component off-gassing, chemicals used in operations, and human waste. It may influence comfort, health, and performance. [[5] pp. 499; [24] pps. 111, 121-122]

Acceleration/Gravity Level

Acceleration/Gravity Level accounts for influences due to linear, rotational, and impact accelerations for dynamic phases of missions, along with the level of gravity during non-dynamic phases of missions such as interplanetary cruise. Limits exist for the amount of each type of acceleration that human bodies can withstand, and health and performance degradations occur before those limits are reached. The limits may differ depending on the conditioning of a crewmember to various gravity levels, and whether the crewmember is injured or ill. This factor also addresses when a crewmember is present in a certain gravity level while operating a remote asset, such as a rover or robotic arm, at a different gravity level. [[47] pps. 45-53; [5] pps. 375-395; [24] pps. 115-116; [51] pps. 279-345; [34] pps. 58-59] 
$\underline{\text { Atmospheric Pressure Level }}$

Atmospheric Pressure Level addresses the influence of the state of the vehicle atmospheric pressure. The pressure level may be altered due to leakage, hull penetration, or damage. This factor affects health and potentially cognitive performance. [[26] pp. 304; [5] pps. 314-331; [47]

27-28; [25]; [24] pps. 104-105, 164; [52] pps. 1-30; [34] pps. 64, 91-92; [53, 54]]

Toxic Substance Level

Toxic Substance Level accounts for the presence of any toxic substance or gas within the vehicle environment. This may be caused by items such as hydrazine from vehicle thrusters deposited on an Extra-Vehicular Activity suit and brought back inside the vehicle, a leak of an ammonia cooling line, or fire suppression devices. This factor influences health and cognitive performance. [[26] pp. 255; [5] pps. 342, 345-353; [47] pps. 26, 34-35, 41-42; [52] pps. 37-57; [25, 27, 54]; [24] pps. 56, 111]

$\underline{\text { Radiation Exposure Level }}$

Radiation Exposure Level refers to effects from acute and long-term exposure to radiation. "Orbits and Trajectories" can influence this factor, as design choices such as avoidance of flying through the South Atlantic Anomaly can reduce exposure. "Warning Capabilities" may also influence this factor because, for example, if a solar radiation event can be detected by the ground and communicated to the crew, they can evacuate to a more shielded location within the vehicle if one exists. Radiation Exposure Level certainly influences health and likely cognitive performance, as well. [[26] pps. 16, 171-190, 263; [47] pps. 63-68; [30] pps. 54-74; [5] pps. 419-474; [51] pps. 365-412; [34] pps. 51-54; [25]; [24] pps. 104, 113-115, 164]

\section{Vehicle Architecture}

$\underline{\text { Arrangement of Functional Areas }}$

Arrangement of Functional Areas addresses the topology or configuration of areas within the vehicle. It takes into account the influence of having equipment or facilities used in logical 
sequences of operations placed relatively close together and of areas that have interfering functions to be physically separate. Example considerations are placing a noisy component distant from sleeping quarters and locating waste management separate from food preparation and dining areas. [[26] pps. 270, 272; [47] pps. 76, 94; [5] pps. 490-491, 507-513, 530-533, 544, 572-577; [24] pp. 164; [52] pps. 142-145; [43]]

\section{$\underline{\text { Access to Work Items }}$}

Access to Work Items refers to the level of ease with which a crewmember may physically access, obtain, or reach physical components or visually view needed displays or information. It capture effects of design aspects such as avoiding the placement of frequently used components in hard-to-reach locations. This factor may be influenced by "Inventory Management Capability" if stowage is obstructing access to or viewing of components. [[5] pps. 517-523]

\section{$\underline{\text { Presence of Location Aids }}$}

Presence of Location Aids addresses aspects of the vehicle architecture employed to assist the crewmember in quickly recognizing location within the vehicle. Aids may include colors for particular modules, consistency of the orientation of labels within modules (e.g. "up" remains consistent throughout the vehicle), and labels, arrows, and/or diagrams to indicate module names, orientations, and locations (similar to road signs). [[26] pp. 270; [5] pps. 578-586; [47] pps. 95-96; [52] pps. 145-146]

\section{Support of Traffic Flow, Translation Paths}

Support of Traffic Flow, Translation Paths addresses the vehicles accommodations for crewmember motion throughout. This is particularly important in emergency egress situations, and may be related to "Presence of Locations Aids" in this respect. This factor may also be influenced by the protrusion of temporary stowage, which can be captured by the factor "Inventory Management Capability". [[26] pps. 270, 272; [5] pps. 587-591; [47] pps. 96-98; [52] pp. 146] 


\section{Availability of Hatches}

Availability of Hatches refers to the presence and ease of use of hatches in the vehicle and their accessibility. It may also cover the appropriateness of their size and shape, especially if suited operation is required. This factor may be especially important in emergency situations. [[5] pps. 592-594; [47] pps. 99-101]

Availability of Windows

Availability of Windows addresses whether windows are present in the spacecraft, and the suitability of their optical quality, size, shape, orientation and accessibility. This factor may influence task performance when viewing supports task completion, such as in a docking manuever. This factor may also influence psychological factors, especially for missions and mission phases when viewing opportunities are available, such as a planetary orbit. [[26] pps. 21, 276; [5] pps. 595-623; [47] pps. 104-107; [52] pp. 148; [24] pp. 175]

\section{Anthropometric Accommodations}

Anthropometric Accommodations accounts for how well the vehicle provides for the fit of crewmembers. It addresses clearance for translation and seating, altered posture in microgravity considerations, and clothing or suit effects on crewmember size. [[26] pp. 274; [47] pps. 17-19; [5] pps. 40-52; [33]]

\section{$\underline{\text { Safety Accommodations }}$}

Safety Accommodations refers to the presence of items such as fire extinguishers and emergency lighting. It also includes features such as rounded, not sharp, corners on hardware, acceptable touch temperatures and electrical hazard protection. [[47] pps. 111-119, 125-129; [26] pp. 269; [29] pps. 243-255; [24] pps. 193-211, 591] 


\section{Habitability}

Microorganism Virulence

Microorganism Virulence addresses the potential effects of increased microorganism virulence in microgravity. This factor may have influences from "Acceleration/Gravity Level" and “Cleanliness of Environment”. It may affect crewmember health and performance. [[26] pp. 290; [47] pps. 41-45; [52] pps. 77-90]

\section{Cleanliness of Environment}

Cleanliness of Environment refers to the sanitary conditions of the vehicle. It includes the sanitary conditions of surfaces and the air, and the vehicle's capabilities for supporting the conditions by providing food preparation surfaces, materials for cleaning the surfaces, and facilities to deal with the accumulation of garbage such as food packaging. [[26] pps. 21, 290, 308; [5] pps. 342-344, 371-374, 490, 503-506, 524-529, 537-543; [47] pps. 41-45, 91-92; [52] pps. 77-90, 153$154 ;[24]$ pps. 593, 594; [25]]

$\underline{\text { Inventory Management Capability }}$

Inventory Management Capability addresses the vehicle's accommodation for tracking, stowage, and organization of items including hardware, food, and supplies. This includes having both the space for inventory and a method for tracking it, automated or not. This factor influences "Support of Traffic Flow, Translation Paths" and "Access to Work Items" due to its relation to keeping inventory out of traffic flow and in known, non-obstructing locations. It also relates to "Suit Design" because of the logistics of suit sizing for each crewmember and the need to maintain spare parts. This factor influences efficiency of performance, and potentially psychological conditions. [[26] pps. 21, 259, 275-276; [5] pps. 507, 517-523; [47] pps. 84-89; [52] pps. 152-153; [29] pp. 163] 


\section{$\underline{\text { Habitable Volume }}$}

Habitable Volume addresses the internal pressurized volume of the vehicle available for crew occupation and activity. It excludes volume taken by equipment and stowage, and is therefore related to "Internal Management Capability". This factor addresses the volume available for each crewmember, and includes influences due to social density and potential overcrowding. It has potential psychological and performance effects. [[26] pps. 21, 272, 308; [5] pps. 507-513, 517529, 552-572; [47] pps. 81, 83, 89, 93-94; [24] pps. 149-151,163; [52] pps. 140-142; [43, 55]] Food System

Food System refers to the capabilities of the vehicle for providing safe and acceptable food and water, including appropriate systems for preparation, consumption and clean-up. It accounts for influences due to a limited variety of food, a lack of fresh food, any altered taste of food in spaceflight, and shelf life considerations. It also addresses the balance needed among the food quality and the power and crew time for the supporting system. This factor influences nutrition, as well as psychological and team factors. [[26] pps. 297-316; [5] pps. 354-370, 483-498; [47] pps. 3542, 69-75; [52] pps. 150-151, 239-259; [25]; [24] pps. 175, 581-586; [34] pps. 95-102]

\section{Nutrition}

Nutrition accounts for influences of the nutritional content of food on the crewmembers. This factor addresses the potential for inadequate caloric intake, nutrient loss in food due to radiation, and inadequate nutrition due to availability and quality of food as captured in "Food System". This factor influences health and likely psychological conditions, as well. [[26] pps. 297316; [5] pps. 483-498; [47] pps. 69-75; [52] pps. 167-173, 223-234; [30] pps. 169-183; [34] pps. 95102] 


\section{$\underline{\text { Confinement }}$}

Confinement captures influences due to being in an enclosed space for the mission time within the vehicle. This may have effects on psychological conditions and performance, especially as mission duration increases. [[26] pps. 10, 48, 66, 69; [29] pp. 163; [24] pp. 166] Availability of Private Space

Availability of Private Space addresses the existence, volume, and level of privacy available to crewmembers in the vehicle, including personal sleeping quarters. It covers aspects of private space such as how thin or thick walls of separation are for visual and auditory privacy, and the availability of space away from ground observation cameras. This factor may relate to fatigue and psychological conditions. [[26] pps. 20, 21; [5] pps. 499, 530-533; [47] pp. 89; [52] pps. 149-150; [24] pps. 164, 587-588; [43]]

\section{$\underline{\text { Level of Sensory Stimulation }}$}

Level of Sensory Stimulation refers to the levels of visual, auditory, tactile, and olfactory inputs in the vehicle environment. Taste is accounted for in "Food System". This factor addresses how a lack of novelty or stimulation may create a monotonous environment, but also how too much stimulation may lead to fatigue (e.g. if too much noise or information is constantly in the environment). [[24] pp. 166; [43, 49]]

\section{Availability of Recreation/Personal Activities}

Availability of Recreation/Personal Activities addresses the suitability of the vehicle in supporting the crewmembers' needs for activities such as exercise, playing instruments, reading, watching movies, or conducting cultural, religious, or spiritual events. It also covers if the vehicle supports individual needs and choices of activities. This factor does not address the scheduling aspects of personal activities, as this would be covered in "Organization" factors. This factor will influence psychological conditions and potentially health and performance, as well. [[26] pp. 45; [5] pp. 544; [47] pps. 81-82, 92; [52] pps. 151-152, 154; [24] pps. 164, 590-592] 


\section{$\underline{\text { Availability of Personal Items }}$}

Availability of Personal Items accounts for the influence of having access to items such as personal office supplies, personal hygiene products, clothing, additional hardware such as batteries for personal devices, and tokens of home of cultural, religious, spiritual, community or family significance. This factor may affect psychological conditions and performance. [[26] pp. 277; [5] pps. 499, 534-536; [47] pps. 90-91; [52] pps. 125-136; [24] pps. 166, 588-589]

\section{Décor of Environment}

Décor of Environment addresses the visual aspects of the vehicle in terms of their ability to provide an appealing sense of comfort, relaxation, and home to the crewmembers. This factor may be influenced by factors such as "Cleanliness of Environment", Inventory Management Capability", and "Presence of Location Aids", such as coloring of module interiors. Décor of Environment may influence psychological conditions and performance. [[26] pp. 21; [52] pps. 146-148; [29] pp. 163; [43]]

Hygiene Support

Hygiene Support refers to the support of body, face, and teeth cleaning, using the restroom, and the fit of the appropriate equipment required to perform these functions in microgravity. This factor also addresses the vehicle's capabilities for processing waste and debris created as a result of hygiene activities. This factor may influence health, psychological conditions, and performance. [[43]; [5] pps. 354, 499-502; [47] pps. 75-81; [24] pp. 588; [52] pps. 125-136, 149, 265-272; [34]

pp. 103]

Availability of Medical Care

Availability of Medical Care refers to the vehicle support for medical events, in terms of supplies and equipment on-board, the shelf-life of the supplies, and support for the power and volume required to operate equipment for both diagnosis and treatment. It does not address the availability of personnel with medical skills, as that is taken into account under "Crew Collaboration 
Quality". This factor influences crew health and potentially psychological conditions, as well, through knowledge of adequacy of the capabilities. [[26] pp. 241; [5] pps. 514-516; [47] pps. 82-84; [30] pps. 239-263; [52] pps. 151-152; [29] pps. 61-134; [24] pps. 589-590]

\subsubsection{Human System Interaction}

The Human System Interaction Domain Category, shown in the middle left of Figure 10, is defined by the User Interfaces Functional Grouping.

\section{User Interfaces $[2,36]$}

Mobility Aids and Restraints Availability and Quality

Mobility Aids and Restraints Availability and Quality addresses the suitability of the vehicle in supporting crewmembers' needs for items such as foot restraints, anchors, translation aids, cords, seat tracks, Velcro and masses with which to react. These items may be for supporting tasks requiring mobility or a stationary position. This factor may affect fatigue conditions and performance of tasks. [[47] pps. 101-104; [5] pps. 679-698; [52] pps. 154-158; [24] pps. 594-595; [43]]

$\underline{\text { Identifiability }}$

Identifiability refers most directly to the quality, availability and accuracy of labeling. This factor includes addressing if labels are readable due to font size, font color, label color, location and language. It also addresses if labels are missing, on incorrect components or incomplete. Identifiability may influence situational awareness and performance of tasks. [[47] pps. 145-147; [5] pps. 802, 874-879; [33]] 
Information Displays and Decision Aids

Information Displays and Decision Aids accounts for influences of display colors, text language, placement, distinction in environment, update timeliness, confirmation of information, modes of presentation, display controls, perceptual thresholds and intuitiveness of use. This factor includes audio displays and characteristics such as intelligibility, sound level and frequency, as well. This factor logically influences situational awareness and performance. [[26] pps. 253-265, 285; [47] pps. 132-133, 137-145; [5] pps. 231, 755-822; [29] pps. 210-213; [33]]

\section{$\underline{\text { Standardization }}$}

Standardization addresses the commonality and consistency of the design and implementation of hardware, tools, labels, displays, controls, software and software navigation. [[26] pps. 263, 270, 274; [5] pp. 746; [47] pps. 110, 131-133]

\section{Control Panels/Input Devices}

Control Panels accounts for the influences of control placement, intuitiveness of use, efficiency, responsiveness and ability to provide user feedback for physical and software controls. This may include items such as keyboards, mice, joysticks, buttons and touch screens. [[26] pps. 287-288; [5] pps. 823-873; [47] pps. 132-133, 138-139, 147-150; [29] pps. 213-215; [24] pp. 138]

\section{$\underline{\text { Hardware Tool Availability }}$}

Hardware Tool Availability addresses whether tools appropriate for the task and environment exist and are accessible to the crewmember. This factor may be influenced by inventory management capabilities with respect to tool physical accessibility. The existence of tools designed for use specifically in microgravity is included with this factor. [[26] pp. 256, 274275, 288; [5] pps. 663-671; [33]; [36, 43]]

\section{Situation-Specific Lighting}

Situation-Specific Lighting accounts for the influences of task lighting, or lighting used specifically for particular work areas. This factor differs from the factor "Lighting (Ambient)", as it 
captures localized lighting conditions, instead of ambient lighting throughout the vehicle. [[26] pp. 271; [5] pps. 624-643; [47] pps. 107-109]

$\underline{\text { Hardware Ease of Use }}$

Hardware Ease of Use addresses the usability of hardware such as vehicle systems hardware, experiment racks, lockers, panels, equipment connectors, cabling, exercise and health care equipment, printers and laptops. It addresses the intuitiveness, physical ease and mental ease of using the hardware, but does not include the existence and availability of equipment designed specifically for use in microgravity, as that is addressed in "Hardware Tool Availability". Hardware Ease of Use also includes considerations for the ease of maintaining hardware. [[26] pps. 256, 261; [5] pps. 653-728; [47] pps. 110-129, 130-131; [52] pps. 159-164; [25, 33, 36]]

\section{$\underline{\text { Software Ease of Use }}$}

Software Ease of Use refers to the usability of software on the vehicle, especially that which is used to accomplish specific tasks and is used directly by the crew for performing these tasks. This factor differs from "Information Management Support", which includes addressing infrastructure software. [[26] pps. 256, 260; [5] pp. 802-804; [47] pps. 130-131; [25, 33]] Information Management Support

Information Management Support accounts for influences due to the information and communication network capabilities on the vehicle, provided by hardware and software. This factor differs from the software ease of use and information display factors in that it does not address task-specific user interface software or display details. It addresses the infrastructure and information provided by the vehicle, such as information models, internet access, networking and backup capabilities. [[26] pps. 256, 260; [5] pps. 896-900; [47] pps. 158-162; [29] pps. 209-210; [33]] 


\section{Human/Vehicle Automation Integration}

Human/Vehicle Automation Integration addresses the adequacy of the level and quality of the complementary behavior of vehicle automation to the tasks that the human crewmembers perform. This factor takes into account whether the vehicle automation helps the crewmember to improve performance, or if in some cases, it hinders performance of tasks. [[26] pps. 258, 289-291; [5] pps. 219-220, 901-923; [47] pps. 154-158; [50]]

\section{Human/Robotics Integration}

Human/Robotics Automation Integration, similar to "Human/Vehicle Automation Integration", addresses the adequacy of the level and quality of the complementary behavior of robotics automation to the tasks that the human crewmembers perform. Robotics may refer to robotic arms, humanoids, rovers, or other non-vehicle components. This factor also takes into account whether the robotics automation helps the crewmember to improve performance, or if in some cases, it hinders performance of tasks. [[26] pp. 283; [5] pps. 901-923; [47] pps. 154-158; [50]]

\section{Caution and Warning Functionality}

Caution and Warning Functionality refers to the capabilities of the vehicle for providing visual, auditory, or other sensory alarms to the crewmembers in ways that can be perceived in the spaceflight environment and throughout all mission phases. This factor also addresses the influence of caution and warning alarm thresholds and the effects of alarm activation too frequently, not frequently enough, missing or false activations. [[26] pp. 261; [5] pps. 219-220, 880-895; [47] pps. 159-162; [29] pps. 209-210; [36]]

\section{Orientation of User Interfaces}

Orientation of User Interfaces accounts for the influence of having user interfaces throughout the vehicle consistently aligned with a common "up" orientation and being aligned conveniently with appropriate equipment, tools, or facilities. This factor may be particularly 
important in the design of large vehicles such as space stations, with multiple sections allowing the opportunity for varied orientations. [[26] pp. 259; [5] pp. 758; [47] pps. 23, 95, 96, 104, 108, 139, $141,142,147 ;[43]]$

Range of Motion Accommodations

Range of Motion Accommodations addresses the capabilities of the vehicle design to allow for potentially altered range of motion, such as that of arms, legs and torso, due to crewmembers' presence in microgravity. [[5] pps. 53-60; [47] pp. 18]

\section{Reach Envelope Accommodations}

Reach Envelope Accommodations refers to how well the vehicle design places system interfaces within the reach of crewmembers. This is particularly important while crewmembers are seated or restrained during dynamic mission phases such as launch, ascent, entry, descent, and landing, when other factors such as vibration and acceleration influence the ability to reach interfaces. [[5] pps. 61-67; [47] pp. 18]

Body Surface Area, Volume, and Mass Properties Accommodations

Body Surface Area, Volume, and Mass Properties Accommodations allows for consideration of how items such as neutral posture and clothing fit may be altered in microgravity. Mass properties must be considered especially when tasks may involve reaction from tools or equipment motion, because gravity is not present to facilitate countermotion prevention. This factor is also influenced by whether a crewmember is suited or not. It additionally takes into account how multiple crewmembers working in the same area may or may not have enough space to perform their tasks without interfering with each other. [[47] pps. 18-19; [5] pps. 40-52, 68-76] Strength Accommodations

Strength Accommodations addresses the capabilities of the vehicle design to allow for potentially altered muscular strength of the crewmembers due to presence in microgravity. This 
factor includes accommodations for the strength of finger, hand, arm, leg, back and other muscles, especially in the context of performing tasks. [[26] pp. 274; [5] pps. 77-83; [47] pps. 19-20]

$\underline{\text { Suit Design }}$

Suit Design addresses influences present when the crewmember is suited, either inside or outside the vehicle. Suit Design accounts for mobility, dexterity, center of gravity, mass and energy expenditure changes that may exist when suited. This factor may influence reach, strength, range of motion, and physical fatigue. It may also be related to inventory management capability and habitable volume factors due to the approach to suit sizing for individuals or groups and the need for spare parts. Suit Design may also influence fatigue, discomfort, pain and injury conditions. [[26] pps. 333-358; [5] pps. 46-65; [47] pps. 163-171]

\subsubsection{HUMAN DOMAIN}

The Human Domain, as represented by the lowest box in the left corner of Figure 10, is decomposed into the Domain Categories of Individual Mental Characteristics and Individual Physical Characteristics. This section discusses the Contributing Factors within the Human Domain.

\subsubsection{Individual Mental Characteristics}

The Individual Mental Characteristics Domain Category, shown near the bottom left side of Figure 10, is decomposed into the Functional Groupings of Situational Awareness, Cognitive Adaptations and Psychological Conditions. 


\section{Situational Awareness}

\section{Perceived Urgency of Situation}

Perceived Urgency of Situation considers the criticality and priority of the task at hand as understood by the crewmember, especially addressing the task's contribution to health and safety versus nominal research, educational or personal tasks. The crewmember's perception of urgency is likely influenced by the time available for the task and the mental model of the situation. This factor may also be influenced by the level of excitement or boredom present; e.g "go fever" or "gethome-itis" may increase the perception of urgency. [[5] pps. 219-220; [47] pp. 24; [33, 36, 44]] Mental Model of Situation and/or System

Mental Model of Situation and/or System accounts for the crewmember's accuracy and appropriateness of understanding the system's current state, characteristics, capabilities, and interactions with the environment. Training and automation factors will likely have influences on this factor. It is foreseeable that this factor affects the appropriateness of task performance. [[26] pp. 56; [5] pps. 911; [47] pp. 24; [27, 44, 50]]

\section{Cognitive Adaptations}

\section{Memory/Knowledge}

Memory/Knowledge refers to the available set of information the crewmember possesses in memory from which to draw upon during a task. This factor is likely influenced by training and experience factors, along with task familiarity factors. The state of this factor may be expected to influence situational awareness factors and performance. [[26] pps. 67, 255; [5] pps. 174-177; [47] pp. 23; [51] pp. 419; [33, 36, 44]]

\section{$\underline{\text { Attention/Alertness }}$}

Attention/Alertness addresses the state of watchfulness, awareness, focus and vigilance of the crewmember. Factor such as task allocation, work load, and level of excitement or boredom 
likely influence this factor. Attention/Alertness is expected to affect performance of tasks, especially during long-duration missions. [[26] pp. 67; [5] pps. 168, 171-173, 181; [47] pp. 23; [51] pp. 419; [33, 36, 42, 44]]

\section{Psychological Conditions}

\section{Pressure [36]}

Pressure is further decomposed into four factors:

Stress

Stress accounts for influences due to being in an environment with different risk or danger levels than typical daily terrestrial environments, or the perception of that being the case. This factor addresses accumulated feelings of tension due to an underlying constant requirement for attention to safety, the environment, and performance. Stress may be influenced by many factors in the operations domain, such as training quality. It may also be influenced by many factors in the vehicle design domain, such as temperature. [[26] pps. 20, 21, 48, 67, 285; [5] pp. 181; [36, 38]] High Public Interest and Visibility

High Public Interest and Visibility refers to the somewhat unique situation of crewmembers' activities being monitored and recorded for general public viewing. This visibility, in addition to the more common visibility of activities to coworkers and family members, may create additional pressure on crewmembers to perform well. [[29] pp. 163] Performance Pressure

Performance Pressure addresses the influences of perceived expectations to perform tasks with few to no mistakes. This feeling of needing to meet a standard of perfection may have beneficial or detrimental performance effects. It may be influenced by organizational and cultural factors. [[26] pp. 20; [51] pp. 419; [24] pp. 166] 


\section{Peer Performance Pressure}

Peer Performance Pressure accounts for influences caused by high levels of performance by peers, either in quality or quantity of task performance. There may be a feeling that because others have gone or are going "the extra mile", each crewmember must also exceed expectations. This type of pressure may influence crewmembers to improve performance or to attempt additional activities. The influence may be positive or negative. [[5] pp. 232]

\section{Level of Trust in Situation/System}

Level of Trust in Situation/System addresses the confidence the crewmember has in the situation and/or the system itself. This includes considerations for trust in the vehicle behavior and automation, robotics behavior and automation, and ground support team members and systems. The positive or negative state of the level of trust may manifest in crewmember calm, anxiety or fear, and may influence the performance of tasks. [[26] pps. 9-11, 13; [5] pps. 182, 911; [24] pp. $164 ;[36,50]]$

\section{Level of Excitement or Boredom}

Level of Excitement or Boredom refers to the influences due to stimulation from activities or the situation, or a lack of stimulation. Excitement may be especially influential near the beginning and end of a mission, as well as any novel portion of a mission providing a thrill due to its rarity, such as a rendezvous and docking. Excitement may contribute to phenomena similarly found in aviation such as "go fever" or "get-home-it-is", that are tendencies to not deviate from a plan despite changing conditions, and may influence the perceived urgency of the situation. Boredom may be a significant factor on long-duration missions, when stimulation may be lower in intensity, duration and frequency. Both boredom and excitement may influence performance. [[26] pps. 20, 48, 64, 68] 


\section{Feelings of Accomplishment or Frustration}

Feelings of Accomplishment or Frustration addresses the influences that my exist when a crewmember feels they have completed a task and done it well, or when tasks are unable to be completed at all or to a level with which the crewmember is satisfied. This factor may be influenced by training and work load, as well as by the relationships with the ground team, especially with respect to desired feedback. [[26] pp. 64; [24] pps. 158, 164-165] Influence of Family, Friends and Society

Influence of Family, Friends and Society is further decomposed into four factors:

\section{Relationships to Family and Friends}

Relationships to Family and Friends addresses the influence the state of relationships with family, friends and coworkers may have on performance. Strong relationships providing support may positively influence performance, while relationship strains such as family or marital distress have the potential to influence performance negatively. [[26] pp. 10; [24] pp. 158] Health and Happiness of Family and Friends

Health and Happiness of Family and Friends refers to the effects on performance that may exist due to the state of family members', friends' and coworkers' physical, mental or emotional health. Healthy supporters on Earth may provide a positive influence on crewmember performance, while troubles with an area of health of people close to a crewmember have the potential to influence performance, as well. This factor is likely influenced by the available workplace support for individuals on the ground, where appropriate support can help provide peace of mind and increased ability to focus to the crewmember while they are physically away. [[26] pps. 10, 22, 24]

Isolation from Family and Friends

Isolation from Family and Friends accounts for the impacts resulting from the physical separation from family, friends and colleagues during a mission. Not having physical proximity to 
the support system provided by these people may influence performance, especially as mission duration increases. It may also be more influential during significant family or friend events. This factor is affected by ground communications availability and ease. [[26] pps. 6, 8, 15, 48, 64, 68;

[29] pp. 163; [5] pp. 181; [24] pp. 166]

Isolation from Society

Isolation from Society addresses the influences due to crewmembers being physically separated from Earth and their respective societies as a whole. This factor includes accessibility to news and the internet to ease the feelings of separation and isolation that may exist, and is influenced by ground communication availability and ease. This factor may be more influential as mission duration increases, especially if Earth is not in view, or during significant world or societal events such as natural disasters or war. It may also support positive influences on performance, such as when perspective of the Earth as a whole contributes to a sense of unity. [[26] pps. 6, 8, 12, $13,15,22,48,64]$

Morale

Morale is further decomposed into three factors: Morale/Motivation/Attitude

Morale/Motivation/Attitude addresses the effects that a crewmember's set of values, drive, ambitions and inspiration, leading to a level of willingness to perform tasks and/or support team efforts, may have on health and performance. [[26] pps. 6,9-11, 14, 30; [51] pp. 419; [36]; [24] pp. $164 ;[33,42,44]]$ Level of Happiness

Level of Happiness accounts for influences due to deep feelings of happiness or depression, or a level of contentment with professional and personal conditions. This factor may be increasingly important as mission duration increases, and may influence fatigue, physical conditions, and performance. [[26] pps. 6, 9-11, 14, 30; [51] pps. 424-425] 
Mood

Mood refers to less permanent feelings than those accounted for in "Level of Happiness". This factor accounts for surface-level feelings and temperament, rather than the deeper levels captured by "Level of Happiness". [[26] pps. 6, 9-11, 14, 30, 101; [51] pps. 424-425; [24] pp. 164]

\subsubsection{Individual Physical Characteristics}

The Individual Physical Characteristics Domain Category, shown at the bottom of the latency axis in Figure 10, is decomposed into the Functional Groupings of Fatigue Conditions, Physiological Adaptations, Non-Standard Physical Conditions and Existing Physical Conditions.

\section{Fatigue Conditions}

\section{Physical (Aerobic and Muscular) Fatigue Conditions [44]}

Physical (Aerobic and Muscular) Fatigue Conditions refers specifically to aerobic and/or muscular fatigue due to overexertion through aerobic or muscular activity. This factor does not include general physical or cognitive fatigue. It's state may be influenced by recent extra-vehicular activities and the duration of those activities. Similarly, it may be affected by exercise countermeasure activities, their intensities, frequencies, and durations. [[30] pps. 101-116; [47] pp. 20; [5] pps. 507-513; [47] pp. 20; [26] pps. 361-362; [53]]

$\underline{\text { Non-Aerobic and Non-Muscular Fatigue }}$

Non-Aerobic and Non-Muscular Fatigue addresses the effects a sense of weariness or exhaustion, beyond specific muscular or aerobic fatigue, may have on health or performance of tasks. This type of fatigue may be influenced by a number of factors such as shift scheduling, work load, crew collaboration quality, habitability, vehicle physical environmental factors, circadian rhythm, hormone function and sleep. [[26] pp. 67, 85, 87; [5] pp. 182; [51] pp. 419, 424; [24] pp. $164 ;[36,42,44]]$ 


\section{Physiological Adaptations [44]}

\section{Fluid Shift}

Fluid Shift refers to the influence bodily fluids shifting towards the head in microgravity may have on performance of tasks or other factors. The fluid shift may induce feelings of head fullness, nasal stuffiness and sinus congestion. The headward fluid shift also leads to reduced overall blood volume, which in turn may contribute to orthostatic intolerance, or a propensity toward fainting, upon gravity re-exposure. [[30] pp. 151; [56] pps. 105-113; [26] pps. 44, 304; [5] pp. 181]

\section{$\underline{\text { Vestibular Function }}$}

Vestibular Function addresses influences on health and performance due to altered balance and spatial orientation capabilities during a mission. The removal of gravity inputs to the inner ear and pressure sensors of the body and resulting dominance of visual inputs may alter the ability to remain balanced and in a desired spatial orientation. Balance reflexes during a fall upon return to gravity may be altered. Any of these changes may influence performance upon re-exposure to gravity before re-adaptation occurs. [[56] pp. 135; [30] pps. 119-136, 189-190; [25] pp. 46; [33]]

\section{$\underline{\text { Nervous System Function }}$}

Nervous System Function refers to effects on performance or other physiological adaptations that alterations to the network of neurons throughout the body may have. This factor may be particularly impacted by radiation exposure. Nervous System Function influences the performance of balance, spatial orientation, sensorimotor, and postural functions, for example. [[56] pps. 135-180; [26] pp. 44; [30] pps. 63-64]

\section{$\underline{\text { Sensorimotor Function }}$}

Sensorimotor Function takes into account effects of changes to skills such as hand-eye coordination and locomotion. Nervous system and vestibular system changes may influence sensorimotor functions such as hand-eye coordination. In addition, locomotion in microgravity 
becomes dominantly driven by small movements, especially with the hands and arms, instead of the larger leg movements on Earth. This adjustment, in combination with user interfaces, task procedures, and physical work load factors, may influence the accomplishment of tasks. [[56] pps. 135-180; [26] pp. 285; [5] pps. 103-118; [47] pp. 23; [25, 33]]

\section{Proprioceptive and Postural Function}

Proprioceptive and Postural Function addresses influences on performance due the body's altered ability to sense the location of its parts such as arms and legs with respect to itself, and its subsequent altered ability to control their location without visual feedback. This factor also accounts for adjusted neutral body posture in microgravity. In gravity, humans stand upright with the gravity vector approximately in line with the spine. This is no longer the case in microgravity, as a more rounded, curved-spine posture is the norm. This factor, especially in combination with user interfaces, may influence performance of tasks. [[30] pps. 79, 199-136; [5] pp. 48; [47] pp. 18; [52] pps. 139-142; [56] pps. 135, 158-164, 167-168; [26] pp. 274; [25]]

\section{Visual Perception Function}

Visual Perception Function refers to influences on performance due to changes in sight or visual acuity and perception capabilities. Vision may become dimmed or limited upon return to gravity during periods of orthostatic intolerance. During a mission, vision may be affected by radiation exposure, such as when cosmic ray particles create the perception of a flash of light to crewmembers. It may be altered when orientation cues cause visual confusion, or during periods of high acceleration, high vibration, reduced oxygen, or reduced pressure. Exposure to particles such as lunar dust and the absence of an atmosphere on a planetary surface may alter visual perception. Head congestion due to fluid shift and lighting conditions may have additional influences on this factor, with consequent effects on performance of tasks. [[56] pps. 173-176; [30] pps. 64, 123, 129131; [5] pps. 119-144; [47] pp. 22; [44]] 


\section{$\underline{\text { Auditory Perception Function }}$}

Auditory Perception Function addresses the effects any altered hearing or auditory perception abilities may have on performance. Hearing threshold shifts have been observed in space, and this may be due to chronic or intense noise in the environment, headward fluid shift, increased carbon dioxide levels, or toxins in the vehicle. Auditory perception may be altered even when thresholds are nominal due to background vehicle noise, atmospheric pressure and composition differences from Earth, and the size and layout of the vehicle. [[30] pp. 244; [5] pps. 145-166; [47] pp. 22-23]

\section{Bone Strength}

Bone Strength accounts for changes in skeletal system strength that may influence performance of tasks. This factor allows for consideration of changes in bone mineral density, bone mass and mechanical strength. Bone mineral density has been shown to decrease in microgravity, along with bone mass in the lower body. Some upper body bones have been shown to have unchanged or even slightly increased bone mass. These changes may influence performance of tasks in microgravity, however, a greater influence on performance likely exists upon return to gravity when bone fracture injury may have an increased likelihood as a result of the changes. [[30] pps. 3-26; [56] pps. 247-261; [25] pp. 46; [34] pps. 58-59]

\section{$\underline{\text { Muscle Performance }}$}

Muscle Performance addresses the influences that any changes in muscle strength, power, endurance or flexibility may have on health and performance. Muscle capabilities may change due to the absence of gravitational loading, altered modes of locomotion, hormonal changes, nutrition, and stress. Exercise countermeasures may prevent these changes from having strong effects, however. [[30] pps. 77-96; [5] pps. 99-101; [56] pps. 231-241; [26] pps. 11, 359; [25] pp. 46; [34] pps. 58-59] 
$\underline{\text { Spinal Lengthening }}$

Spinal Lengthening refers to the effects on performance that increased height may introduce. In space, gravity is not present to compress the spine as on Earth, and as a result the spine lengthens. This may influence performance due to resulting discomfort or an improper new fit of a spacesuit. [[30] pp. 17]

Cardiovascular/Cardiopulmonary Function

Cardiovascular/Cardiopulmonary Function addresses the influences that cardiovascular and cardiopulmonary system changes may have on crewmember performance. Cardiac muscle mass may decrease, which may have a stronger effect on performance upon gravity re-exposure. Aerobic capacity as indicated by maximal oxygen uptake does not appear to decrease in flight, but has been shown to decrease post-flight. This may have performance effects depending on the intensity of cardiac demands of tasks required after landing. Cardiac arrhythmias have also been noted in space, although many factors such as stress and reduced sleep quantity and quality may have contributed. [[30] pps. 139-163; [47] pp. 20-21; [56] pps. 63-82; [34] pps. 58-59]

\section{Hormone Function}

Hormone Function refers to the effects on performance due to altered hormone function. For example, hormones are a part of the regulation of bodily fluids, and as fluids are redistributed in microgravity, hormone changes have been observed. In addition, hormones that regulate metabolism may be affected by the change in mineral balance as load-bearing bones lose calcium. Certainly circadian rhythm changes influence hormone levels and homeostasis. This factor may have wide-ranging effects on other physiological, psychological, health, and performance factors. [[56] pps. 89-101; [26] pp. 95]

\section{Hunger Level}

Hunger Level accounts for influences due to a change in appetite. Hormone effects on metabolism may influence this factor. Reduced appetites have been noted during spaceflight, 
possibly due to additional influences. For example, food generates heat, and convective cooling does not occur in microgravity because warmer air does not "rise" to carry heat away from the body. The warmer conditions may decrease appetite. Exercise countermeasures performed during a mission may also decrease appetite, along with busy schedules of activities or EVAs, or a lack of variety in food choices. Alternatively, on long-duration missions, there may be the potential for boredom to contribute to increased appetite. This factor may influence health and performance. [[30] pps. 169-183; [26] pps. 44, 304]

\section{$\underline{\text { Hydration Level }}$}

Hydration Level refers to any effects induced by altered thirst and hydration level during a mission. Decreased level of thirst has been observed, especially during the early stage of spaceflight when fluid shifting toward the upper body stimulates hypothalamic receptors in a way to potentially decrease thirst. Intense schedules and the taste of water in the vehicle, influenced by the storage and sterilization approaches, may contribute to a decreased desire to drink water. The level of exercise or stress, and therefore respiration and perspiration, also influence hydration level. This factor, similar to "Hunger Level", may influence health and performance. [[30] pp. 181; [5] pp. $354 ;[25]]$

\section{Circadian Rhythm Function}

Circadian Rhythm Function allows consideration of the effects that changes to the crewmember's circadian rhythm may have on health and performance. Circadian rhythm may be altered due to the fact that day and night have different meanings in microgravity. In Low-Earth Orbit, for example, there is a day/night cycle approximately every 90 minutes. The International Space Station practice of "slam shifting", which is when a large sleep schedule shift occurs due to an upcoming critical event such as docking, may alter the state of this factor. Circadian Rhythm may influence hormonal, sleep quantity and quality, fatigue and cognitive functions, and consequently health and performance. [[26] pps. 85-116; [5] pps. 181-182, 236; [24] pp. 164; [25] pp. 49; [2]] 


\section{$\underline{\text { Immune System Function }}$}

Immune System Function accounts for influences on health and performance due to altered immunity that is possible during a mission. Exposure to radiation, altered nutrition, vehicle cleanliness, availability of medical care, sleep, fatigue, pressure and social support are examples of factors that may influence the functioning of crewmembers' immune systems. [[30] pps. 169-183; [56] pps. 117-130; [34] pp. 59]

Sleep Quantity and Quality

Sleep Quantity and Quality addresses influences to due altered amounts or quality of sleep on health and performance. Sleep may be altered during missions due to factors such as a shift in circadian rhythm, whole body vibration during sleep times, lighting conditions, environmental noise, availability of privacy, psychological factors such as pressure or excitement, nutrition, task scheduling, and shift scheduling, especially when sleep shifting occurs. [[47] pps. 89-90; [26] pps. 11, 16, 20, 27, 28, 44, 85-116; [5] pp. 181-182, 236, 530-533; [25] pp. 49; [24] pp. 166; [53]

\section{Non-Standard Physical Conditions}

Medication Side Effects

Medication Side Effects is a factor that takes into account influences on health and performance that may occur during a mission due to altered responses from medication. An example is that medication taken to ease symptoms of Space Motion Sickness may affect alertness, response time and the accuracy of performing tasks. [[30] pps. 18, 48, 195, 197; [5] pp. 181; [53, 54]]

Injury, Pain, or Discomfort

Injury, Pain, or Discomfort factors address influences on health and performance possible if a crewmember is in discomfort, pain, or injured. It is decomposed into factors based on the International Classification of Diseases (ICD) 10th Revision, or ICD-10. ICD-10 Chapter XIX, “Injury, 
poisoning, and certain other consequences of external causes". ICD-10 informs the inclusion of the following decomposed factors:

Head, Neck, Chest, Abdomen/Lower Back, Shoulder/Upper Arm, Elbow/Forearm, Wrist/Hand, Hip/Thigh, Knee/Lower Leg, Ankle/Foot, Genitourinary, Burns/Corrosion and Poison/Toxin. [27, $44,57]$

$\underline{\text { Illness }}$

Illness factors account for health and performance consequences of crewmembers being ill. The factors decomposed under Illness are taken from 13 of the first 14 ICD-10 chapters, excluding mental and behavioral disorders because they are incorporated in psychological factors. The factors included under Illness are:

Infectious/Parasitic, Tumor, Blood/Blood-forming Organs/Immune, Endocrine/Nutritional/Metabolic, Nervous System, Eye, Ear/Inner Ear, Circulatory, Respiratory, Digestive/Mouth/Stomach, Skin and Subcutaneous Tissue, Musculoskeletal and Connective Tissue, and Genitourinary. [27, 44, 57]

\section{Existing Physical Conditions}

Pre-existing Medical Conditions

Pre-existing Medical Conditions is present as a factor in order to account for any influences such conditions or medical history may have on other physical conditions. [[26] pp. 246] $\underline{\text { Gender }}$

Gender is present as a factor in order to address any influences gender may have on other physical conditions, such as differences in the side effects of certain medications. [[26] pp. 66; [30] pps. 207-219]

Age

Age is present as a factor in order to address any influences age may have on other physical conditions. [[26] pp. 244] 


\subsection{USE OF FACTORS AND CFM DIAGRAM FOR COMMUNICATING RISKS}

One of the ways this organization scheme and the Contributing Factor Map (CFM) diagram are useful is in communicating risk statements like those documented in the NASA Human System Risk Board Risk Management Analysis Templates [10]. In reading statements such as "Given condition X... there is a possibility that $Y$ consequence will occur" [10], one can place $\mathrm{X}$ and $\mathrm{Y}$ in this hierarchy and on the CFM. One example is for a statement with $\mathrm{X}$ as sensorimotor changes and $\mathrm{Y}$ as loss of performance of vehicle control [11]. In this case, $\mathrm{X}$ is a Contributing Factor, circled in Figure 11, within the Physiological Adaptations Functional Grouping. An influence arrow is shown pointing to $Y$, an outcome in performance of an Execution task. In contrast, another example provides $\mathrm{X}$ as the possibility of an inadequate food system, and $\mathrm{Y}$ as crew illness [11]. The given condition $\mathrm{X}$ is shown as the Food System Contributing Factor within Habitability in Figure 11, and the consequence of Illness is another Contributing Factor within Non-Standard Physical Conditions. Illness is a health concern and consequence in its own right, but has the additional potential to influence the performance of tasks, as well. A dashed arrow indicates the potentially decreased ability to perform tasks. The identification and visual display of the factors in this manner allows for different types of consequences, such as in these examples, to be discussed within the same framework. 


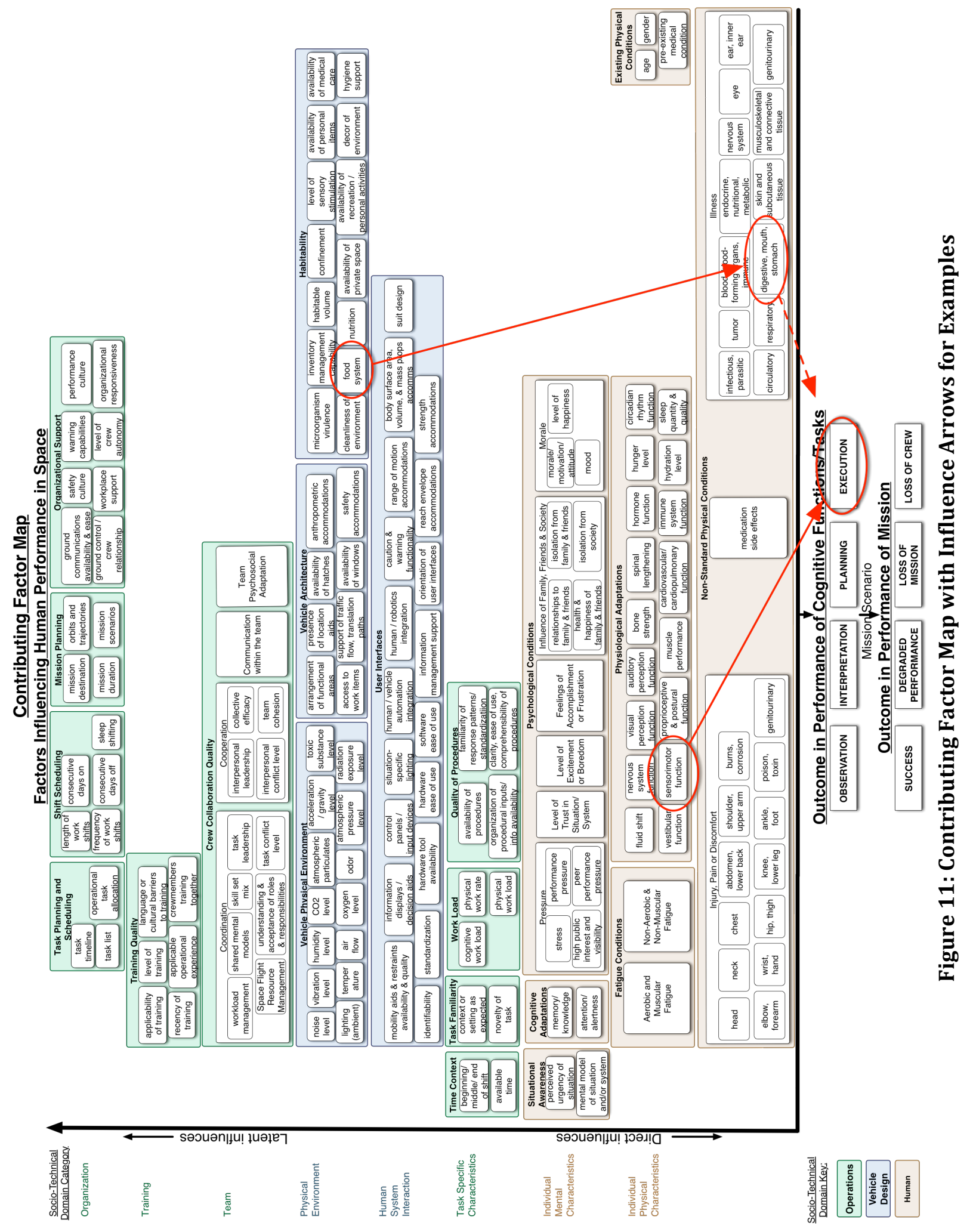




\subsection{CONCLUSIONS FOR FACTOR IDENTIFICATION AND ORGANIZATION}

This section identifies a detailed set of factors that are capable of influencing human performance in a spaceflight environment, along with context-specific definitions and references from aerospace, human performance and human reliability domains. This in-depth set of factors provides a comprehensive starting point for defining a quantitatively modeled set of Performance Shaping Factors tailored for spaceflight applications.

The organization scheme and set of factors presented in this section provide a common language framework for factors across disciplines to be discussed, compared and contrasted using common terminology. The organization scheme and diagram support integrated communication of the context of individual factors or groups of factors when viewed as potential risks to human health and performance, along with their relevant consequences.

\section{CHAPTER 3 RESULTING PRESENTATIONS AND/OR PUBLICATIONS}

Mindock, J. Applying Human Reliability Analysis Methods to Assess the Effects of Spaceflight on Crew Performance for Spacecraft Risk Quantification. Presentation given to the NASA Johnson Space Center Human System Risk Board. July 2010.

Mindock, J. Update on the Development and Organization of Spaceflight Performance Shaping Factors for Human Reliability Analysis. Presentation given to the NASA Johnson Space Center Human System Risk Board Working Group. Nov. 2010.

Mindock, J. Discussion on the Development and Organization of Factors Influencing Human Performance in Space. Presentation given to the NASA Johnson Space Center Habitability and Human Factors Branch. March 2011.

Mindock, J., Boyer, R., Hamlin, T., Heydorn, R. Development and Application of Space Flight Performance Shaping Factors for Human Reliability Analysis. Research summary featured in NASA Johnson Space Center Biennial Report. TM-20110216163. Dec. 2011.

Mindock, J. and Hamlin, T. Space-Based Human Reliability Model. Poster displayed during NASA Johnson Space Center Innovation and Inclusion Day for Safety \& Mission Assurance. May 2011. 
Mindock, J. Risk Factor Organization Scheme and Diagram. Presentation given to the NASA Johnson Space Center Human System Risk Board Working Group. June 2011.

Mindock, J. and Klaus, D. Development and Application of Spaceflight Performance Shaping Factors for Human Reliability Analysis. Paper and presentation at the 41st International Conference on Environmental Systems. Portland, OR. July 2011.

Mindock, J. and Klaus, D. Identification and Organization of Factors Influencing Performance in Spaceflight for Human Reliability Analysis. Journal article in preparation June 2012. 


\section{CHAPTER 4}

\section{FRAMEWORK FOR QUANTIFICATION OF FACTOR INFLUENCES}

\subsection{BAYESIAN NETWORK INTRODUCTION AND DEVELOPMENT CONTEXT}

Given the Contributing Factors and Functional Groupings in the Contributing Factor Map (CFM) shown in Figure 10, we next consider what approach to use for modeling their influences on the performance of tasks. An important issue with current sets of Performance Shaping Factors in Human Reliability Analysis (HRA) is the lack of explicit identification of factor dependencies [21]. The approach to capture PSFs and their relationships investigated in this research is the use of Bayesian Networks (BNs). BNs have been used in domains with similar needs for understanding complex systems in the presence of uncertainty such as medical diagnostic systems [58-63], aviation safety [64], maritime transportation [65], search and rescue operations [66], and real-time weapons scheduling [59]. Applications include decision-making and planning support [58, 59, 67, 68], data mining and analysis [59, 67], various systems reliability efforts [69-72], information

retrieval $[68,71]$, and recommender systems [73]. See [70] for an overview of recent applications. BNs model a system in the form of a network or graph with nodes and links. Nodes represent variables or factors of importance, and the links represent a causal dependency relationship between the "parent" and "child" connected factors. These dependencies are then quantified with probabilistic expressions rather than deterministic ones. BNs offer a visual way to represent factors and their influences, instead of lists or tables commonly used in HRA methods. The use of BNs in modeling factors influencing human performance is a concept that has already begun to be explored in recent years, especially within the context of nuclear power plants $[21,33,74-76]$. 
Sigurdsson, Walls and Quigley [71] describe three stages for building and using a BN;

Problem Structuring, Instantiation and Inference. In the Problem Structuring phase, there are three steps, Identify Variables, Identify Network Structure, and Express as Statistical Variables. The previous work described in [23] and Chapter 3 captures information for step 1, the identification of variables. This section of the dissertation focuses on step two, determining the structure of a BN. Following this, the factors in the network can be expressed as statistical variables for step three. Stage two then involves quantifying the network with conditional probabilities. Finally, in stage three, observations of variable states in scenarios of interest can be entered into the network, and outcome probabilities can be calculated [71].

There are two types of approaches for building the structure of a BN, data-based and knowledge-based [59]. Data-based approaches are typically employed in fields where large amounts of data can be mined to determine relationships between factors and outcomes $[59,77]$. An example of this approach would be mining medical databases containing patient symptoms and diseases to determine a network structure [60]. When large sets of data are not available, but expert domain knowledge is available, knowledge-based techniques can be used $[59,60,68]$. This is the case for the human spaceflight domain, as there is no unified set of data capturing the states of a common set of environmental factors, such as the set described in [23] and Chapter 3, and their influences on the performance of tasks. Efforts at creating such data sets for the nuclear safety industry have been underway $[78,79]$. The human spaceflight domain has not similarly progressed as of yet, although some efforts are described in $[40,80]$. Data from the spaceflight domain more typically support characterization of factors in localized disciplines such as physiological adaptations, behavioral health or human factors engineering [26]. Due to the lack of a data set encompassing a global set of factors as shown in Figure 10, the knowledge-based approach is utilized in this research to build the initial structure for a BN. 
Various options exist for executing a knowledge-based approach to BN structure construction. In [59], expert elicitation techniques are categorized into those that are unstructured and those that are structured. Unstructured methods rely on interviews in which the expert provides a narrative in response to open-ended questions, and factors of importance and their relationships are identified through textual analysis [59]. Another unstructured approach described in [66] is to show a simple example network for an unrelated topic, such as weather prediction, and allow experts to brainstorm factors and relationships for their domain application. In contrast, within structured techniques the experts are generally provided with previously identified variables of importance and are queried regarding the relationships among them. Because of the existence of the spaceflight domain-specific taxonomy of variables shown in Figure 10 , this paper shows the use of structured techniques for our application in order to build upon that taxonomy and more efficiently focus future expert participation.

A common structured technique for creating the structure of a $\mathrm{BN}$ is the use of adjacency matrices [59]. These types of matrices typically have the complete set of factors along each axis, with one axis representing causes and the other axis representing effects $[36,59]$. The entry in each cell of the matrix captures information about the relationship between the corresponding row and column factors, such as the causal direction and possibly the strength of the relationship. This type of information can be determined based on literature review and/or expert opinion [36, 59].

At this point, we must return to the application at hand, that of developing a BN structure for use by spaceflight-domain HRA analysts with limitations on the number of factors that can be evaluated in a reasonable amount of time. This brings about the typical modeling trade-off between comprehensive but complex and limited but simple models. Figure 10 represents a model of factors that is quite comprehensive, but overly complex for use in traditional predictive HRAs. Working at the Functional Grouping level of the hierarchy of factors still leaves 21 factors to be evaluated for each type of task. In forming a BN from these 21 factors, the number of conditional 
probabilities that must be determined to quantify the network is the sum of $2^{\mathrm{n}}$ over all 21 factors, with $n$ being the number of parents for each of the 21 factors and with the assumption that the states of the factors are all modeled as binary [81]. Because the initial quantification of BN probabilities is expected to begin with expert opinion until additional data can be incorporated [68], a smaller number of factors to include in the initial BN structure is desired in order to reduce the number of probabilities to be elicited. Working at the next higher level of the hierarchy, at the level of the 8 Socio-Technical Domain Categories, may be a reasonable option, however was not chosen due to that level's separation from the definitions of the detailed, domain-specific Contributing Factors. As a result, a way to identify the dominant factors at the Functional Grouping level to include in a network model was sought.

The desired simplification is not easily supported by common structured techniques such as the adjacency matrix, which aids in identifying relationships of already defined sets of factors. This section discusses how the Analytic Hierarchy Process (AHP), a decision support technique, was used to aid in the identification of factors believed to have the greatest influences, and are therefore of the most importance for inclusion in an initial simplified BN model. We also show how the Human Factors Analysis and Classification System (HFACS) structure supported the use of the AHP method. Further, we discuss how the AHP results can be used instead of an adjacency matrix for identifying relationships to include in the BN model. 


\subsection{BAYESIAN NETWORK STRUCTURE DEVELOPMENT}

\subsubsection{BACKGROUND ON METHODS}

\subsubsection{Analytic Hierarchy Process}

The developer of the Analytic Hierarchy Process (AHP), Thomas Saaty, describes the AHP in [82] as "a theory of measurement concerned with deriving dominance priorities from paired comparisons of homogenous elements with respect to a common criteria or attribute". It is this derivation of dominance that is of interest to us in deciding which factors to include in a simplified Bayesian Network (BN) model. AHP uses relative pair-wise comparisons as it is generally more intuitive for people to make relative comparisons between two elements than to make absolute judgments [83].

There are four main steps in the AHP [84]:

1. Setting up the hierarchy of elements

2. Making pair-wise comparisons of the elements

3. Finding the eigenvalue of the comparison matrices to estimate relative priorities of the elements

4. Aggregating the relative, or local, priorities of the elements into global priorities The pair-wise comparisons made in step 2 are performed using the scale shown in Table 5, given by Saaty [82]. 


\begin{tabular}{|c|l|l|}
\hline $\begin{array}{l}\text { Intensity of } \\
\text { Importance }\end{array}$ & Definition & Explanation \\
\hline $\mathbf{1}$ & Equal importance & Two activities contribute equally to the objective \\
\hline 2 & Weak & \\
\hline $\mathbf{3}$ & Moderate importance & Experience and judgment slightly favor one activity over another \\
\hline 4 & Moderate plus & \\
\hline $\mathbf{5}$ & Strong importance & $\begin{array}{l}\text { Experience and judgment strongly favor one activity over } \\
\text { another }\end{array}$ \\
\hline 6 & Strong plus & \\
\hline $\mathbf{7}$ & Very strong & $\begin{array}{l}\text { An activity is favored very strongly over another; its dominance } \\
\text { demonstrated in practice }\end{array}$ \\
\hline 8 & Very, very strong & \\
\hline $\mathbf{9}$ & Extreme importance & $\begin{array}{l}\text { The evidence favoring one activity over another is of the highest } \\
\text { possible order of affirmation }\end{array}$ \\
\hline
\end{tabular}

Table 5: Scale for AHP Comparisons [82]

\subsubsection{Human Factors Analysis and Classification System}

The Human Factors Analysis and Classification System (HFACS) [44] was created for the aviation community. It is a taxonomy of human performance causal factors developed based on input from the U.S. Naval Safety Center, the U.S. Army Safety Center, the U.S. Air Force Safety Center, the National Transportation Safety Board and the Federal Aviation Administration [44]. It builds on an approach to accident analysis proposed by James Reason [85] in which accidents involving human error are not merely caused by the human at the "sharp end" [2]. Reason's approach, and that adopted by HFACS, brings forward the concept of latent factors, such as environmental and organizational conditions, contributing to accidents, as well. As a result, the HFACS taxonomy of factors is organized into four levels of increasing latency of influence: Unsafe Acts, Preconditions for Unsafe Acts, Unsafe Supervision, and Organizational Influences [44]. This concept of identifying multiple levels of causal influence on human performance is what we used to help structure our AHP analysis and Bayesian Network, as described next. 


\subsubsection{APPLICATION OF METHODS}

Celik and Cebi [86] demonstrated the use of the AHP to bring quantification to the structure of HFACS for accident analysis in the shipping industry. A case study of a 2007 boiler accident on a bulk carrier ship was analyzed. The authors performed AHP on the factors at each level of the HFACS as applied to the accident scenario in order to determine the major contributing factors to the accident. We demonstrate a similar approach to determine the dominant factors for inclusion in a simplified BN model of the many spaceflight-domain factors shown in the CFM.

The scenario used as context for our analysis takes place during the return of a transfer vehicle from the International Space Station (ISS). The scenario assumes vehicle configuration requiring crew actions during the landing phase. The specific task in mind for this analysis was a crewmember pushing the appropriate button to release retractable landing gear in the "down" position. Any similar push button task may have been used in the case that the reference vehicle does not have landing gear (e.g. a capsule design). The total duration of the mission was assumed to be two weeks.

\subsubsection{AHP Step 1: Hierarchy Setup}

First we grouped the Contributing Factor Map (CFM) Functional Groupings into levels to form our AHP hierarchy. The level of the CFM analogous to the "Unsafe Acts" level of HFACS is the set of four cognitive functions or tasks from the Cognitive Reliability and Error Analysis Method (CREAM), Observation, Interpretation, Planning and Execution, shown near the bottom of the CFM. The push-button example used in this case is an Execution task, so that will represent the overall goal for this AHP analysis of performing the Execution task successfully. The next level of the AHP 
hierarchy, what we call Level A, is where inclusion of the factors begins. Level A consists of the Functional Groupings from the Individual Physical Characteristics and Individual Mental Characteristics Categories. These are the Functional Groupings shown in the bottom three rows of factors in the CFM. Level B incorporates the Functional Groupings in the next higher three rows in the CFM, those in the Task Specific Characteristics, Human System Interaction and Physical Environment Categories. Level C comprises the remaining Functional Groupings from the Team, Training and Organization Categories. The resulting AHP hierarchy is shown in Figure 12.

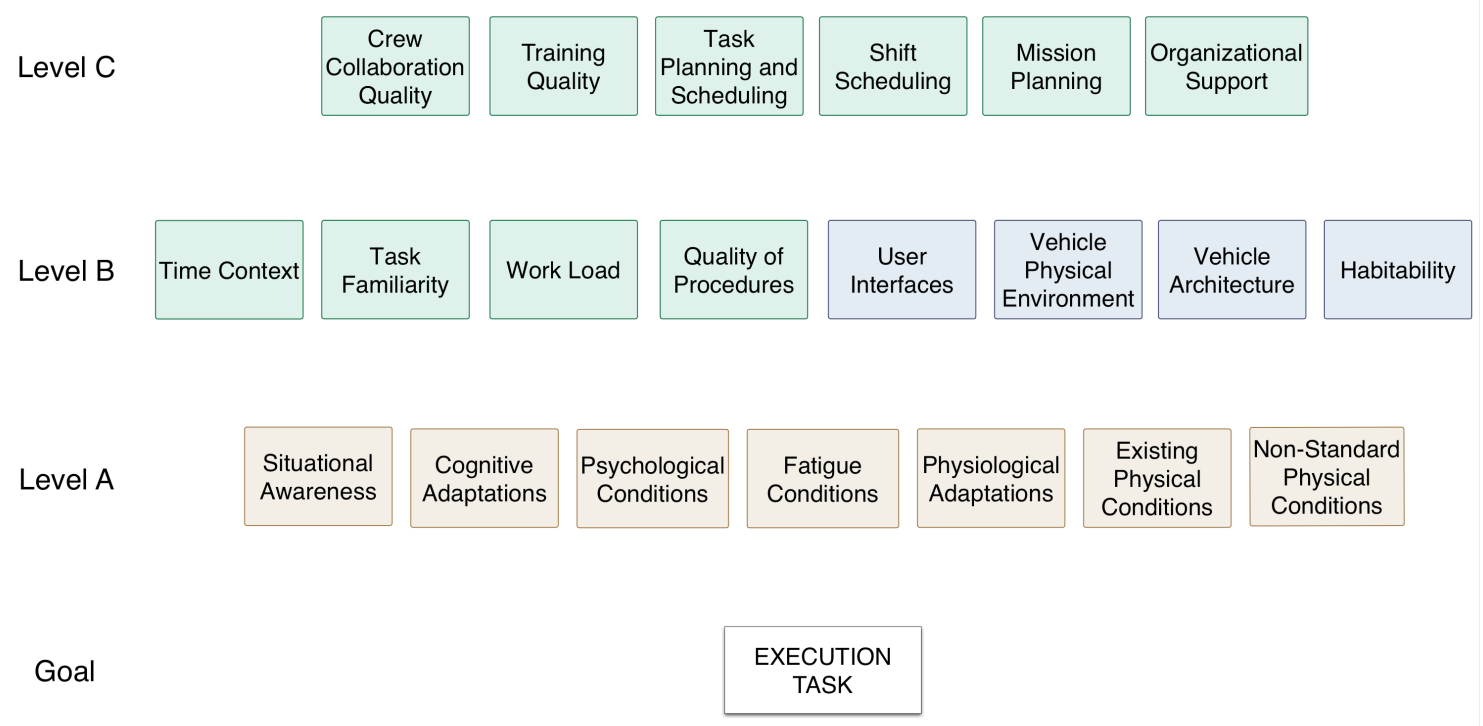

Figure 12: Hierarchy for AHP Analysis

\subsubsection{AHP Step 2: Pair-Wise Comparisons}

The next step in the AHP analysis is to compare the factors at each level in a pair-wise fashion to the preceding level. At Level A, this means comparing, for example, Situational Awareness and Cognitive Adaptations with respect to the Execution Task goal by asking, "Which of these factors has a stronger influence on the successful completion of the Execution Task, and by 
how much?". This question is repeated for all possible pairs of factors at Level A. The assessments given as the elements of the matrix shown for reference in Figure 13 are based on the authors' judgments.

\begin{tabular}{|r|c|c|c|c|c|c|c|}
\hline EXECUTION TASK & $\begin{array}{c}\text { Situational } \\
\text { Awareness }\end{array}$ & $\begin{array}{c}\text { Cognitive } \\
\text { Adaptations }\end{array}$ & $\begin{array}{c}\text { Psychological } \\
\text { Conditions }\end{array}$ & $\begin{array}{c}\text { Fatigue } \\
\text { Conditions }\end{array}$ & $\begin{array}{c}\text { Physiological } \\
\text { Conditions }\end{array}$ & $\begin{array}{c}\text { Existing } \\
\text { Physical } \\
\text { Conditions }\end{array}$ & $\begin{array}{c}\text { Non-Standard } \\
\text { Physical } \\
\text { Conditions }\end{array}$ \\
\hline $\begin{array}{r}\text { Situational } \\
\text { Awareness }\end{array}$ & 1 & 3 & 5 & 5 & 3 & 7 & 1 \\
\hline $\begin{array}{r}\text { Cognitive } \\
\text { Adaptations }\end{array}$ & $1 / 3$ & 1 & $1 / 3$ & 3 & 3 & 7 & 1 \\
\hline $\begin{array}{r}\text { Psychological } \\
\text { Conditions }\end{array}$ & $1 / 5$ & 3 & 1 & 5 & 1 & 7 & 1 \\
\hline $\begin{array}{r}\text { Fatigue } \\
\text { Conditions }\end{array}$ & $1 / 5$ & $1 / 3$ & $1 / 5$ & 1 & $1 / 3$ & 7 & 1 \\
\hline $\begin{array}{r}\text { Physiological } \\
\text { Conditions }\end{array}$ & $1 / 3$ & $1 / 3$ & 1 & 3 & 1 & 7 & 1 \\
\hline $\begin{array}{r}\text { Existing Physical } \\
\text { Conditions }\end{array}$ & $1 / 7$ & $1 / 7$ & $1 / 7$ & $1 / 7$ & $1 / 7$ & 1 & $1 / 7$ \\
\hline $\begin{array}{r}\text { Non-Standard } \\
\text { Physical }\end{array}$ & 1 & 1 & 1 & 1 & 1 & 7 & 1 \\
\hline
\end{tabular}

Figure 13: Level A Comparisons Matrix

The diagonal elements of the matrix are equal to one, as this is a factor's comparison to itself. The entries are read as the comparison of the row entry's strength of influence to the column entry's strength of influence on the state of the Execution Task goal. The numerical value for each entry is the ratio of the strengths using the AHP scale shown in Table 5. The lower triangular elements are the reciprocals of the upper triangular elements, as each comparison pair was evaluated only once and the reciprocal taken for the corresponding pair entry. This approach saves evaluation time and improves matrix consistency. In some situations, one may wish to elicit explicit comparisons for both pairs to evaluate an expert's consistency, although that would require additional time and effort.

Next we move to Level B evaluations. Because there are 7 elements at Level A, Level B requires 7 individual matrices, in which each matrix has one of the Level A elements as its pivot. For example, the first matrix begins with the comparison of Level B factors Time Context and Task Familiarity with respect to the Level A pivot factor Situational Awareness. The question is asked, "In the context of the example scenario, which of these factors has a stronger influence on the state 
of Situational Awareness, and by how much?". The matrix for this example developed at Level B is given in Figure 14.

\begin{tabular}{|c|c|c|c|c|c|c|c|c|}
\hline $\begin{array}{l}\text { SITUATIONAL } \\
\text { AWARENESS }\end{array}$ & Time Context & $\begin{array}{c}\text { Task } \\
\text { Familiarity } \\
\end{array}$ & Work Load & $\begin{array}{c}\text { Quality of } \\
\text { Procedures }\end{array}$ & $\begin{array}{c}\text { User } \\
\text { Interfaces }\end{array}$ & $\begin{array}{c}\text { Vehicle } \\
\text { Physical } \\
\text { Environment }\end{array}$ & $\begin{array}{c}\text { Vehicle } \\
\text { Architecture } \\
\end{array}$ & Habitability \\
\hline Time Context & 1 & 3 & 1 & 5 & 1 & 1 & 5 & 7 \\
\hline Task Familiarity & $1 / 3$ & 1 & 1 & 3 & 1 & 1 & 5 & 7 \\
\hline Work Load & 1 & 1 & 1 & 1 & 1 & 1 & 3 & 7 \\
\hline $\begin{array}{r}\text { Quality of } \\
\text { Procedures }\end{array}$ & $1 / 5$ & $1 / 3$ & 1 & 1 & 1 & 1 & 3 & 7 \\
\hline User Interfaces & 1 & 1 & 1 & 1 & 1 & 1 & 5 & 9 \\
\hline $\begin{array}{r}\text { Vehicle Physical } \\
\text { Environment }\end{array}$ & 1 & 1 & 1 & 1 & 1 & 1 & 5 & 7 \\
\hline $\begin{array}{r}\text { Vehicle } \\
\text { Architecture }\end{array}$ & $1 / 5$ & $1 / 5$ & $1 / 3$ & $1 / 3$ & $1 / 5$ & $1 / 5$ & 1 & 5 \\
\hline Habitability & $1 / 7$ & $1 / 7$ & $1 / 7$ & $1 / 7$ & $1 / 9$ & $1 / 7$ & $1 / 5$ & 1 \\
\hline
\end{tabular}

Figure 14: Level B Comparisons Matrix

The pair-wise evaluations conclude at Level C. The 8 elements at Level B each have their own comparison matrices with the 6 Level C factors as the row and column entries. An example question at this level is, "In the context of the example scenario, which of the factors Training Quality or Task Planning and Scheduling has a stronger influence on the state of Task Familiarity, and by how much?". Figure 15 provides an example matrix determined at Level C.

\begin{tabular}{|r|c|c|c|c|c|c|}
\hline $\begin{array}{r}\text { TASK } \\
\text { FAMILIARITY }\end{array}$ & $\begin{array}{c}\text { Crew } \\
\text { Collaboration } \\
\text { Quality }\end{array}$ & $\begin{array}{c}\text { Training } \\
\text { Quality }\end{array}$ & $\begin{array}{c}\text { Task } \\
\text { Planning \& } \\
\text { Scheduling }\end{array}$ & $\begin{array}{c}\text { Shift } \\
\text { Scheduling }\end{array}$ & $\begin{array}{c}\text { Mission } \\
\text { Planning }\end{array}$ & $\begin{array}{c}\text { Organization- } \\
\text { al Support }\end{array}$ \\
\cline { 2 - 7 } $\begin{array}{r}\text { Crew } \\
\text { Collaboration } \\
\text { Quality }\end{array}$ & 1 & $1 / 5$ & 3 & 5 & 5 & 3 \\
\hline $\begin{array}{r}\text { Traning Quality } \\
\text { Task Planning \& } \\
\text { Scheduling }\end{array}$ & $1 / 3$ & $1 / 5$ & 1 & 5 & 5 & 5 \\
\hline $\begin{array}{r}\text { Shift Scheduling } \\
\text { Mission Planning }\end{array}$ & $1 / 5$ & $1 / 9$ & $1 / 5$ & 1 & 1 & 7 \\
\hline $\begin{array}{r}\text { Organizational } \\
\text { Support }\end{array}$ & $1 / 3$ & $1 / 5$ & $1 / 5$ & 1 & 1 & 7 \\
\hline
\end{tabular}

Figure 15: Level C Comparisons Matrix 


\subsubsection{AHP Step 3: Local Priority Calculations}

The calculations based on the matrices represented by Figure 13 through Figure 15 then proceed as follows. First, the eigenvector of each matrix is found, giving one set of local priorities at Level A, 7 sets of local priorities at Level B, and 8 sets of local priorities at Level C. The eigenvectors shown in Figure 16 were calculated using an approach described in [82].

\begin{tabular}{|c|c|c|c|c|c|c|c|c|c|}
\hline LEVEL A & $\begin{array}{c}\text { EXECUTION } \\
\text { TASK }\end{array}$ & LEVEL B & $\begin{array}{l}\text { SITUATIONAL } \\
\text { AWARENESS }\end{array}$ & $\begin{array}{c}\text { COGNITIVE } \\
\text { ADAPTATIONS }\end{array}$ & $\begin{array}{l}\text { PSYCHOLOGICAL } \\
\text { CONDITIONS }\end{array}$ & $\begin{array}{c}\text { FATIGUE } \\
\text { CONDITIONS }\end{array}$ & $\begin{array}{l}\text { PHYSIOLOGICAL } \\
\text { ADAPTATIONS }\end{array}$ & $\begin{array}{c}\text { EXISTING } \\
\text { PHYSICAL } \\
\text { CONDITIONS }\end{array}$ & $\begin{array}{l}\text { NON-STANDARD } \\
\text { PHYSICAL } \\
\text { CONDITIONS }\end{array}$ \\
\hline $\begin{array}{l}\text { Situational } \\
\text { Awareness }\end{array}$ & 0.33 & Time Context & 0.24 & 0.23 & 0.26 & 0.04 & 0.03 & 0.125 & 0.17 \\
\hline $\begin{array}{r}\text { Cognitive } \\
\text { Adaptations }\end{array}$ & 0.14 & Task Familiarity & 0.16 & 0.20 & 0.13 & 0.04 & 0.02 & 0.125 & 0.12 \\
\hline $\begin{array}{r}\text { Psychological } \\
\text { Conditions }\end{array}$ & 0.18 & Work Load & 0.14 & 0.19 & 0.18 & 0.25 & 0.21 & 0.125 & 0.18 \\
\hline $\begin{array}{r}\text { Fatigue } \\
\text { Conditions }\end{array}$ & 0.07 & $\begin{array}{r}\text { Quality of } \\
\text { Procedures }\end{array}$ & 0.10 & 0.08 & 0.12 & 0.12 & 0.02 & 0.125 & 0.09 \\
\hline $\begin{array}{r}\text { Physiological } \\
\text { Adaptations }\end{array}$ & 0.12 & User Interfaces & 0.15 & 0.10 & 0.10 & 0.19 & 0.09 & 0.125 & 0.12 \\
\hline $\begin{array}{r}\text { Existing Physical } \\
\text { Conditions }\end{array}$ & 0.02 & $\begin{array}{r}\text { Vehicle Physical } \\
\text { Environment }\end{array}$ & 0.15 & 0.12 & 0.09 & 0.23 & 0.40 & 0.125 & 0.19 \\
\hline \multirow[t]{2}{*}{$\begin{array}{r}\text { Non-Standard } \\
\text { Physical } \\
\text { Conditions } \\
\end{array}$} & 0.14 & $\begin{array}{r}\text { Vehicle } \\
\text { Architecture }\end{array}$ & 0.04 & 0.02 & 0.06 & 0.05 & 0.04 & 0.125 & 0.07 \\
\hline & & Habitability & 0.02 & 0.03 & 0.05 & 0.08 & 0.18 & 0.125 & 0.07 \\
\hline
\end{tabular}

\begin{tabular}{|c|c|c|c|c|c|c|c|c|}
\hline LEVEL C & TIME CONTEXT & $\begin{array}{c}\text { TASK } \\
\text { FAMILIARITY }\end{array}$ & WORK LOAD & $\begin{array}{l}\text { QUALITY OF } \\
\text { PROCEDURES }\end{array}$ & $\begin{array}{c}\text { USER } \\
\text { INTERFACES }\end{array}$ & $\begin{array}{c}\text { VEHICLE } \\
\text { PHYSICAL } \\
\text { ENVIRONMENT }\end{array}$ & $\begin{array}{c}\text { VEHICLE } \\
\text { ARCHITECTURE }\end{array}$ & HABITABILITY \\
\hline $\begin{array}{r}\text { Crew } \\
\text { Collaboration } \\
\text { Quality }\end{array}$ & 0.04 & 0.21 & 0.20 & 0.06 & 0.08 & 0.06 & 0.08 & 0.07 \\
\hline Training Quality & 0.04 & 0.47 & 0.13 & 0.17 & 0.22 & 0.09 & 0.08 & 0.07 \\
\hline $\begin{array}{r}\text { Task Planning \& } \\
\text { Scheduling }\end{array}$ & 0.34 & 0.15 & 0.43 & 0.06 & 0.08 & 0.06 & 0.08 & 0.07 \\
\hline Shift Scheduling & 0.34 & 0.07 & 0.15 & 0.06 & 0.08 & 0.06 & 0.08 & 0.07 \\
\hline Mission Planning & 0.15 & 0.07 & 0.03 & 0.06 & 0.08 & 0.33 & 0.36 & 0.36 \\
\hline $\begin{array}{l}\text { Organizational } \\
\text { Support }\end{array}$ & 0.10 & 0.04 & 0.06 & 0.60 & 0.45 & 0.41 & 0.32 & 0.36 \\
\hline
\end{tabular}

Figure 16: Local Priorities

\subsubsection{AHP Step 4: Global Priority Calculations}

We are more interested in the global priorities of each factor, meaning the factor's priority within its level taking into account the weights of the previous level(s). Let us define the following variables in order to calculate the global priorities. Let $i$ be the index for each Level A factor, $i=1,2$, $\ldots$, 7. Similarly, let $j$ be the index for each Level B factor, $j=1,2, \ldots, 8$, and let $k$ be the index for each Level $C$ factor, $k=1,2, \ldots, 6$. Now let $A$ be the vector of Level A priorities with respect to the 
Execution Task goal; this is the eigenvector of the Level A comparison matrix. Next let $B_{A i}$ be the vector giving the priorities of all Level B factors with respect to each Level $A_{i}$ factor; this is the eigenvector of each of the $i=1,2, \ldots, 7$ Level B comparison matrices. Finally, let $C_{B j}$ be the vector giving the priorities of all Level C factors with respect to each Level $\mathrm{B}_{\mathrm{j}}$ factor; this is the eigenvector of each of the $j=1,2, \ldots, 8$ Level C comparison matrices.

To find the global ranking of each Level $B$ factor with respect to one factor $A_{i}$, we calculate the vector

$$
B_{\text {Aiglobal }}=A(i) * B_{A i}
$$

This new vector results from the global weight of factor $A_{i}$ multiplying the local priority ranking of each Level B factor with respect to $A_{i}$.

Next we must add the contributions from all $i$ global rankings to obtain the global ranking for element $B_{j}[82]$,

$$
B_{\text {jglobal }}=\sum_{i=1}^{7} B_{\text {Aiglobal }}(j) .
$$

This summation is repeated for $j=1,2, \ldots, 8$ for the full global priority vector at Level B,

$$
B_{\text {global }}=\left[\begin{array}{llllllll}
B_{\text {lglobal }} & B_{2 \text { global }} & B_{3 \text { global }} & B_{4 \text { global }} & B_{5 \text { global }} & B_{6 g l o b a l} & B_{7 g l o b a l} & B_{8 g l o b a l}
\end{array}\right]^{T} .
$$

As a sanity check, the sum of all elements in the global priority vector at each level should be unity. 
The same process is followed for Level $\mathrm{C}$ with the equations

$$
\begin{aligned}
& C_{B j g l o b a l}=B_{j g l o b a l} * C_{B j} \text { and } \\
& C_{k g l o b a l}=\sum_{j=1}^{8} C_{B j g l o b a l}(k) .
\end{aligned}
$$

Similar to Level B, the summation repeated for $k=1,2, \ldots, 6$ provides the full global priority vector at Level C,

$$
C_{\text {global }}=\left[\begin{array}{llllll}
C_{1 \text { global }} & C_{2 \text { global }} & C_{3 \text { global }} & C_{4 \text { global }} & C_{5 \text { global }} & C_{6 g l o b a l}
\end{array}\right]^{T} .
$$

\begin{tabular}{|c|c|c|c|c|c|}
\hline \multicolumn{2}{|c|}{ LEVEL A } & \multicolumn{2}{|c|}{ LEVEL B } & \multicolumn{2}{|c|}{ LEVEL C } \\
\hline $\begin{array}{l}\text { Situational } \\
\text { Awareness }\end{array}$ & 0.33 & Time Context & 0.17 & $\begin{array}{r}\text { Crew } \\
\begin{array}{r}\text { Collaboration } \\
\text { Quality }\end{array} \\
\end{array}$ & 0.10 \\
\hline $\begin{array}{r}\text { Cognitive } \\
\text { Adaptations }\end{array}$ & 0.14 & $\begin{array}{r}\text { Task } \\
\text { Familiarity }\end{array}$ & 0.12 & $\begin{array}{l}\text { Traning } \\
\text { Quality }\end{array}$ & 0.15 \\
\hline $\begin{array}{r}\text { Psychological } \\
\text { Conditions }\end{array}$ & 0.18 & Work Load & 0.18 & $\begin{array}{l}\text { Task Planning } \\
\text { \& Scheduling }\end{array}$ & 0.19 \\
\hline $\begin{array}{r}\text { Fatigue } \\
\text { Conditions }\end{array}$ & 0.07 & $\begin{array}{r}\text { Quality of } \\
\text { Procedures }\end{array}$ & 0.09 & $\begin{array}{r}\text { Shift } \\
\text { Scheduling }\end{array}$ & 0.13 \\
\hline $\begin{array}{r}\text { Physiological } \\
\text { Conditions }\end{array}$ & 0.12 & $\begin{array}{r}\text { User } \\
\text { Interfaces }\end{array}$ & 0.12 & $\begin{array}{r}\text { Mission } \\
\text { Planning }\end{array}$ & 0.17 \\
\hline $\begin{array}{r}\text { Existing Physical } \\
\text { Conditions }\end{array}$ & 0.02 & $\begin{array}{r}\text { Vehicle } \\
\text { Physical } \\
\text { Environment }\end{array}$ & 0.19 & $\begin{array}{r}\text { Organizational } \\
\text { Support }\end{array}$ & 0.26 \\
\hline \multirow[t]{2}{*}{$\begin{array}{r}\text { Non-Standard } \\
\text { Physical } \\
\text { Conditions }\end{array}$} & 0.14 & $\begin{array}{r}\text { Vehicle } \\
\text { Architecture }\end{array}$ & 0.07 & & \\
\hline & & Habitability & 0.07 & & \\
\hline
\end{tabular}

Again, the sum of the vector elements should be unity.

The global priorities calculated in this example are given in Figure 17.

\section{Figure 17: Global Priorities}

\subsubsection{RESULTS AND DISCUSSION}

With the global priorities as shown in Figure 17, we were next able to use these values to support the decision-making process for choosing which of the 21 Functional Groupings to include in our simplified model. At Level A, if all elements were equally weighted, their weight values would be 0.14 . This value could be used as an initial threshold, meaning that factors with values at 
or above this threshold would be included in the simplified model. This threshold value would lead to the inclusion of Situational Awareness, Cognitive Adaptations, Psychological Conditions, and Non-Standard Physical Conditions. The influence of Physiological Adaptations was judged to be additionally important to include, and the Level A threshold was therefore decreased to 0.12 .

At Level B, the starting threshold for equally weighted elements was 0.125 . This threshold would lead to the inclusion of the Time Context, Work Load, and Vehicle Physical Environment factors. In this case, Task Familiarity and User Interfaces were also judged to be influential, and again the threshold was lowered to 0.12 .

Finally, at Level C, the starting threshold for equal weighting was 0.167 . This value leads to the inclusion of Task Planning \& Scheduling and Organizational Support. For Level C, the Training Quality and Mission Planning elements were identified for inclusion, consistent with a reduced threshold of 0.15 .

Now we turn to the question of which factor relationships to include in our simplified model. Level A factor relationships to the Execution task goal are the simplest case to decide. Because there is only one item, the Execution task, to which to create a relationship, all factors chosen for inclusion in the model will have relationships to the Execution task included.

Next we look at which relationships from Level B factors to Level A factors we will model. At this level we must look at each of the Level A factors and how the Level B factors are weighted with respect to each one in its local priority vector. We used our starting threshold of equally weighted Level B factors, 0.125 to guide this decision. For Cognitive Adaptations, for example, this lead to the inclusion of influences from Time Context, Task Familiarity and Work Load.

The same logic was used for deciding which relationships from Level C to Level B factors to model. We began with the initial threshold of equally weighted Level C factors, 0.167 . Looking at the local priority vector for Time Context, for example, we see the factors with values at or above this threshold are Task Planning \& Scheduling and Shift Scheduling. Shift Scheduling, however, did 
not have a high enough global priority to be included in the model. Its influence on Time Context will therefore not be included. The next highest value of 0.15 in the local priority vector is associated with the Mission Planning factor. The Mission Scenarios component of Mission Planning was thought to be important enough to be included in the model due to its influences on the state of the Time Context. This indicates a threshold for Time Context contributors of $\geq 0.15$. Similar logic was used for the remaining Level B factors and their Level C contributors. Table 6 shows the thresholds used for the Level B factors' contributors at Level C.

\begin{tabular}{|c|c|c|c|c|c|}
\hline & $\begin{array}{c}\text { Time } \\
\text { Context }\end{array}$ & $\begin{array}{c}\text { Task } \\
\text { Familiarity }\end{array}$ & Work Load & $\begin{array}{c}\text { User } \\
\text { Interfaces }\end{array}$ & $\begin{array}{c}\text { Vehicle Physical } \\
\text { Environment }\end{array}$ \\
\cline { 2 - 6 } Threshold & 0.15 & 0.15 & 0.13 & 0.167 & 0.167 \\
\cline { 2 - 6 } & & &
\end{tabular}

Table 6: Thresholds for Model Inclusion of Level C Factor Relationships to Level B

The AHP analysis supported the determination of believed factor dominance. This insight supported decisions made in choosing a subset of original factors and relationships for inclusion in a simplified model. These decisions resulted in the Bayesian Network structure shown in Figure 18. 


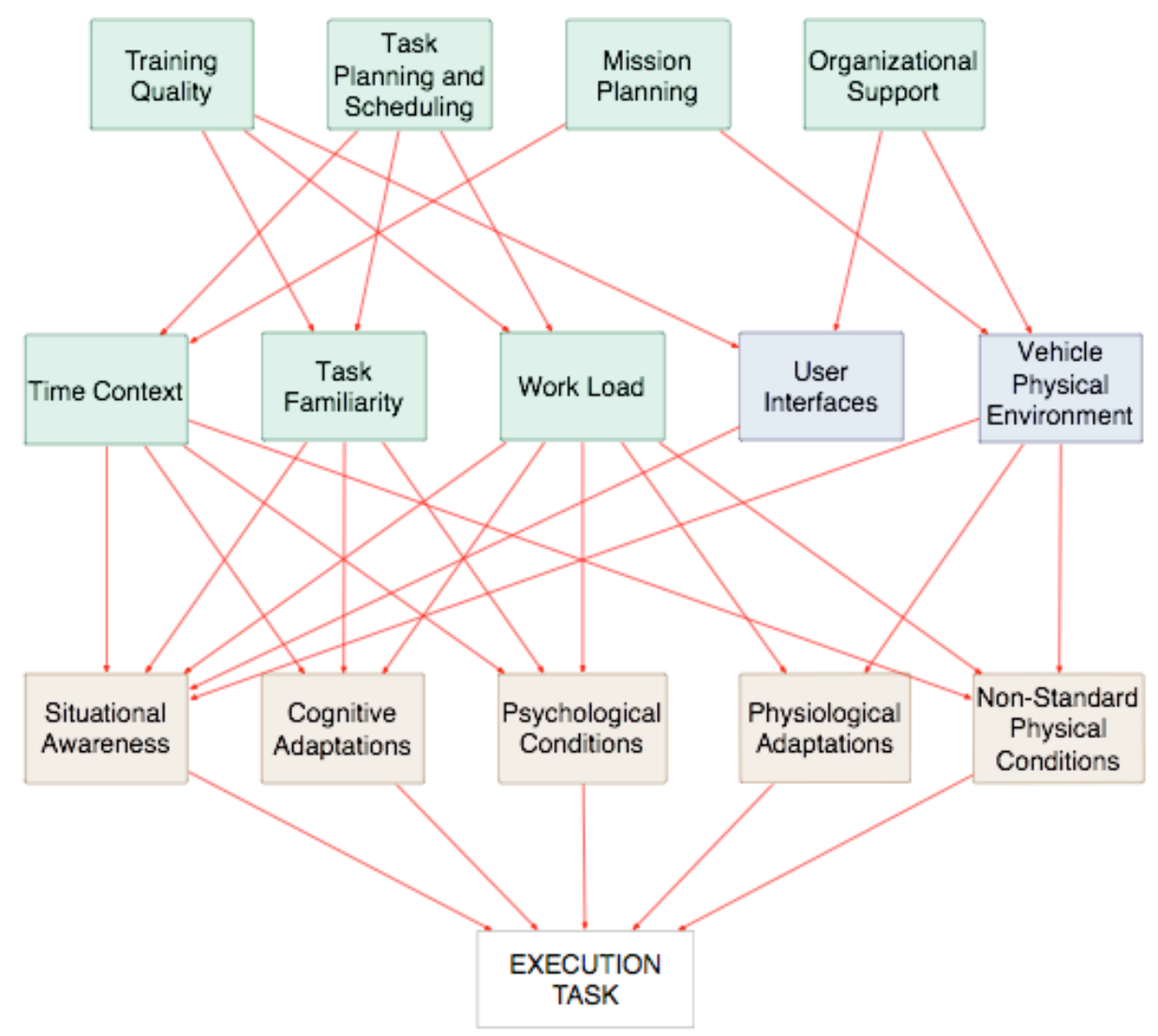

Figure 18: Bayesian Network Structure Resulting from AHP Analysis

Let us discuss the resulting structure. At Level A, it is interesting to note that Fatigue Conditions and Existing Physical Conditions were the two factors not included in the simplified model. The context scenario used for the pair-wise comparisons provides an explanation for this result. Since the scenario involved only the task of pushing a button and not a more physically demanding Execution task, one can rationalize Fatigue Conditions and Existing Physical Conditions not being as influential. The presence of Physiological Adaptations and Non-Standard Physical Conditions capture physical state such as illness or injury that may still affect even push-button task performance.

At Level B, the factors not included were Quality of Procedures, Vehicle Architecture and Habitability. Again, we can see the context scenario shaped these results. The nature of the pushbutton task as a simple step would support the inclusion of Task Familiarity for addressing 
knowledge of the button's location and feel. Since the task is not a complicated one, however, the Quality of Procedures would appear less important. The Vehicle Architecture and Habitability factors would seem to have greater influences in the context of tasks other than Execution tasks after mission durations of longer than the two weeks in our example. For instance, one might expect their influences on Psychological Conditions at Level A, and then Interpretation or Planning tasks to be greater in a long-duration scenario.

Finally at Level C, we observe the factors Crew Collaboration Quality and Shift Scheduling were not included. Because the task in our context scenario is not one requiring elaborate coordination with other crewmembers, it is reasonable to see Crew Collaboration Quality not being included. As for Shift Scheduling, it is possible this did not weigh above the Level C global threshold because its main influence may eventually be seen through Fatigue Conditions, which were not evaluated as strongly influencing this type of Execution task.

\subsubsection{FUTURE WORK FOR STRUCTURE DEVELOPMENT}

Future work includes performing the same analysis process using different context scenarios for the same type of task. For example, using a more physically demanding Execution Task as the context scenario action, such as opening a spacecraft hatch instead of pushing a button, may produce results with Fatigue Conditions and related factors more dominant in the resulting structure. This type of work would lead to the determination of different network structures required for subcategories of tasks (e.g. Physically Demanding Execution Tasks vs. Not-Physically Demanding Execution Tasks).

Similarly, the analysis process can be performed for the other three types of cognitive tasks: Observation, Interpretation and Planning Tasks. It is expected that slightly different network 
structures will result for tasks of a more mental than physical nature. Altering the context scenario mission duration may be an additionally influential context variable across the types of tasks.

Additional efforts may also include opinion elicitation from multiple experts for the comparison matrix entries. There are various techniques available for combining inputs from multiple experts $[60,64,87]$.

With a traceable approach supporting the determination of a simplified BN structure in place, efforts can next address the ascertainment of the probabilities needed to quantify the BN. The network structure developed in this example analysis requires 112 probabilities for full quantification. This is opposed to the $\left(2^{7}\right)+\left(2^{8}\right)(7)+\left(2^{6}\right)(8)=2432$ probabilities required if all 21 Functional Groupings and their relationships, even as constrained by the hierarchy, were modeled. This reduced number is especially important in our situation in which a global database of probabilities for factor influences does not exist, and expert opinion elicitation is the primary reasonable initial source of probabilistic information.

\subsubsection{CONCLUSIONS FOR STRUCTURE DEVELOPMENT}

This section demonstrates a method for determining the structure of a Bayesian Network when a global set of data for algorithmic analysis is not available. This method was built on an existing set of detailed factors influencing the performance of tasks in the spaceflight domain. It

employed a commonly used decision-support method, the Analytic Hierarchy Process, and causal latency concepts from the Human Factors Analysis and Classification System in a novel way to guide choices for modeling the dominant set of factors and relationships in a simplified Bayesian Network model structure. This structure allows for the next task in Bayesian Network development of probabilistic quantification to be more tractable, especially when using expert opinion. 


\subsection{BAYESIAN NETWORK QUANTIFICATION}

Now that we have discussed an initial approach for Bayesian Network (BN) structure development, we turn to what Sigurdsson, Walls and Quigley [71] identify as step 3 in stage 1 of the Bayesian Network development process, the expression of the factors as statistical variables. We also address stage 2, Instantiation, or the quantification of factor influences. Ideally, our network model would evolve from the more abstracted level of the Functional Groupings used in Section 4.2 to the more detailed level of the Contributing Factors. A major motivation behind this eventual goal is that many human performance research studies operate at the more detailed level, examining influences of the more specific variables on each other and on performance. This section therefore describes an approach for modeling the Contributing Factors as statistical variables. It also provides an approach for using existing design requirements, standards and human performance data in the quantification of the factor influences.

It is worth noting that work has been done in the area of object-oriented Bayesian Networks (OOBNs) $[88,89]$. Frameworks and implementations of networks have been developed that allow for various levels of abstraction to be modeled, such as the levels in the hierarchy shown in the Contributing Factor Map (CFM) of Figure 10. OOBNs can be used to support more efficient and rich modeling achieved by allowing subclasses of model elements, such as the Contributing Factors, to relate to properties of more abstract elements, such as the Functional Groupings. This capability would allow the connection to be made between a more abstract model, such as the example in Figure 18 quantified by expert opinion, and detailed quantification as described in this section.

Let us begin the discussion of network quantification in the spaceflight domain with a simplified BN example relevant to conditions in a space vehicle, shown in Figure 19. The two variables modeled are shown as the Acceleration/Gravity Level and Visual Perception Function 
nodes. The link is the arrow showing the direction of influence from the Acceleration/Gravity Level parent to the Visual Perception Function child. A root node is that which has no parent [21] ,which in this example is the Acceleration/Gravity Level node.

In order to quantify the relationships indicated by the links, BNs make use of Conditional Probability Tables (CPTs). The state of a node is conditional upon the states of its parent nodes. If the node is a root node, the table is the unconditional probability distribution of that node [90]. In the simple example shown in Figure 19, each node can have a state of OK, or Not OK. The root node Acceleration/Gravity Level has the given probability distribution, and the node Visual Perception Function has a distribution that depends on the state of the Acceleration/Gravity Level node. Local relationships such as the one shown in Figure 19 can be combined into a global BN model of a spacecraft system using factors such as those shown on the Contributing Factor Map (CFM) in Figure 10. In such a global model, the child nodes of the greatest interest are health factors shown near the bottom of the CFM, and the performance of tasks represented by the four cognitive functions from the Cognitive Reliability and Error Analysis Method (CREAM) [2], just below the horizontal line on the CFM. When the CPTs of all nodes in the network are defined, the outcome marginal probabilities for the child nodes of interest can be calculated using conditional probability laws and algorithms developed over decades [58, 91, 92].

The BN approach to understanding the influences of factors on crew health and performance has shaped the thinking for gathering information about the factors. The relation of this approach to how it may be used for requirements development applications is discussed next. 


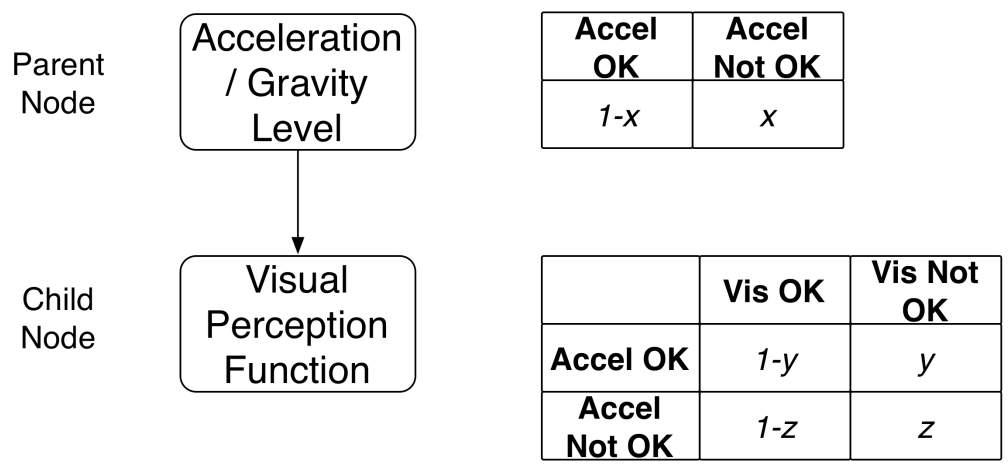

Figure 19: Representative Nodes and their CPTs in a Bayesian Network

\subsubsection{REQUIREMENT-AND DATA-INFORMED FACTOR MODELING}

Figure 19 shows the most basic probability information required to quantify the relationships between BN nodes, captured in CPTs. In determining the values for probabilities such as $x, y$ and $z$, there is additional information we would like to gather in order to characterize each node and the relationship between nodes. We describe this additional information in Section 4.3.1, with an example following in Section 4.3.2.

\subsubsection{Parent Factor Characterization}

The parent factor characterization information allows ties to be made between the description of the factor as a variable and existing requirements or standards.

\section{Metric}

The metric is how the "goodness" of the state of the factor may be measured [93]. A simple example is for the factor Acceleration/Gravity Level, the metric Acceleration, in terms of g's, may be 
used. If a relevant requirement exists, the metric used for verification is likely an appropriate metric to use for this information.

\section{Possible States}

The definition of possible states for a factor supports its use as a statistical variable in the Bayesian Network. Often the states are modeled as discrete, not continuous, variables for simplification of calculations [71]. The simplest set of states is a discrete binary set such as "OK" and "Not OK".

\section{Observables}

Observables are a separate piece of information from the factor's metric, although in many cases the observable and metric may be the same. Observables may be necessary to identify in cases when the metric is not directly measurable itself, but observable quantities must be used as proxies, instead. An example is for the Bone Strength factor, for which there is no direct measurement. Bone strength indices exist, using dual energy X-ray absorptiometry (DXA) and quantitative computed tomographic (QCT) measurements of bone density and geometry, for example [8]. A mapping from the observable to the metric should ideally be captured here, as well.

\section{Threshold for Acceptable States}

The threshold for acceptable states is the level on the scale of the metric at which the factor's state is no longer adequate for the desired performance. This threshold should ideally be determined by a standard or requirement if an appropriate one exists. An example using the Acceleration/Gravity Level factor is to define a threshold for acceptable g-levels during launch.

\section{References for Threshold Definition}

This information field is where the documents or sources used in the definition of the threshold for acceptable state are captured. The existing standard, requirement, data or expert 
sources should be logged for future reference and analysis, along with its corresponding level of evidence. A possible scale for the level of evidence, similar to a scale from NASA's Human Research Program Evidence Book [26], is:

- Category I data are based on flight or mission data from the same vehicle, set of vehicles or environment.

- Category II data are based on flight or mission data from a similar vehicle, set of vehicles or environment.

- Category III data are based on ground analog or simulation studies.

- Category IV data are based on expert reports or opinions of respected authorities that are based on clinical experiences, bench research, or 'first principles'.

\section{Probability of State Occurrence}

The probability of a factor being in any of its possible states is captured here. These are the probability values as shown in a factor's CPT, such as $x$ and (1-x) in Figure 19. Ideally this type of probability distribution information would come from data, but expert opinion is often used as the starting point for an initial distribution.

\section{References for State Probabilities}

This information field is where the documents or sources used in the estimation of the probabilities of occurrences of the factor's various states are captured. The existing standard, requirement, data or expert sources should be logged for future reference and analysis, along with their level of evidence. 


\section{Mission Phase}

This piece of information addresses during which mission phase(s) the factor and its probability distribution are applicable. Different distributions may be required for different mission phases.

\section{Mission Category}

This piece of information addresses during which types of missions the factor and its probability distribution are applicable. Examples of mission categories are a lunar sortie or a round-trip mission to Mars. Different distributions may be required for different mission categories.

\subsubsection{Relationship Characterization}

Just as for the nodes, there is information we would like to capture characterizing the relationships themselves. This information aids in the development of the network by supporting the existence of links between nodes and the strength of those links.

\section{References for Relationship Existence}

This field provides a way to capture the type and level of evidence supporting the existence of a relationship. Similar to the reference information fields for the parent node, this should capture the existing standard, requirement, data or expert sources supporting the existence of a relationship, along with their level of evidence. 


\section{Strength of Relationship}

Not only is the existence of a relationship between two factors important, but the strength of that relationship must be understood, as well. In the Bayesian Network model, this information is translated into the conditional probabilities for the child node, such as $y$ and $z$ shown in Figure 19. An initial set of qualitative value options may be as simple as High, Medium and Low.

\section{References for Relationship Strength}

This piece of information captures the uncertainty in the understanding of the strength of the relationship. Again, similar to the reference information fields for the parent node, this should capture the existing standard, requirement, data or expert sources supporting the definition of the strength of a relationship, along with their level of evidence.

\subsubsection{Child Factor Characterization}

The characterization information for a child node is largely the same as for a parent node. The difference lies in capturing the probability distributions.

\section{Probability of State Occurrence}

The probability of a factor being in any of its possible states is captured here, just as for the parent factors. With a child node, however, the conditional probabilities given the state of the parent node(s) are defined in order for marginal probabilities to be calculated and captured here. This is discussed further in the example in Section 4.3.2. 


\subsubsection{EXAMPLE FACTOR MODELS}

\subsubsection{Acceleration/Gravity Level Parent Factor Characterization}

The Parent Factor Characterization information is shown in Table 7 with illustrative content for the Acceleration/Gravity Level node.

\begin{tabular}{|l|l|}
\hline $\begin{array}{l}\text { Factor Characterization } \\
\text { Information }\end{array}$ & Example Values \\
\hline Metric & Acceleration (g's) \\
\hline Possible States & OK; Not OK \\
\hline Observables & Acceleration (g's) \\
\hline Acceptable States & OK \\
\hline Threshold for Acceptable States & $\begin{array}{l}\text { Acceleration < Requirement 6.5.1, Fig. 4, }+\mathrm{G}_{\mathrm{z}} \text { Sustained } \\
\text { Translational Acceleration Limits, Limit for Launch to } \\
\text { Mission Destination [47] }\end{array}$ \\
\hline References for Threshold Definition & NASA-STD-3001, Vol. 2 [47] - Category II \\
\hline Probability of State Occurrence & Not OK $=x ;$ OK $=(1-x)$ \\
\hline References for State Probabilities & $\begin{array}{l}\text { Example historical data set based on similar vehicle - } \\
\text { Category II }\end{array}$ \\
\hline Mission Phase & Launch \\
\hline Mission Category & Lunar Sortie \\
\hline
\end{tabular}

Table 7: Acceleration/Gravity Level Factor Characterization Information

Some of the characterization information can be shown on a probability distribution graph, as in Figure 20. The horizontal axis is defined by the metric, Acceleration, with the corresponding unit of g's. The vertical axis is defined by probability values between zero and one. The dashed vertical line represents the threshold for acceptable levels of acceleration, in this case defined by the dashed blue middle line in Figure 21. The probability of having acceleration levels greater than the threshold is shown illustratively by the variable $x$ in Figure 20, along with its corresponding state of Not OK. 


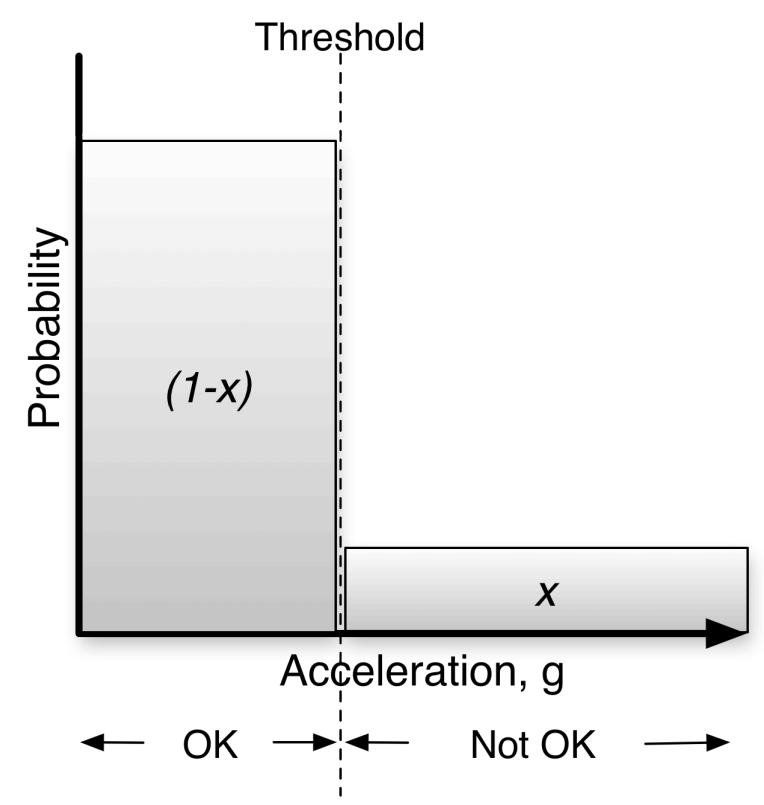

Figure 20: Example Parent Factor Characterization Information

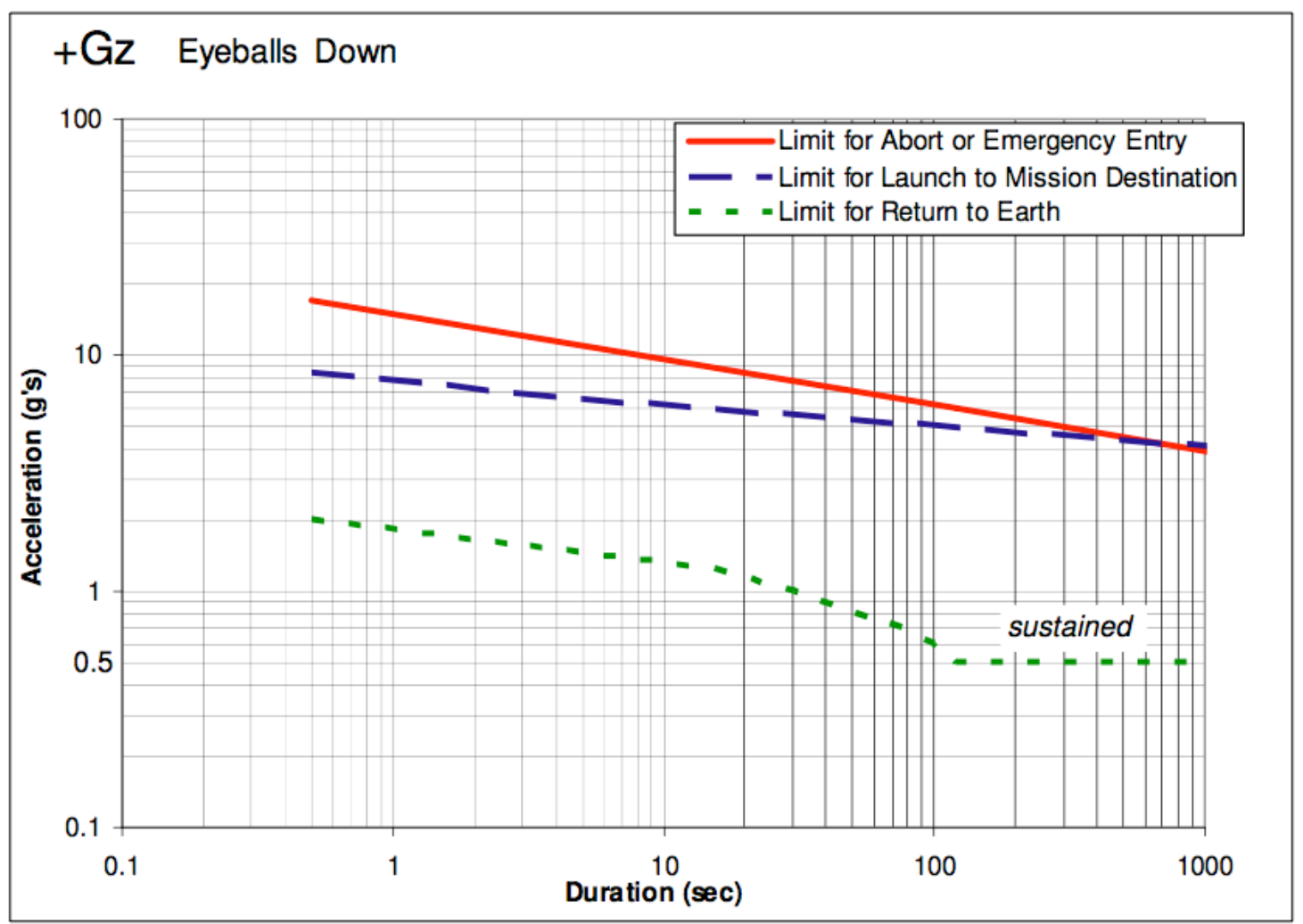

Figure 21: Requirement Reference for Threshold Definition, Section 6.5.1 Fig. 4 of [47] 


\subsubsection{Relationship Characterization}

Example inputs for relationship characterization information are shown in Table 8.

\begin{tabular}{|l|l|}
\hline $\begin{array}{l}\text { Factor Characterization } \\
\text { Information }\end{array}$ & Example Values \\
\hline $\begin{array}{l}\text { References for Relationship } \\
\text { Existence }\end{array}$ & Balldin, 2002 [94] - Category III \\
\hline Strength of Relationship & High \\
\hline References for Relationship Strength & $\begin{array}{l}\text { Fig. 33-6 in Balldin, 2002 [94] - Category III; } \\
\text { Fig. 17 in Ch. 1 of Huntoon et al., 2004 [51] } \\
\text { Fig. 7 in Stoll, 1956 [95] - Category III }\end{array}$ \\
\hline
\end{tabular}

Table 8: Relationship Characterization Information

\subsubsection{Visual Perception Function Child Factor Characterization}

The Child Factor Characterization information is shown in Table 9 with example content for the Visual Perception Function node. The marginal probability distribution, in this example the quantities $v$ and (1-v), is listed in Table 9 and discussed next.

\begin{tabular}{|l|l|}
\hline $\begin{array}{l}\text { Factor Characterization } \\
\text { Information }\end{array}$ & Example Values \\
\hline Metric & Presence of visual symptoms \\
\hline Possible States & $\begin{array}{l}\text { OK = no symptoms present; Not OK = visual symptoms or } \\
\text { unconsciousness present }\end{array}$ \\
\hline Observables & Presence of visual symptoms \\
\hline Acceptable States & OK \\
\hline Threshold for Acceptable States & No visual symptoms \\
\hline References for Threshold Definition & $\begin{array}{l}\text { None identified as of yet, therefore base initial threshold } \\
\text { determination on expert opinion. - Category IV }\end{array}$ \\
\hline Probability of State Occurrence & Not OK = v; OK = (1-v) \\
\hline References for State Probabilities & $\begin{array}{l}\text { Calculations using conditional probabilities obtained by } \\
\text { expert opinion - Category IV }\end{array}$ \\
\hline Mission Phase & Launch \\
\hline Mission Category & Lunar Sortie \\
\hline
\end{tabular}

Table 9: Visual Perception Child Factor Characterization Information 
In order to calculate the marginal probability distribution, we use the data from the CPTs of both the child and parent nodes. Let us define variables for the terms in the CPT where $V$ represents the Visual Perception Function node being in the OK state, and $V^{\prime}$ represents it being in the Not OK state. Similarly, let $A$ be defined as the Acceleration/Gravity Level being in the OK state, and $A^{\prime}$ as it being in the Not OK state. Then the marginal probability $v$ is given by

$$
v=P\left(V^{\prime}\right)=P\left(V^{\prime} \mid A\right) \times P(A)+P\left(V^{\prime} \mid A^{\prime}\right) \times P\left(A^{\prime}\right) .
$$

Substituting variables from the CPTs in Figure 19, we have

$$
v=P\left(V^{\prime}\right)=(y) \times(1-x)+(z) \times(x) .
$$

Similarly, the marginal probability $(1-v)$ is given by

$$
1-v=P(V)=P(V \mid A) \times P(A)+P\left(V \mid A^{\prime}\right) \times P\left(A^{\prime}\right)
$$

Again substituting variables from the CPTs in Figure 19, we have

$$
1-v=P(V)=(1-y) \times(1-x)+(1-z) \times(x) .
$$

The results of these marginal probability calculations can also be shown on a probability distribution graph, as illustrated in Figure 22. 


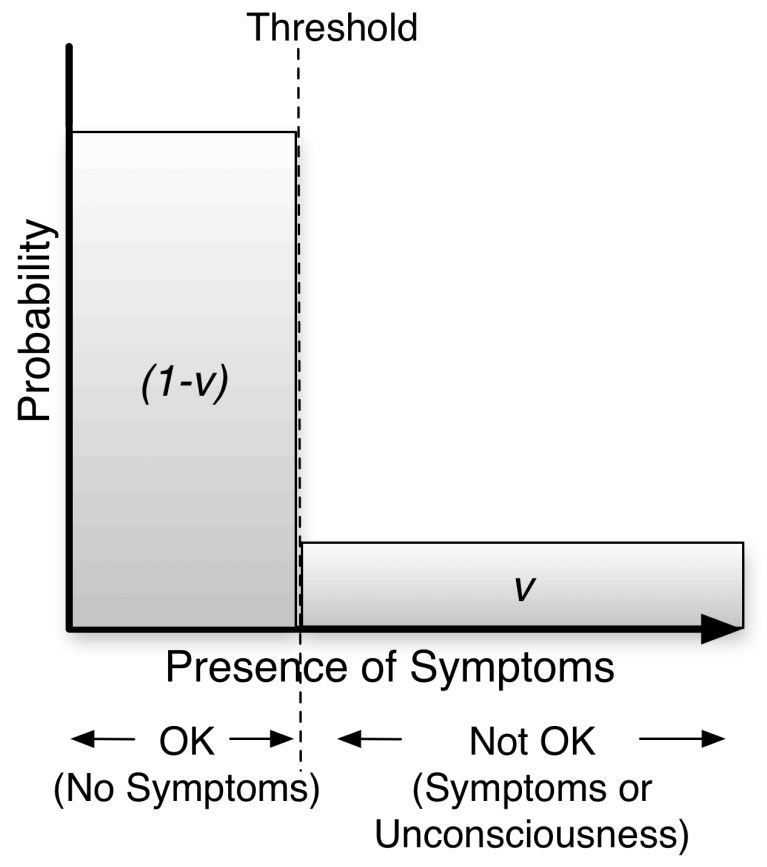

Figure 22: Example Child Factor Characterization Information.

\subsubsection{ANALYSES ENABLED}

\subsubsection{Requirement and Knowledge Gap Identification}

When the Contributing Factor Map (CFM) is used as the global framework allowing integration of the information described in Section 4.3.1, gaps can be identified for factors that are thought to be relevant, but do not have associated requirements or standards. Even before a BN model is built to calculate probabilistic predictions quantitatively, a searchable model or database containing the information from Section 4.3.1 allows such gap identification. For example, if a particular factor is thought to be important for consideration in the vehicle design, but there are no associated standards, requirements or design documents capturing its necessary state and metric thresholds, this approach allows that fact to be identified. Consequently, a new requirement may need to be added to the current baseline set. Identifying such gaps across different mission types 
and mission phases may also illuminate areas in which additional understanding should be captured in requirements or standards.

Similarly, factors in a model or database that do not have evidence or that have high uncertainty in the evidence supporting their probability distributions can support the identification of gaps in knowledge regarding those factors. In addition, relationships and their strengths that do not have high certainty references identified may also indicate knowledge gaps. These types of gaps may indicate the need for future research in factor and/or relationship characterization.

\subsubsection{Commonality Assessment}

Capturing the information described in Section 4.3.1 also supports the assessment of standards and requirements across various organizations. Using the CFM as an organizational scheme provides a framework, or a set of structured bins, for relating requirements or standards on the same or similar factors from different organizations. Thus, references from various organizations supporting a factor's threshold values and probabilities of state occurrences, for example, can be compared and evaluated to assess their commonality and understand any differences in values.

\subsubsection{Relevancy and Impact Assessments}

Again, even before a BN is created based on the data in Section 4.3.1, simple relevancy and impact assessments can be made based on information in a searchable model or database. For example, with relationships identified explicitly in the database, all of the immediate parents and children for any particular factor can be identified. With relationship strength information 
captured, we can assess, for example, which parents are believed to have the strongest influences on a particular child node. This may guide decisions for which design "knobs" may be the most effective to put effort into "turning". For example, the requirements related to a specific factor may be selected for adjustment when the factor's impact on crewmember health or performance is more clearly understood to be high with the help of the relationship characterization.

Once child factor probabilities are calculated, they can be evaluated in terms of whether the values are in acceptable ranges or not. If the probabilities for the child factor states are not as desired, this may motivate requirement or design changes. As an example from our simple case, if the probability that visual symptoms exist is viewed as too high, acceleration requirements and design profiles meeting those requirements may be adjusted for the vehicle. Additionally, when an entire Bayesian Network is developed, sensitivity analyses can be performed that would provide more global understanding of the impacts of various factors on health and performance outcomes of interest. This would further support identification of design "knobs" to adjust in trades throughout the design process.

\subsubsection{CONCLUSIONS FOR REQUIREMENT- AND DATA-INFORMED BN QUANTIFICATION}

The Contributing Factor Map (CFM) has been developed within the context of the Safety and Mission Assurance domain application of Human Reliability Analysis, but has the potential to support requirements development activities during the design process, as well. The CFM can be used as a roadmap for requirement gap identification given its breadth and depth of coverage. If additional information as described in this section is used to characterize the factors on the CFM, insight may be gained to support analysis of similar requirements from different organizations and to enable requirement validity and impact assessments. Because the CFM addresses factors influencing the health and performance of crewmembers, its use can allow improved incorporation 
of these design variables into the trade space and provide additional structure to the efforts of spacecraft designers whose goal is to develop a safe and efficiently operated vehicle.

In addition to the potential for requirements development support in the design phases of vehicle development, efforts towards quantification of the CFM can be used to aid in the identification of future research. Capturing the information described in this section would identify factors and relationships whose characterizations are not well understood. Factors with high impacts on other factors or performance, but with high uncertainty in their characterizations, may be targets for additional research. Similarly, if relationships are identified as strong but have high uncertainty in their supporting references, those relationships may require additional research for improved understanding.

\section{CHAPTER 4 RESULTING PRESENTATIONS AND/OR PUBLICATIONS}

Mindock, J. and Klaus, D. Application of a Spaceflight Contributing Factor Map for Definition and Assessment of Spacecraft Design Requirements. Paper and presentation submitted March 2012 to the 42nd International Conference on Environmental Systems. San Diego, CA. July 2012.

Mindock, J. and Klaus, D. Using the Analytic Hierarchy Process to Develop a Bayesian Network Structure to Model Factors Influencing Human Reliability in Space. International Journal of Approximate Reasoning. Submitted April 2012. 


\section{CHAPTER 5}

\section{APPROACH FOR APPLICATION OF FACTORS IN HUMAN RELIABILITY ANALYSIS}

\subsection{DESCRIPTION OF EXAMPLE BAYESIAN NETWORK}

\subsubsection{REVIEW OF BN STRUCTURE AND DEVELOPMENT}

Let us now recall the stages of Bayesian Network (BN) development and application as described by Sigurdsson, Walls and Quigley [71] and mentioned in Chapter 4; Problem Structuring, Instantiation, and Inference. Chapter 3 discussed step 1 in the Problem Structuring phase, the identification of variables, captured in the Contributing Factor Map (CFM). Chapter 4 discussed step 2 and step 3 in stage 1, identifying the network structure and expressing the factors as statistical variables. The second stage, Instantiation, defined by step 4 that is the quantification of the network with conditional probabilities, was also discussed in Chapter 4 in terms of the options of using data or expert opinion. This chapter will describe an example quantification based on the author's opinion, for illustrative purposes. This chapter then moves on to stage three, Inference. We will demonstrate how to incorporate observations of variable states from an example spaceflight scenario into the network, and show how outcome probabilities result.

\subsubsection{QUANTIFICATION OF EXAMPLE BN}

The network used for our example is that described in Chapter 4 and shown in Figure 18. We began the quantification activity by setting the absolute scale with the probabilities in the Conditional Probability Table (CPT) for the outcome node, Execution Task Success. The marginal 
probability for the False state of this node, calculated once the entire network is quantified, provides the quantity similar to the nominal Human Error Probability (HEP) provided by other Human Reliability Analysis (HRA) methods. Many HRA methods use values such as 1 E-03 for a nominal task execution HEP [6], and we used this value for the probability of the Execution Task Success node being False for all CPT entries in which 1 out of 5 of the parent nodes are Not OK. We then used an order-of-magnitude adjustment for three of the other categories of CPT entries, just as Groth and Mosleh did in [75], for similar illustrative purposes. The Groth and Mosleh example has a maximum error probability of 1 when 4 parent error conditions are present, however, our model has 5 parents. We therefore used the probability complement of the CPT entries with 1 parent Not OK condition for CPT entries with 4 parent Not OK conditions. We used the same complement approach for the CPT entries with 5 parent Not OK conditions. The resulting values chosen for the Execution Task Success example CPT are summarized in Table 10.

\begin{tabular}{|c|c|c|}
\hline & \multicolumn{2}{|c|}{ Execution Task Success } \\
\hline \# NOT OK Parents & TRUE & FALSE \\
\hline 0 & 0.9999 & $1 \mathrm{E}-04$ \\
\hline 1 & 0.999 & $1 \mathrm{E}-03$ \\
\hline 2 & 0.99 & $1 \mathrm{E}-02$ \\
\hline 3 & 0.9 & $1 \mathrm{E}-01$ \\
\hline 4 & $1 \mathrm{E}-03$ & .999 \\
\hline 5 & $1 \mathrm{E}-04$ & .9999 \\
\hline
\end{tabular}

Table 10: Execution Task Success Conditional Probability Table Values

We continued the network quantification activity by populating the CPTs for the factor nodes. These quantifications are of a relative nature, covering the probabilities from $0 \%$ to $100 \%$ in order to span the entire range of possibilities of the parent influences on the child node. We used the scale developed by Renooij and Witteman [96] due to its common adoption in the field of Bayesian Network probability elicitation, its roots in multiple experiments, and its verbal and numerical presentation. The scale relates the following probabilities to verbal expressions: 


\begin{tabular}{|l|c|c|c|c|c|c|c|}
\hline Prob. (\%) & 0 & 15 & 25 & 50 & 75 & 85 & 100 \\
\hline Expression & Impossible & Improbable & Uncertain & Fifty-fifty & Expected & Probable & Certain \\
\hline
\end{tabular}

Table 11: Probability Scale From [96]

An example Conditional Probability Table (CPT) for the Cognitive Adaptations node is shown in Table 12. The full set of CPTs quantified based on the author's judgment for this illustrative example network is given in the Appendix.

\begin{tabular}{|c|c|c|c|c|}
\hline & & & \multicolumn{2}{|c|}{ Cognitive Adaptations } \\
\hline Time Context & Task Familiarity & Work Load & OK & NOT OK \\
\hline OK & OK & OK & 0.99 & 0.01 \\
\hline OK & OK & Not OK & 0.85 & 0.15 \\
\hline OK & Not OK & OK & 0.85 & 0.15 \\
\hline Not OK & OK & OK & 0.85 & 0.15 \\
\hline OK & Not OK & Not OK & 0.75 & 0.25 \\
\hline Not OK & OK & Not OK & 0.75 & 0.25 \\
\hline Not OK & Not OK & OK & 0.75 & 0.25 \\
\hline Not OK & Not OK & Not OK & 0.5 & 0.5 \\
\hline
\end{tabular}

Table 12: Example Conditional Probability Table for Cognitive Adaptations

\subsubsection{RESULTING EXAMPLE BN}

Once the Conditional Probability Tables for each node in the network are populated, the initial marginal probabilities for each node can then be calculated, a task much simplified by the limited structure of the network. The software program NeticaTM [97] was used in the creation of the network shown in Figure 23. The nodes were created and the quantities for their CPTs were entered into the program. The values are calculated by applying

$$
P(x)=\prod_{i} P\left(x_{i} \mid x_{\pi_{i}}\right)
$$

where $\mathrm{P}\left(x_{i} \mid \mathrm{x}_{\mathrm{mi}}\right)$ is the local conditional probability for node $i$ given the probabilities from its parents indicated by the subscript $\pi_{i}[91]$. 


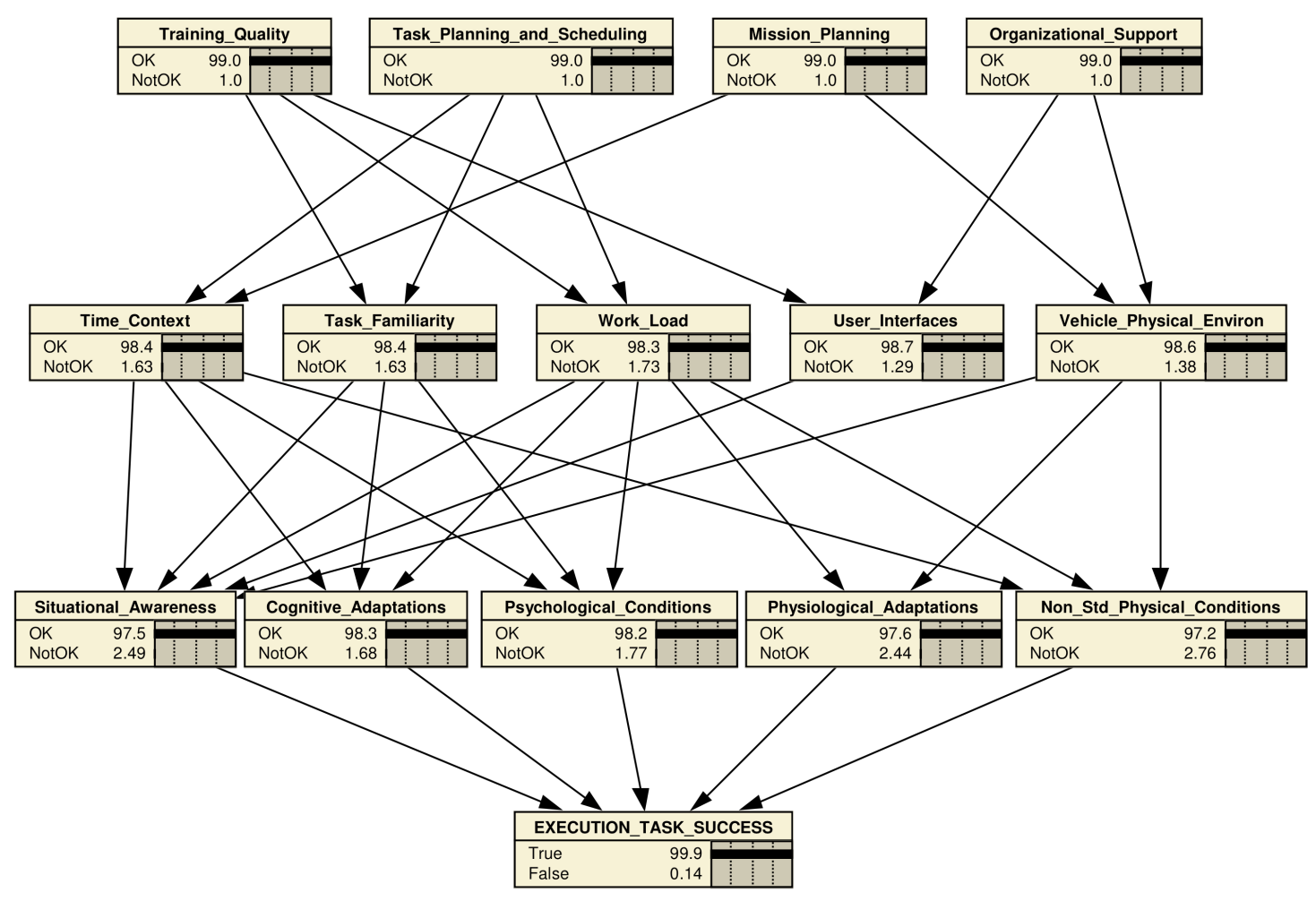

Figure 23: Example Quantified Bayesian Network. Output provided by NETICA [97].

A key point to recognize is that this network represents prior information in the Bayesian sense [75]. It models what is known about the relationships between factors and the outcome task without observations of particular node states for any given specific example. Once an analyst has information regarding the states of particular nodes within a scenario, this information is entered into the network, and the probabilities throughout the network are updated through Bayesian inference. An illustrative example of this process is described in the upcoming sections. 


\subsection{ENTERING SCENARIO EVIDENCE}

We now progress to the third and final stage of those described by Sigurdsson, Walls and Quigley [71] , Inference. Within stage 3, step 5 of the overall process is entering evidence in the network for the scenario of interest. Recall the scenario used as context for the analysis in Chapter 4. The scenario takes place during the return of a transfer vehicle from the International Space Station (ISS), and assumes vehicle configuration requiring crew actions during the landing phase. The specific task in mind was a crewmember pushing the appropriate button to release retractable landing gear in the "down" position, although any similar push button task may have been used in the case that the reference vehicle does not have landing gear (e.g. a capsule design). The total duration of the mission was assumed to be two weeks.

One of the most powerful advantages of using a Bayesian Network for factor evaluations in a Human Reliability Analysis is that evaluations of factors that the analyst has information about can be entered in the network, but evaluations of factors that the analyst does not have insight into do not need to be entered [76]. The factors that are not observable by the analyst are left with their prior probability distributions given by the original network for the evidence setting stage [75].

In this example, we enter the evidence shown in Table 13. The evaluations for factors in the Operations Domain are similar to those given in [20] for a Mission Control scenario used in a Human Reliability Analysis. The Vehicle Design Domain factor User Interfaces is also evaluated favorably, similar to what is shown in [20]. 


\begin{tabular}{|c|c|}
\hline Node & State Evaluation \\
\hline Training Quality & OK \\
\hline Organizational Support & OK \\
\hline Time Context & OK \\
\hline Task Familiarity & OK \\
\hline Work Load & OK \\
\hline User Interfaces & OK \\
\hline
\end{tabular}

Table 13: Evidence Entered in Example Bayesian Network for Scenario

The remaining nodes do not have evidence set. The majority of the remaining nodes, such as Cognitive Adaptations and Psychological Conditions, are in the Human Domain. An analyst would likely have less insight into the state of the Human Domain variables; therefore, these are left with their prior distributions. The node Vehicle Physical Environment also does not have evidence set, to account for the unknown state of its Contributing Factors such as Acceleration/Gravity Level and Vibration Level during this landing phase of flight. The Task Planning \& Scheduling and Mission Planning nodes are also left with their prior distributions to account for unknowns in the timing of the reentry and the accompanying preparatory tasks.

To actually set the evidence for the nodes as given in Table 13, the probabilities for the states evaluated are changed from their prior value to $100 \%$. For example, in Figure 23, the node Time Context has a prior value of $98.4 \%$ of being in the OK state. We now enter the evidence for this node by changing that value to $100 \%$, and the Not OK value correspondingly is changed to $0 \%$. Bayesian Networks also allow evidence to be entered in the form of updated distributions. This means that if an analyst has insight into a different distribution for a particular scenario, such as a $60 \%$ chance of being in the OK state and $40 \%$ chance for Not $\mathrm{OK}$, that evidence can be entered in the same way [76].

With the evidence for the appropriate nodes entered in the network, we are now ready to progress to the next step in the process, evidence propagation. 


\subsection{PROPAGATING EVIDENCE IN THE NETWORK}

In the Inference stage, the overall step 6 as given by Sigurdsson, Walls and Quigley [71] is for propagating the evidence entered for the scenario throughout the network. For our purposes, the commercially available software Netica ${ }^{\mathrm{TM}}$ by Norsys [97] performed this step automatically. This software makes use of an algorithm called the junction tree in order to calculate the updated probabilities based on the evidence entered in the network $[91,92,98]$. Pearl pioneered the discussion of algorithms for belief updating by network propagation [58], and algorithms such as the junction tree followed [98]. Additional techniques taking into account laws of large numbers have allowed approximate inference approaches to be developed, as well, such as Monte Carlo and variational algorithms [91]. Therefore, if one wishes to explore the implementation of the evidence propagation in various commercially available tools or to develop independent implementations, options such as these exist.

\subsection{DISCUSSION OF THE RESULTS}

The last step in the process of developing and using a Bayesian Network is to interpret the results of the evidence propagation [71]. The outcome node Execution Task Success has an updated failure probability of 3.4 E-04 in this example, as shown by the bottom node in Figure 24 . This is a reduction of approximately a factor of 4 below the original failure probability of $1.4 \mathrm{E}-03$ due to the positively evaluated factor evidence entered from the example scenario. This result is the same order of magnitude obtained for an Execution task example in the Human Reliability Analysis shown by Hamlin [20]. Clearly this comparison is not detailed enough for quantitative validation, however, it does provide an initial sanity check. 


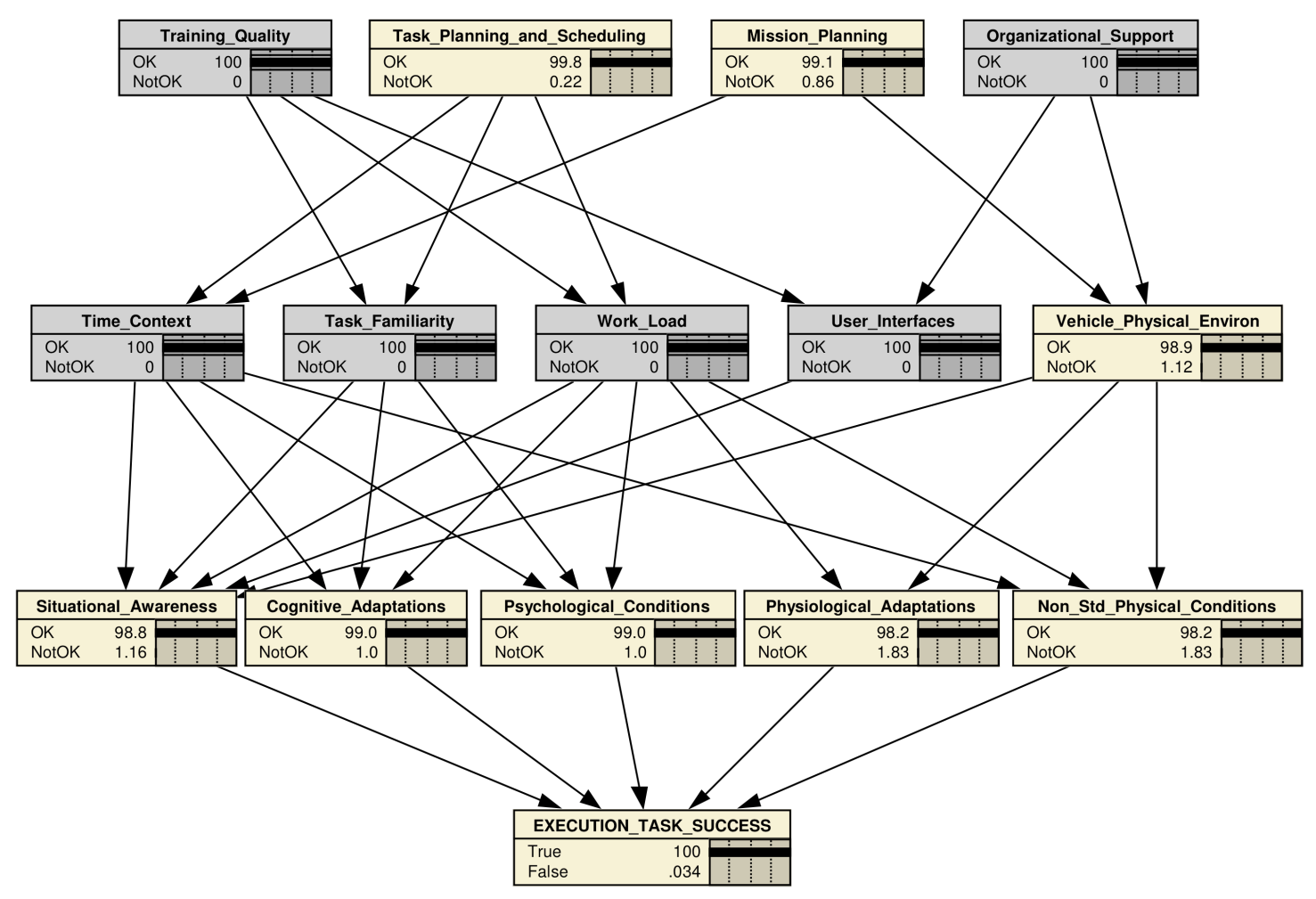

\section{Figure 24: Example Bayesian Network with Output Based on Evidence Set. Output provided by NETICA [97].}

It is also interesting to note the updated probability distributions for the other nodes in the network. The nodes in gray in Figure 24 have had their evidence set, and the remaining nodes have had their probabilities updated as a result of the evidence propagation. When the distributions of these factors are compared to the prior distributions as shown in Figure 23, we notice that the values for the Not OK states have decreased for all of these factors, as well. This result is quite logical, as the evidence entered was indicative of a more supportive environment, and the updated distributions reflect those influences. 


\subsection{INCORPORATING RESULTS IN HRA AND PRA}

Once the failure probability for a particular task, such as the Execution Task example, has been derived, the analysis is repeated for other tasks in the scenario. Dependencies between the tasks are evaluated, and the failure probability for the scenario is calculated based on the contributions from the multiple tasks involved [20]. This overall Human Error Probability (HEP) can then be incorporated into the higher-level system Probabilistic Risk Assessment, as discussed in Chapter 2 and represented by the Fault Tree diagram in Figure 6.

\subsection{CONCLUSIONS FOR THE BAYESIAN NETWORK APPLICATION EXAMPLE}

Major strengths of the Bayesian Network for use in Human Reliability Analysis have been demonstrated in this chapter. First, we have shown the ability of the network to explicitly model the influences of factors on one another and on the performance of tasks. The existence of these relationships is captured in the structure of the network by the connections between nodes, and the strengths of these relationships are captured in the Conditional Probability Tables for each node in the network. We also have shown an advantage the network provides for entering evidence during the analysis of a scenario. This advantage allows an analyst to enter information for nodes in which they have insight, but does not require scenario-specific inputs for nodes whose states are unknown. 


\section{CHAPTER 5 RESULTING PRESENTATIONS AND/OR PUBLICATIONS}

Mindock, J. Development and Application of Spaceflight Performance Shaping Factors for Human Reliability Analysis. Presentation given at NASA Deep Space Habitat Human Performance and Reliability Technical Interchange Meeting. March 2012.

Mindock, J. and Klaus, D. Application of a Spaceflight Contributing Factor Map for Human Reliability Analysis. Journal paper in preparation April 2012. 


\section{CHAPTER 6}

\section{CONCLUSIONS}

Each chapter will now be summarized, and the outcomes of the research related to their significance in the broader human spaceflight domain.

\subsection{SUMMARY OF CHAPTERS}

Chapter 1 provided the rationale and motivation for the research. Crew performance is fundamental to the success of human spaceflight missions, and the factors that influence crewmember performance in space have not previously been identified in a comprehensive, structured manner, especially for use in Human Reliability Analysis (HRA).

Chapter 2 gave insight into the background and context for the research, from high-level spacecraft design, next to the risk quantification portion of project and risk management processes, followed by an introduction to Human Reliability Analysis. The chapter concluded with motivations for identifying factors specifically for the spaceflight environment, and a list of the research objectives.

The next chapters in the dissertation addressed the objectives of the research:

1. Identify factors influencing the performance of crewmembers in spaceflight.

2. Develop a framework to quantify Performance Shaping Factor influences on task performance for spaceflight applications.

3. Develop an approach to apply new Performance Shaping Factors within a Human Reliability Analysis method for spaceflight applications.

Chapter 3 addressed objective 1, the identification of factors influencing the performance of crewmembers in spaceflight. Prior to the list of factors given, the generalization/specialization 
hierarchy defined in this chapter is a contribution in its own right, providing a reference for the classification of various influences. The hierarchy allows for the differentiation among various levels of abstraction when using the terminology developed, such as Functional Grouping and Contributing Factor. Next, the list of factors as defined within the hierarchy was presented, an important step in building a set of factors specifically developed to encompass influences on crew health and performance in the spaceflight environment, instead of nuclear power plant-based factors as in existing HRA methods. This list supports the standardization of terminology for those discussing risks across spaceflight domain disciplines. Also presented in this chapter was the visual representation of the factors on the Contributing Factor Map (CFM). The CFM can be used as a communication tool. It can support researchers specializing in certain areas to see the broader context and gain insights into relationships with research in other areas. It may support the identification of potential synergistic efforts and collaboration with other disciplines or organizations. It can also aid in bridging gaps between detailed views of the factors and high-level management views of the entire socio-technical system.

Chapter 4 addressed objective 2, the development of a framework to quantify factor influences on task performance for spaceflight applications. Techniques within current HRA methods are mainly ones in which the relationships between factors are not explicitly quantified. Bayesian Networks were described as the approach investigated in this research due to their explicit modeling of relationships and their common use in modeling complex systems in the presence of uncertainty.

Chapter 4 next addressed the question of how to develop the structure for a Bayesian Network in the spaceflight domain. The Human Factors Analysis and Classification System provided an initial guide to the network structure. The Analytic Hierarchy Process was then applied in order to determine the dominant factors in our system to include in a simplified model. The process presented in the chapter provides a repeatable procedure that can be followed to 
develop structures for networks related to tasks other than the Execution Task example. The procedure provides a transparent way to start with a large list of factors, such as those on the CFM, and progress to a simplified model. The process provides visibility into why modeling decisions were made. In the future those decisions can be changed or accepted as desired, but using this technique, the rationale is available for examination.

Chapter 4 continued with the discussion of Bayesian Network quantification informed by existing standards, requirements, and human performance data. It discussed how to use these existing resources to inform the model and clarify the definition of probabilities required for quantification. In the spaceflight domain, the contribution of how to utilize this type of local information is important because there does not currently exist a global data set for analysis of factor relationships and their influences on crew health and performance. This chapter continued with a discussion of how, even before a Bayesian Network is built, capturing the factor and relationship characterization information as described enables many useful analyses, such as the determination of requirement gaps, requirements commonality assessments, and requirements relevancy and impact assessments.

Chapter 5 then addressed objective 3 by demonstrating an example application of a Bayesian Network built on the factors developed in this research within a Human Reliability Analysis in the spaceflight domain. An example quantified Bayesian Network was shown, and the process of setting evidence in the network for a scenario of interest was described. The chapter briefly introduced evidence propagation. It then discussed the example results and conceptually how to incorporate them in the higher-level Human Reliability Analysis and Probabilistic Risk Assessment processes. 


\subsection{ADDITIONAL OUTCOMES}

A secondary goal of this research was to facilitate the sharing of knowledge, experience, and methods of problem solving across the Safety and Mission Assurance and Space Life Sciences communities. Both of these communities have the overarching goal of contributing to safe human space missions. The desire to identify and manage risk is a common component of this goal, and the different viewpoints from these communities provide valuable insights when shared.

Since the requirements, standards, and human performance data discussed in this research are typically developed by those in the Space Life Sciences community, that community is in the best position to provide the proper data to inform a Bayesian Network model. The application of such a model within the Safety and Mission Assurance community and the project design process have been the main contexts of this dissertation, however, the advantages of applying these concepts to the implementation of risk management processes within the Space Life Sciences research community are apparent, as well. These benefits include:

1. The factor organizational hierarchy and Contributing Factor Map (CFM) can be applied as the common framework and set of terminology for organizing human system risks, such as those found in the Human Research Program Integrated Research Plan [11]. This allows integration of risk-related research efforts across disciplines as common Contributing Factors are identified.

2. Factor characterization information gathered for the factors can support the identification of research gaps. For example, if a relationship is thought to be strong, but there exists only a low level of evidence, additional research may be required.

3. The Bayesian Network approach brings statistical modeling concepts forward to support the evaluation of risk outcome probabilities. Risks can be modeled by the identification of the crew health and performance outcomes of interest and quantification of their associated conditional 
probabilities based on the states of parent factors. This approach can support quantitative likelihood assessments to inform the risk management process.

4. The statistical variable modeling required for the Bayesian Network approach can also support the determination of appropriate tracking metrics for risks. For example, the closure metric for a risk may be the probability of an outcome factor being in the "Not OK" state. In this situation, the risk related to that outcome factor may be closed if the probability is below an acceptable level.

5. After a Bayesian Network is built, it may be possible to use it to perform sensitivity analyses of the impact of factors on outcome probabilities of interest. This type of impact analysis may be combined with funding information to support risk reduction effort prioritization decisions.

A Bayesian Network built using the factors described in this research can support the vehicle and operations design processes, as well. Designers of spacecraft typically work within a trade space defined by variables such as mass, power, volume, functionality, performance level, cost and schedule in order to efficiently build operational vehicles and achieve mission success. Designers developing spacecraft intended for human occupancy must also account for additional dimensions in the trade space that address variables supporting crew health and performance. These trade space variables may be looked upon as "knobs" to "turn" during the design process, and have requirements that must be defined, designed to, and eventually verified that they have been met. The set of factors identified in Chapter 3 can be used to address crew health and performance and represent these dimensions in the trade space. Having a quantified Bayesian Network capturing the influences of design choices on human performance can provide a way for past system performance data to inform new design choices for next-generation systems. 


\subsection{FUTURE RESEARCH}

There will likely always be some degree of refinement possible related to the identification and organization of factors influencing human performance in space. Factor terminology could be modified, groupings could be adjusted, and factor definitions could be defined in greater detail, depending on the needs of the specific application of the factor list and Contributing Factor Map. In the area of applying Analytic Hierarchy Process analysis techniques for developing a Bayesian Network structure, future work includes using different context scenarios for the same type of task to evaluate difference in the resulting network structure. Similarly, additional investigations include performing the analysis for other types of tasks than the Execution Task example. Once Bayesian Networks with particular structures are quantified, sensitivity studies analyzing the structural choices could provide insight into additional factors and relationships to include, or into factors and relationships initially included that could be removed.

A significant portion of future work is in the area of data collection. Ideally, a database for collecting relevant spaceflight domain-specific Human Reliability Analysis data would be created to inform the quantification of a Bayesian Network model. Finally, model validation through simulation and experiments would support the adoption of Bayesian Network techniques within the Human Reliability Analysis and Probabilistic Risk Assessment communities. 


\section{REFERENCES}

1. Swain, A.D. and H.E. Guttman, Handbook of Human Reliability Analysis with Emphasis on Nuclear Power Plant Applications, 1983: Washington, DC.

2. Hollnagel, E., Cognitive Reliability and Error Analysis Method (CREAM)1998, New York: Elsevier Science.

3. Shappell, S. and D. Wiegmann, HFACS Analysis of Military and Civilian Aviation Accidents: A North American Comparison, in International Society of Air Safety Investigators Conference. 2004.

4. $\quad$ NASA, Human-Rating Requirements for Space Systems, 2008.

5. $\quad$ NASA, Human Integration Design Handbook (HIDH), 2010.

6. NASA, Human Reliability Analysis Methods, Selection Guidance for NASA, N. OSMA, Editor 2006.

7. NASA, Bioastronautics Roadmap, A Risk Reduction Strategy for Human Space Exploration, 2005.

8. Longnecker, D. and R. Molins, A Risk Reduction Strategy for Human Exploration of Space: A Review of NASA's Bioastronautics Roadmap2006, Washington, DC: The National Academies Press.

9. Davis, J., J. Fogarty, and E. Richard, Human health and performance risk management - an approach for exploration missions. Acta Astronautica, 2008. 63: p. 988-995.

10. Corbin, B., et al., A Strategy to Manage Human Health and Performance Risks for Space Flight, in 59th International Astronautical Conference. 2008.

11. NASA, Human Research Program Integrated Research Plan, 2011.

12. NASA, NASA Systems Engineering Handbook, 2007.

13. NASA, Agency Risk Management and Procedural Requirements, 2008.

14. Tumer, I.Y., F.A. Barrientos, and A.F. Mehr, Towards Risk Based Design (RBD) of Space Exploration Missions: A Review of RBD Practice and Research Trends at NASA., in ASME 2005 International Design Engineering Technical Conferences and Computers and Information in Engineering Conference2005: Long Beach, CA.

15. Dezfuli, H., G. Maggio, and C. Everett, Risk-Informed Decision Making, Application to Technology Development Alternative Selection, in 4th International Association for the Advancement of Space Safety Conference. 2010.

16. NASA, Probabilistic Risk Assessment Procedures Guide for NASA Managers and Practitioners, version 1.1, O.o.S.a.M. Assurance, Editor 2002: Washington, DC.

17. NASA, Technical Probabilistic Risk Assessment (PRA) Procedures for Safety and Mission Success for NASA Programs and Projects, 2010.

18. NASA, Risk Classification for NASA Payloads (Revalidated July 9, 2008), 2008.

19. Mosleh, A., et al., A Model-Based Human Reliability Analysis Framework, in 10th International Probabilistic Safety Assessment and Management Conference. 2010.

20. Hamlin, T., The Importance of Human Reliability Analysis in Human Space Flight: Understanding the Risks, N.S.M. Assurance, Editor 2010: Johnson Space Center, Houston, TX.

21. Groth, K., A data-informed model of performance shaping factors for use in human reliability analysis, 2009, University of Maryland: College Park, MD.

22. Hamlin, T., Space Shuttle Program Human Reliability Analysis (HRA) Data Report, 2008.

23. Mindock, J.A. and D.M. Klaus, Development and Application of Spaceflight Performance Shaping Factors for Human Reliability Analysis, in 41st International Conference on Environmental Systems2011: Portland, OR.

24. Larson, W. and L. Pranke, Human Spaceflight Mission Analysis and Design. Space Technology Series1999, New York: The McGraw-Hill Companies, Inc. 
25. (IISTF), I.S.S.I.S.T.F., Final Report of the International Space Station Independent Safety Task Force, 2007.

26. McPhee, J. and J. Charles, Human Health and Performance Risks of Space Exploration Missions, Evidence Reviewed by the NASA Human Research Program, 2009.

27. Thelen, D., B. Wood, and D. Pate, Significant Incidents and Close Calls in Human Spaceflight, in NASA S\&MA Flight Safety Office Rapid Information Page. 2010.

28. Russell, J.F. and D.M. Klaus, Maintenance, reliability and policies for orbital space station life support systems. Reliability Engineering \& System Safety, 2007. 92: p. 808-820.

29. Dietlein, L.F. and I.D. Pestov, Health, Performance, and Safety of Space Crews. Space Biology and Medicine, ed. A.E. Nicogossian, et al. Vol. IV. 2004, Washington, D.C.: American Institute of Aeronautics and Astronautics, Inc.

30. Buckey, J., Space Physiology2006: Oxford University Press.

31. Lujan, B. and R. White, Human Physiology in Space Student's Manual1994: NASA.

32. Shepanek, M., Human Behavioral Research in Space: Quandaries for Research Subjects and Researchers. Aviation, Space, and Environmental Medicine, 2005. Vol. 76(No. 6, Section II).

33. Groth, K. and A. Mosleh, A Performance Shaping Factors Causal Model for Nuclear Power Plant Human Reliability Analysis, in 10th International Probabilistic Safety Assessment and Management Conference. 2010.

34. Eckart, P., Spaceflight Life Support and Biospherics. Space Technology Library1996: Microcosm Press and Kluwer Academic Publishers.

35. Chang, Y.H.J. and A. Mosleh, Cognitive Modeling and Dynamic Probabilistic Simulation of Operating Crew Response to Complex System Accidents -- Part 1 Overview of the IDAC Model. Reliability Engineering \& System Safety, 2006.

36. Chang, Y.H.J. and A. Mosleh, Cognitive Modeling and Dynamic Probabilistic Simulation of Operating Crew Response to Complex System Accidents -- Part 2 IDAC Performance Influencing Factors Model. Reliability Engineering \& System Safety, 2006.

37. Chang, Y.H.J. and A. Mosleh, Cognitive Modeling and Dynamic Probabilistic Simulation of Operating Crew Response to Complex System Accidents -- Part 4 IDAC Causal Model of Operator Problem-Solving Response. Reliability Engineering \& System Safety, 2006.

38. Chang, Y.H.J. and A. Mosleh, Cognitive Modeling and Dynamic Probabilistic Simulation of Operating Crew Response to Complex System Accidents -- Part 5 Dynamic Probabilistic Simulation of IDAC Model. Reliability Engineering \& System Safety, 2006.

39. Chang, Y.H.J. and A. Mosleh, Cognitive Modeling and Dynamic Probabilistic Simulation of Operating Crew Response to Complex System Accidents -- Part 3 IDAC Operator Response Model. Reliability Engineering \& System Safety, 2006.

40. Chandler, F., et al., NASA Human Error Analysis, 2010.

41. Osburg, J., W. Sipes, and E. Fiedler, The MEOW Experiment: Measuring Cognitive Performance of Planetary Analog Base Crewmembers. Society of Automotive Engineers International, 2003(SAE-2003-01-2539).

42. Osburg, J. and W. Sipes, Mars Analog Station Cognitive Testing (MASCOT): Results of First Field Season. Society of Automotive Engineers International, 2004(SAE-2004-01-2586).

43. Peacock, B., J. Blume, and S. Vallance, Habitability Measurement in Space Vehicles and Earth Analogs, in Handbook of Human Factors and Ergonomics Methods, N. Stanton, et al., Editors. 2006, CRC Press.

44. Shappell, S.A. and D.A. Wiegmann, The Human Factors Analysis and Classification SystemHFACS, 2000, U.S. Department of Transportation.

45. Reason, J., The Contribution of Latent Human Failures to the Breakdown of Complex Systems. Philosophical Transactions of the Royal Society of London, 1990. 327(1241 Human Factors in Hazardous Situations): p. 475-484. 
46. Moore-Ede, M., et al., Circadian Alertness Simulator for Fatigue Risk Assessment in Transportation: Application to Reduce Frequency and Severity of Truck Accidents. Aviation, Space, and Environmental Medicine, 2004. 75(3).

47. NASA, NASA Space Flight Human-System Standard Volume 2: Human Factors, Habitability, and Environmental Health, 2011.

48. Reason, J., Human error: models and management. BMJ, 2000. 320(7237): p. 768-770.

49. Seaton, K.A., K.E. Bowie, and W.A. Sipes, Behavioral and Psychological Issues in LongDuration Head-Down Bed Rest. Aviation, Space, and Environmental Medicine, 2009. 80(5).

50. Parasuraman, R., T.B. Sheridan, and C.D. Wickens, A Model for Types and Levels of Human Interaction with Automation. IEEE Transactions on Systems, Man, and Cybernetics-Part A: Systems and Humans, 2000. 30(3).

51. Huntoon, C.S.L., V.V. Antipov, and A.I. Grigoriev, Humans in Spaceflight Book 2. Space Biology and Medicine, ed. A.E. Nicogossian, et al. Vol. III. 2004, Washington, D.C.: American Institute of Aeronautics and Astronautics.

52. Sulzman, F.M. and A.M. Genin, Life Support and Habitability. Space Biology and Medicine, ed. A.E. Nicogossian, et al. Vol. II. 2004, Washington, D.C.: American Institute of Aeronautics and Astronautics.

53. Kane, R., et al., Development and Validation of the Spaceflight Cognitive Assessment Tool for Windows (WinSCAT). Aviation, Space, and Environmental Medicine, 2005. 76(6).

54. Seaton, K.A., et al., Cognitive Functioning In Long-Duration Head-Down Bed Rest. Aviation, Space, and Environmental Medicine, 2009. 80(5).

55. Celentano, J., D. Amorelli, and G. Freeman, Establishing a Habitability Index for Space Stations and Planetary Bases, in AIAA/ASMA Manned Space Laboratory Conference1963.

56. Huntoon, C.S.L., V.V. Antipov, and A.I. Grigoriev, Humans in Spaceflight Book 1. Space Biology and Medicine, ed. A.E. Nicogossian, et al. Vol. III. 2004, Washington, D.C.: American Institute of Aeronautics and Astronautics.

57. Organization, W.H. International Statistical Classification of Diseases and Related Health Problems 10th Revision. 2010 [cited 2010; Available from: http://apps.who.int/classifications/apps/icd/icd10online.

58. Pearl, J., Probabilistic Reasoning in Intelligent Systems: Networks of Plausible Inference1988, San Mateo, CA: Morgan Kaufmann.

59. Nadkarni, S. and P. Shenoy, A causal mapping approach to constructing Bayesian networks. Decision Support Systems, 2004. 38: p. 259-281.

60. Monti, S. and G. Carenini, Dealing with the Expert Inconsistency in Probability Elicitation. IEEE Transactions on Knowledge and Data Engineering, 2000. 12(4).

61. Wang, H. and M.J. Druzdzel. User Interface Tools for Navigation in Conditional Probability Tables and Elcitation of Probabilities in Bayesian Networks. in Sixteenth Annual Conference on Uncertainty in Artificial Intelligence (UAI-2000). 2000. Stanford, CA: Morgan Kauffmann Publishers, Inc.

62. Druzdzel, M.J. and L.C. Van der Gaag. Elicitation of Probabilities for Belief Networks: Combining Qualitative and Quantitative Information. in Eleventh Annual Conference on Uncertainty in Artificial Intelligence (UAI-95). 1995. Montreal, Quebec, Canada: Morgan Kaufmann Publishers, Inc.

63. Pradhan, M., et al. Knowledge Engineering for Large Belief Networks. in Conference on Uncertainty in Artificial Intelligence. 1994. Seattle, WA.

64. Wiegmann, D., Developing a Methodology for Eliciting Subjective Probability Estimates During Expert Evaluations of Safety Interventions: Application for Bayesian Belief Networks, 2005, NASA Langley Research Center: Hampton, VA. 
65. Trucco, P., et al., A Bayesian Belief Network modelling of organisational factors in risk analysis: A case study in maritime transportation. Reliability Engineering \& System Safety, 2008. 93: p. 823-834.

66. Norrington, L., et al., Modelling the reliability of search and rescue operations with Bayesian Belief Networks. Reliability Engineering \& System Safety, 2008. 93: p. 940-949.

67. Xiao-xuan, H., W. Hui, and W. Shuo, Using Expert's Knowledge to Build Bayesian Networks, in 2007 International Conference on Computational Intelligence and Security Workshops. 2007, IEEE.

68. Druzdzel, M.J. and L.C. Van der Gaag, Building probabilistic networks: "Where do the numbers come from?". IEEE Transactions on Knowledge and Data Engineering, 2000. 12(4): p. 481486.

69. Wilson, A.G. and A.V. Huzurbazar, Bayesian networks for multilevel system reliability. Reliability Engineering \& System Safety, 2007. 92: p. 1413-1420.

70. Weber, P., et al., Overview on Bayesian networks applications for dependability, risk analysis and maintenance areas. Engineering Applications of Artificial Intelligence, 2010.

71. Sigurdsson, J.H., L.A. Walls, and J.L. Quigley, Bayesian Belief Nets for Managing Expert Judgement and Modelling Reliability. Quality and Reliability Engineering International, 2001. 17: p. 181-190.

72. Celeux, G., et al., Designing a Bayesian network for preventive maintenance from expert opinions in a rapid and reliable way. Reliability Engineering \& System Safety, 2006. 91: p. 849-856.

73. Goldenberg, A. and A. Moore. Tractable Lerning of Large Bayes Net Structures from Sparse Data. in Proceedings of the 21st International Conference on Machine Learning. 2004. Banff, Canada.

74. Groth, K. and A. Mosleh, Deriving causal Bayesian Networks from Human Reliability Analysis data: A methodology and example model. Proceedings of the Institution of Mechanical Engineere, Part O, Journal of Risk and Reliability, 2011.

75. Groth, K. and A. Mosleh, Development and Use of A Bayesian Network to Estimate Human Error Probability, in ANS PSA 2011 International Topical Meeting on Probabilistic Safety ASsessment and Analysis2011, American Nuclear Society: Wilmington, NC.

76. Groth, K. and L. Swiler, Use of a SPAR-H Bayesian Network for predicting Human Error Probabilities with missing observations, in 11th International Probabilistic Safety Assessment and Management Conference.2012: Helsinki, Finland.

77. Heckerman, D., A Tutorial on Learning With Bayesian Networks, 1995, Microsoft Corporation: Redmond, WA.

78. Hallbert, B., et al., Human Event Repository and Analysis (HERA) System, Overview, NUREG/CR-6903, 2006, U.S. Nuclear Regulatory Commission: Washington, D.C.

79. Gertman, D., et al., Nuclear Computerized Library for Assessing Reactor Reliability (NUCLARR), NUREG/CR-4639, 1994, US Nuclear Regulatory Commission: Washington, D.C.

80. Boring, R., et al., A Taxonomy and Database for Capturing Human Reliability and Human Performance Data, in Proceedings of the Human Factors and Ergonomics Society 50th Annual Meeting2006.

81. Lee, C. and K. Lee, Application of Bayesian network to the probabilistic risk assessment of nuclear waste disposal. Reliability Engineering \& System Safety, 2006. 91: p. 515-532.

82. Saaty, T.L., Fundamentals of Decision Making and Priority Theory with the Analytic Hierarchy Process2006, Pittsburgh, PA: RWS Publications.

83. Park, K.S. and J. Lee, A new method for estimating human error probabilities: AHP-SLIM. Reliability Engineering \& System Safety, 2008. 93: p. 578-587.

84. Zahedi, F., The Analytic Hierarchy Process: A Survey of the Method and Its Applications. Interfaces, 1986. 16(4): p. 96-108. 
85. Reason, J., Human Error1990, New York: Cambridge University Press.

86. Celik, M. and S. Cebi, Analytical HFACS for investigating human errors in shipping accidents. Accident Analysis and Prevention, 2009: p. 66-75.

87. Clemen, R. and R. Winkler, Combining Probability Distributions From Experts in Risk Analysis. Risk Analysis, 1999. 19(2): p. 187-203.

88. Koller, D. and A. Pfeffer, Object-Oriented Bayesian Networks, in Thirteenth Annual Conference on Uncertainty on Artificial Intelligence1997: Providence, Rhode Island. p. 302-313.

89. Pfeffer, A., et al., SPOOK: A system for probabilistic object-oriented knowledge representation, in Fifteenth Annual Conference on Uncertainty in Artificial Intelligence1999: Stockholm, Sweden. p. 541-550.

90. Wooldridge, S., Bayesian Belief Networks, in Prepared for CSIRO Centre for Complex Systems Science. 2003.

91. Jordan, M.I. and Y. Weiss, Probabilistic inference in graphical models, in The Handbook of Brain Theory and Neural Networks, M. Arbib, Editor 2002, MIT Press: Cambridge, MA.

92. Cowell, R., Introduction to Inference for Bayesian Networks, in Learning in Graphical Models, M.I. Jordan, Editor 1998, Kluwer Academic Publishers: Boston, MA.

93. NASA, NASA Risk-Informed Decision Making Handbook, N.H. Office of Safety and Mission Assurance, Editor 2010.

94. Balldin, U., Acceleration Effects on Fighter Pilots, in Medical Aspects of Harsh Environments, K.B. Pandolf and R.E. Burr, Editors. 2002, Office of the Surgeon General, United States Army: Falls Church, VA.

95. Stoll, A., Human tolerance to positive $G$ as determined by the physiological end-points. Journal of Aviation Medicine, 1956. 27(No. 4): p. 356-367.

96. Renooij, S. and C. Witteman, Talking probabilities: commuincating probabilistic information with words and numbers. International Journal of Approximate Reasoning, 1999. 22: p. 169194.

97. Norsys, S.C., Netica Applicaion, 2011.

98. Lauritzen, S.L. and D.J. Spiegelhalter, Local Computations with Probabilities on Graphical Structures and Their Application to Expert Systems. Journal of the Royal Statistical Society, 1988. Vol. 50(No. 2): p. pp. 157-224. 


\section{APPENDIX A: ACRONYM LIST}

\begin{tabular}{ll} 
AHP & Analytic Hierarchy Process \\
BN & Bayesian Network \\
CFM & Contributing Factor Map \\
CPC & Common Performance Condition \\
CPT & Conditional Probability Table \\
CREAM & Cognitive Reliability and Error Analysis Method \\
CRM & Continuous Risk Management \\
HEP & Human Error Probability \\
HFACS & Human Factors Analysis and Classification System \\
HRA & Human Reliability Analysis \\
HSRB & Human System Risk Board \\
ISS & International Space Station \\
NASA & National Aeronautics and Space Administration \\
PRA & Probabilistic Risk Assessment \\
PSF & Performance Shaping Factor \\
RIDM & Risk-Informed Decision Making \\
TIM & Technical Interchange Meeting \\
\hline
\end{tabular}


Table B.1: Execution Task Success Node Probabilities

\begin{tabular}{|c|c|c|c|c|c|c|}
\hline \multirow[b]{2}{*}{$\begin{array}{l}\text { Situational } \\
\text { Awareness }\end{array}$} & \multirow[b]{2}{*}{$\begin{array}{l}\text { Psychological } \\
\text { Conditions }\end{array}$} & \multirow[b]{2}{*}{$\begin{array}{c}\text { Non- } \\
\text { Standard } \\
\text { Physical } \\
\text { Conditions }\end{array}$} & \multirow[b]{2}{*}{$\begin{array}{c}\text { Cognitive } \\
\text { Adaptations }\end{array}$} & \multirow[b]{2}{*}{$\begin{array}{c}\text { Physiological } \\
\text { Adaptations }\end{array}$} & \multicolumn{2}{|c|}{$\begin{array}{c}\text { EXECUTION TASK } \\
\text { SUCCESS }\end{array}$} \\
\hline & & & & & TRUE & FALSE \\
\hline OK & OK & OK & $\mathrm{OK}$ & $\mathrm{OK}$ & 0.9999 & 1E-04 \\
\hline $\mathrm{OK}$ & $\mathrm{OK}$ & $\mathrm{OK}$ & $\mathrm{OK}$ & Not OK & 0.999 & 0.001 \\
\hline $\mathrm{OK}$ & $\mathrm{OK}$ & $\mathrm{OK}$ & Not OK & $\mathrm{OK}$ & 0.999 & 0.001 \\
\hline $\mathrm{OK}$ & $\mathrm{OK}$ & Not OK & $\mathrm{OK}$ & $\mathrm{OK}$ & 0.999 & 0.001 \\
\hline $\mathrm{OK}$ & Not OK & $\mathrm{OK}$ & $\mathrm{OK}$ & $\mathrm{OK}$ & 0.999 & 0.001 \\
\hline Not OK & OK & $\mathrm{OK}$ & $\mathrm{OK}$ & $\mathrm{OK}$ & 0.999 & 0.001 \\
\hline OK & OK & OK & Not OK & Not OK & 0.99 & 0.01 \\
\hline $\mathrm{OK}$ & $\mathrm{OK}$ & Not OK & $\mathrm{OK}$ & Not OK & 0.99 & 0.01 \\
\hline OK & OK & Not OK & Not OK & OK & 0.99 & 0.01 \\
\hline $\mathrm{OK}$ & Not OK & $\mathrm{OK}$ & $\mathrm{OK}$ & Not OK & 0.99 & 0.01 \\
\hline $\mathrm{OK}$ & Not OK & OK & Not OK & $\mathrm{OK}$ & 0.99 & 0.01 \\
\hline $\mathrm{OK}$ & Not OK & Not OK & $\mathrm{OK}$ & $\mathrm{OK}$ & 0.99 & 0.01 \\
\hline Not OK & OK & $\mathrm{OK}$ & $\mathrm{OK}$ & Not OK & 0.99 & 0.01 \\
\hline Not OK & OK & $\mathrm{OK}$ & Not OK & $\mathrm{OK}$ & 0.99 & 0.01 \\
\hline Not OK & OK & Not OK & $\mathrm{OK}$ & OK & 0.99 & 0.01 \\
\hline Not OK & Not OK & OK & $\mathrm{OK}$ & OK & 0.99 & 0.01 \\
\hline $\mathrm{OK}$ & OK & Not OK & Not OK & Not OK & 0.9 & 0.1 \\
\hline $\mathrm{OK}$ & Not OK & $\mathrm{OK}$ & Not OK & Not OK & 0.9 & 0.1 \\
\hline OK & Not OK & Not OK & $\mathrm{OK}$ & Not OK & 0.9 & 0.1 \\
\hline $\mathrm{OK}$ & Not OK & Not OK & Not OK & $\mathrm{OK}$ & 0.9 & 0.1 \\
\hline Not OK & $\mathrm{OK}$ & $\mathrm{OK}$ & Not OK & Not OK & 0.9 & 0.1 \\
\hline Not OK & $\mathrm{OK}$ & Not OK & $\mathrm{OK}$ & Not OK & 0.9 & 0.1 \\
\hline Not OK & $\mathrm{OK}$ & Not OK & Not OK & $\mathrm{OK}$ & 0.9 & 0.1 \\
\hline Not OK & Not OK & $\mathrm{OK}$ & $\mathrm{OK}$ & Not OK & 0.9 & 0.1 \\
\hline Not OK & Not OK & $\mathrm{OK}$ & Not OK & OK & 0.9 & 0.1 \\
\hline Not OK & Not OK & Not OK & $\mathrm{OK}$ & $\mathrm{OK}$ & 0.9 & 0.1 \\
\hline OK & Not OK & Not OK & Not OK & Not OK & 0.001 & 0.999 \\
\hline Not OK & OK & Not OK & Not OK & Not OK & 0.001 & 0.999 \\
\hline Not OK & Not OK & $\mathrm{OK}$ & Not OK & Not OK & 0.001 & 0.999 \\
\hline Not OK & Not OK & Not OK & $\mathrm{OK}$ & Not OK & 0.001 & 0.999 \\
\hline Not OK & Not OK & Not OK & Not OK & $\mathrm{OK}$ & 0.001 & 0.999 \\
\hline Not OK & Not OK & Not OK & Not OK & Not OK & $1 \mathrm{E}-04$ & 0.9999 \\
\hline
\end{tabular}


Table B.2: Situational Awareness Node Probabilities

\begin{tabular}{|c|c|c|c|c|c|c|}
\hline \multirow[b]{2}{*}{$\begin{array}{c}\text { Time } \\
\text { Context }\end{array}$} & \multirow[b]{2}{*}{$\begin{array}{c}\text { Task } \\
\text { Familiarity }\end{array}$} & \multirow[b]{2}{*}{$\begin{array}{c}\text { User } \\
\text { Interfaces }\end{array}$} & \multirow{2}{*}{$\begin{array}{c}\text { Vehicle } \\
\text { Physical } \\
\text { Environment }\end{array}$} & \multirow[b]{2}{*}{ Work Load } & \multicolumn{2}{|c|}{$\begin{array}{c}\text { SITUATIONAL } \\
\text { AWARENESS OK }\end{array}$} \\
\hline & & & & & TRUE & FALSE \\
\hline $\mathrm{OK}$ & $\mathrm{OK}$ & $\mathrm{OK}$ & $\mathrm{OK}$ & $\mathrm{OK}$ & 0.99 & 0.01 \\
\hline Not OK & $\mathrm{OK}$ & OK & $\mathrm{OK}$ & $\mathrm{OK}$ & 0.75 & 0.25 \\
\hline $\mathrm{OK}$ & Not OK & $\mathrm{OK}$ & $\mathrm{OK}$ & $\mathrm{OK}$ & 0.75 & 0.25 \\
\hline $\mathrm{OK}$ & $\mathrm{OK}$ & Not OK & $\mathrm{OK}$ & $\mathrm{OK}$ & 0.85 & 0.15 \\
\hline $\mathrm{OK}$ & $\mathrm{OK}$ & $\mathrm{OK}$ & Not OK & $\mathrm{OK}$ & 0.85 & 0.15 \\
\hline $\mathrm{OK}$ & $\mathrm{OK}$ & $\mathrm{OK}$ & $\mathrm{OK}$ & Not OK & 0.85 & 0.15 \\
\hline $\mathrm{OK}$ & $\mathrm{OK}$ & Not OK & Not OK & $\mathrm{OK}$ & 0.5 & 0.5 \\
\hline $\mathrm{OK}$ & Not OK & $\mathrm{OK}$ & Not OK & $\mathrm{OK}$ & 0.5 & 0.5 \\
\hline $\mathrm{OK}$ & Not OK & Not OK & $\mathrm{OK}$ & $\mathrm{OK}$ & 0.5 & 0.5 \\
\hline Not OK & $\mathrm{OK}$ & $\mathrm{OK}$ & Not OK & $\mathrm{OK}$ & 0.5 & 0.5 \\
\hline Not OK & $\mathrm{OK}$ & Not OK & $\mathrm{OK}$ & $\mathrm{OK}$ & 0.5 & 0.5 \\
\hline Not OK & Not OK & $\mathrm{OK}$ & $\mathrm{OK}$ & $\mathrm{OK}$ & 0.5 & 0.5 \\
\hline $\mathrm{OK}$ & $\mathrm{OK}$ & $\mathrm{OK}$ & Not OK & Not OK & 0.5 & 0.5 \\
\hline $\mathrm{OK}$ & $\mathrm{OK}$ & Not OK & $\mathrm{OK}$ & Not OK & 0.5 & 0.5 \\
\hline $\mathrm{OK}$ & Not OK & $\mathrm{OK}$ & $\mathrm{OK}$ & Not OK & 0.5 & 0.5 \\
\hline Not OK & $\mathrm{OK}$ & $\mathrm{OK}$ & $\mathrm{OK}$ & Not OK & 0.5 & 0.5 \\
\hline OK & Not OK & Not OK & Not OK & $\mathrm{OK}$ & 0.25 & 0.75 \\
\hline Not OK & $\mathrm{OK}$ & Not OK & Not OK & OK & 0.25 & 0.75 \\
\hline Not OK & Not OK & $\mathrm{OK}$ & Not OK & $\mathrm{OK}$ & 0.25 & 0.75 \\
\hline Not OK & Not OK & Not OK & $\mathrm{OK}$ & $\mathrm{OK}$ & 0.25 & 0.75 \\
\hline $\mathrm{OK}$ & $\mathrm{OK}$ & Not OK & Not OK & Not OK & 0.25 & 0.75 \\
\hline $\mathrm{OK}$ & Not OK & $\mathrm{OK}$ & Not OK & Not OK & 0.25 & 0.75 \\
\hline $\mathrm{OK}$ & Not OK & Not OK & $\mathrm{OK}$ & Not OK & 0.25 & 0.75 \\
\hline Not OK & $\mathrm{OK}$ & $\mathrm{OK}$ & Not OK & Not OK & 0.25 & 0.75 \\
\hline Not OK & $\mathrm{OK}$ & Not OK & $\mathrm{OK}$ & Not OK & 0.25 & 0.75 \\
\hline Not OK & Not OK & $\mathrm{OK}$ & $\mathrm{OK}$ & Not OK & 0.25 & 0.75 \\
\hline Not OK & Not OK & Not OK & Not OK & $\mathrm{OK}$ & 0.15 & 0.85 \\
\hline $\mathrm{OK}$ & Not OK & Not OK & Not OK & Not OK & 0.15 & 0.85 \\
\hline Not OK & $\mathrm{OK}$ & Not OK & Not OK & Not OK & 0.15 & 0.85 \\
\hline Not OK & Not OK & $\mathrm{OK}$ & Not OK & Not OK & 0.15 & 0.85 \\
\hline Not OK & Not OK & Not OK & $\mathrm{OK}$ & Not OK & 0.15 & 0.85 \\
\hline Not OK & Not OK & Not OK & Not OK & Not OK & 0.99 & 0.01 \\
\hline
\end{tabular}


Table B.3: Cognitive Adaptations Node Probabilities

\begin{tabular}{|c|c|c|c|c|}
\hline & & & \multicolumn{2}{|c|}{ COGNITIVE ADAPTATIONS OK } \\
\hline Time Context & Task Familiarity & Work Load & TRUE & FALSE \\
\hline OK & OK & OK & 0.99 & 0.01 \\
\hline OK & OK & Not OK & 0.85 & 0.15 \\
\hline OK & Not OK & OK & 0.85 & 0.15 \\
\hline Not OK & OK & OK & 0.85 & 0.15 \\
\hline OK & Not OK & Not OK & 0.75 & 0.25 \\
\hline Not OK & OK & Not OK & 0.75 & 0.25 \\
\hline Not OK & Not OK & OK & 0.75 & 0.25 \\
\hline Not OK & Not OK & Not OK & 0.5 & 0.5 \\
\hline
\end{tabular}

Table B.4: Psychological Conditions Node Probabilities

\begin{tabular}{|c|c|c|c|c|}
\hline & & & \multicolumn{2}{c|}{ PSYCHOLOGICAL CONDITIONS OK } \\
\hline Time Context & Work Load & Task Familiarity & TRUE & FALSE \\
\hline OK & OK & OK & 0.99 & 0.01 \\
\hline OK & OK & Not OK & 0.85 & 0.15 \\
\hline OK & Not OK & OK & 0.85 & 0.15 \\
\hline Not OK & OK & OK & 0.85 & 0.15 \\
\hline OK & Not OK & Not OK & 0.75 & 0.25 \\
\hline Not OK & OK & Not OK & 0.5 & 0.5 \\
\hline Not OK & Not OK & OK & 0.5 & 0.5 \\
\hline Not OK & Not OK & Not OK & 0.15 & 0.85 \\
\hline
\end{tabular}

Table B.5: Non-Standard Physical Conditions Node Probabilities

\begin{tabular}{|c|c|c|c|c|}
\hline & & & \multicolumn{2}{|c|}{$\begin{array}{c}\text { NON-STANDARD PHYSICAL } \\
\text { CONDITIONS OK }\end{array}$} \\
\hline $\begin{array}{c}\text { Vehicle Physical } \\
\text { Environment }\end{array}$ & Work Load & Time Context & TRUE & FALSE \\
\hline OK & OK & OK & 0.99 & 0.01 \\
\hline Not OK & OK & OK & 0.25 & 0.75 \\
\hline OK & Not OK & OK & 0.75 & 0.25 \\
\hline OK & OK & Not OK & 0.85 & 0.15 \\
\hline Not OK & Not OK & OK & 0.15 & 0.85 \\
\hline Not OK & OK & Not OK & 0.15 & 0.85 \\
\hline OK & Not OK & Not OK & 0.25 & 0.75 \\
\hline Not OK & Not OK & Not OK & 0.15 & 0.85 \\
\hline
\end{tabular}


Table B.6: Physiological Adaptations Node Probabilities

\begin{tabular}{|c|c|c|c|}
\hline & & \multicolumn{2}{|c|}{$\begin{array}{c}\text { NON-STANDARD PHYSICAL } \\
\text { CONDITIONS OK }\end{array}$} \\
\hline $\begin{array}{c}\text { Vehicle Physical } \\
\text { Environment }\end{array}$ & Work Load & TRUE & FALSE \\
\hline OK & OK & 0.99 & 0.01 \\
\hline Not OK & OK & 0.25 & 0.75 \\
\hline OK & Not OK & 0.75 & 0.25 \\
\hline Not OK & Not OK & 0.15 & 0.85 \\
\hline
\end{tabular}

Table B.7: Time Context Node Probabilities

\begin{tabular}{|c|c|c|c|}
\hline & & \multicolumn{2}{|c|}{ TIME CONTEXT OK } \\
\hline $\begin{array}{c}\text { Task Planning \& } \\
\text { Scheduling }\end{array}$ & Mission Planning & TRUE & FALSE \\
\hline OK & OK & 0.99 & 0.01 \\
\hline OK & Not OK & 0.85 & 0.15 \\
\hline Not OK & OK & 0.5 & 0.5 \\
\hline Not OK & Not OK & 0.15 & 0.85 \\
\hline
\end{tabular}

Table B.8: Task Familiarity Node Probabilities

\begin{tabular}{|c|c|c|c|}
\hline & & \multicolumn{2}{|c|}{ TASK FAMILIARITY OK } \\
\hline $\begin{array}{c}\text { Task Planning \& } \\
\text { Scheduling }\end{array}$ & Training Quality & TRUE & FALSE \\
\hline OK & OK & 0.99 & 0.01 \\
\hline OK & Not OK & 0.5 & 0.5 \\
\hline Not OK & OK & 0.85 & 0.15 \\
\hline Not OK & Not OK & 0.15 & 0.85 \\
\hline
\end{tabular}

Table B.9: Vehicle Physical Environment Node Probabilities

\begin{tabular}{|c|c|c|c|}
\hline & & \multicolumn{2}{|c|}{ VEHICLE PHYSICAL ENVIRONMENT OK } \\
\hline $\begin{array}{c}\text { Organizational } \\
\text { Support }\end{array}$ & Mission Planning & TRUE & FALSE \\
\hline OK & OK & 0.99 & 0.01 \\
\hline OK & Not OK & 0.85 & 0.15 \\
\hline Not OK & OK & 0.75 & 0.25 \\
\hline Not OK & Not OK & 0.25 & 0.75 \\
\hline
\end{tabular}


Table B.10: Work Load Node Probabilities

\begin{tabular}{|c|c|c|c|}
\hline & & \multicolumn{2}{|c|}{ WORK LOAD OK } \\
\hline $\begin{array}{c}\text { Task Planning \& } \\
\text { Scheduling }\end{array}$ & Training Quality & TRUE & FALSE \\
\hline OK & OK & 0.99 & 0.01 \\
\hline OK & Not OK & 0.75 & 0.25 \\
\hline Not OK & OK & 0.5 & 0.5 \\
\hline Not OK & Not OK & 0.15 & 0.85 \\
\hline
\end{tabular}

Table B.11: User Interfaces Node Probabilities

\begin{tabular}{|c|c|c|c|}
\hline & & \multicolumn{2}{|c|}{ USER INTERFACES OK } \\
\hline $\begin{array}{c}\text { Organizational } \\
\text { Support }\end{array}$ & Training Quality & TRUE & FALSE \\
\hline OK & OK & 0.99 & 0.01 \\
\hline OK & Not OK & 0.85 & 0.15 \\
\hline Not OK & OK & 0.85 & 0.15 \\
\hline Not OK & Not OK & 0.15 & 0.85 \\
\hline
\end{tabular}

Table B.12: Task Planning and Scheduling Node Probabilities

\begin{tabular}{|c|c|}
\hline \multicolumn{2}{|c|}{ TASK PLANNING AND SCHEDULING OK } \\
\hline TRUE & FALSE \\
\hline 0.99 & 0.01 \\
\hline
\end{tabular}

Table B.13: Training Quality Node Probabilities

\begin{tabular}{|c|c|}
\hline \multicolumn{2}{|c|}{ TRAINING QUALITY OK } \\
\hline TRUE & FALSE \\
\hline 0.99 & 0.01 \\
\hline
\end{tabular}

Table B.14: Mission Planning Node Probabilities

\begin{tabular}{|c|c|}
\hline \multicolumn{2}{|c|}{ MISSION PLANNING OK } \\
\hline TRUE & FALSE \\
\hline 0.99 & 0.01 \\
\hline
\end{tabular}

Table B.15: Organizational Support Node Probabilities

\begin{tabular}{|c|c|}
\hline \multicolumn{2}{|c|}{ ORGANIZATIONAL SUPPORT OK } \\
\hline TRUE & FALSE \\
\hline 0.99 & 0.01 \\
\hline
\end{tabular}

